


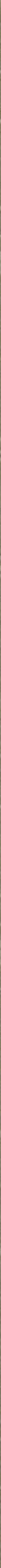




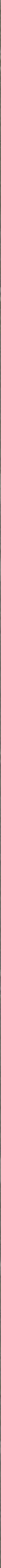



DAIRY CHEMISTRY 
The $>$ X 


\section{DAIRY CHEMISTRY}

BY

\section{HARRY SNYDER, B.S.}

PROFESSOR OF AGRICULTURAL CHEMISTRY, UNIVERSITY OF MINNESOTA, AND CHEMIST OF THE MINNESOTA

EXPERIMENT STATION

\section{Newo Tark \\ THE MACMILLAN COMPANY \\ LONDON: MACMILLAN \& CO., LTD. \\ 1906}

All rights reserved 

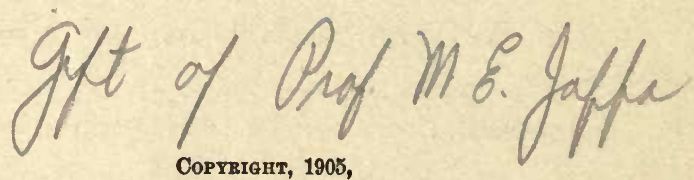

BY THE MACMILLAN COMPANY.

Set up and electrotyped. Published December, 1905.

Norbood 租ress

J. S. Cushing \& Co. - Berwick \& Smith Co.

Norwood, Mass., U.S.A. 


\section{PREFACE}

THIs work is the outgrowth of a course of lectures given by the author for a number of years to the students of the Agricultural Department of the University of Minnesota. During recent years material progress has been made in dairying, and in writing this book it has been the aim briefly to incorporate the results of the more important investigations on the subject. In the preparation of the work extensive use has been made of the bulletins and reports of the Agricultural Experiment Stations of the United States and of other works on the subject. It is the aim to present in as concise a form as possible the principal changes that take place in the handling of milk and in its manufacture into butter and cheese. While our present knowledge of some phases of the subject is incomplete, there are many facts that are known and have been found very useful as an aid in the production of dairy products of the highest sanitary and market value.

It is believed that a knowledge of the general 
principles of dairy chemistry will be found useful alike to the farmer, to the factoryman, and to the consumer, and this work has been prepared with the view of giving information to the layman rather than to the scientist.

\section{HARRY SNYDER.}

College of Agriculture,

UNIVERSITY OF MiNNESOTA,

St. Anthony Park, Minnesota,

December 1, 1905. 


\section{CONTENTS}

\section{CHAPTER I \\ The Composition of Milk}

Complexity of composition; Milk serum; Milk solids; Milk fats ; Casein ; Albumin; Milk sugar; Ash ; Variations in composition of milk; Percentage composition, and total yields; First or fore milk and strippings; Milk serum, Constancy of its composition . . . .

\section{CHAPTER II}

\section{Milk Testing}

Importance of milk testing; Reliability of the Babcock test; Sampling milk; Measuring milk with the pipette; Making the test ; Reading the fat; Calibration of test bottles ; Speeding the machine; Centrifugal action; The acid; Composite sample; Testing skim milk; Sampling frozen milk; Cleaning glassware; Water used in milk testing; Care of test bottles and apparatus . . . . .

\section{CHAPTER III}

\section{Milk Fats}

Composition of fats ; Kinds of butter fats ; Palmitin ; Stearin ; Olein; Butyrin; Caproin and Caprylin; Glycerine and fatty acid content of fats ; Food value of fats ; Saponifcation of fats ; Iodine absorption of butter fats; Volatile fatty acids of butter ; Melting point and physical properties of butter . . . . . . . . . 


\section{CHAPTER IV}

The Lactometer and its Use in determining Milk Adulteration

Quevenne's lactometer; Specific gravity of milk ; Influence of temperature; Other lactometers ; Influence of skimming and watering; Calculation of solids in milk; Joint use of lactometer and Babcock test . . . . .

\section{CHAPTER V}

\section{Mili Sugar and Lactic Acid}

Physical properties of milk sugar; Fermentation of milk sugar ; Production of lactic acid in the milk; Determining the acidity of milk; Calculating the acidity of milk; Alkaline tablets; Acidity of cream . . . . .

\section{CHAPTER VI}

\section{Cream}

Composition of cream ; Testing cream ; Methods of creaming ; Adulteration of cream; Ripening of cream; The use of pure cultures; Influence of delay on the creaming of milk; Creaming of mixed milks; Cream raising by dilution

\section{CHAPTER VII}

\section{The Chemistry of Butter Making}

Churning; Dairy salt; Buttermilk; Losses of fat in butter making; Composition of butter; Butter colors ; Overruns; Dividends; Judging butter . . . . . 


\section{CHAPTER VIII}

\section{The Sanitary Condition of Milk}

Unwholesome milk; Factors influencing the sanitary condition of milk; Condition of the animals as to health ; Care of the animals ; Care of milk and dairy utensils ; Food and water which the animals receive; Colostrum milk; Tyrotoxicon; Fibrin in milk; Gases in milk; Keeping qualities of milk . . . . . . . .

\section{CHAPTER IX}

\section{The Chemistry of Cheese Making}

Cheese making and butter making compared; Proteids in

- milk; Casein; Albumin; Rennet; The rennet test; Process of cheddar cheese making; Process of stirredcurd cheese making; Distribution of milk solids in cheese making; Curing of cheese; The cheese yield of milk; Testing cheese by the Babcock milk test; Composition of cheese ; Testing whey ; Making out dividends in cheese factories; Comparative butter and cheese returns from milk; Different kinds of cheese . . . . .

\section{CHAPTER $\mathrm{X}$}

\section{MiLK BY-PRODUCTS}

Uses of by-products ; Skim milk - composition, value, and use; Whey - composition, value, and use; Fertilizer value of milk by-products; Comparative value of skim milk compared with milk of other domestic animals

\section{CHAPTER XI}

\section{The Adulteration of Dairy Products}

Oleomargarine; Simple methods for detecting oleomargarine; Renovated butter; Adulteration of cheese; Adulteration of milk; Other methods for testing milk; Dairy laws . 


\section{CHAPTER XII \\ Market Milk and Cream}

Variable character of market milk; Changes in composition of milk during transportation; Pasteurizing milk and cream ; Condensed milk ; Milk as human food .

\section{CHAPTER XIII}

Influence of Different Foods upon the Quality of Milk and Dairy Products

Food and milk secretion; Feeding fat; Production of hard butters; Production of soft butters ; Effects of individual foods; Desirable flavors in milk products ; Influence of balanced rations; Milk secretion . . . .

\section{CHAPTER XIV}

The Rational Feeding of Dairy Stock

Uses of food; Nutrients and their functions; Dry matter; Ash ; Organic matter; Proteids; Carbohydrates ; Crude fiber; Crude fat; Digestible nutrients ; Caloric value or heat units of a ration; Nutritive ratio; Selection of foods for rations; How to calculate a ration ; Comparative cost and value of grains . . . . .

\section{APPENDIX}

Tables of composition of fodders and feeding stuffs; Tables for correction of lactometer readings ; Review questions ;

References . . . . . . . 


\section{DAIRY CHEMISTRY}





\title{
DAIRY CHEMISTRY
}

\author{
CHAPTER I \\ THE COMPOSITION OF MILK
}

1. Complexity of Composition. - When milk is separated into its component parts, as water, fat, casein, albumin, sugar, and ash, the process is called analysis. While these are the principal compounds obtained when milk is analyzed, there are a number of other substances present in smaller amounts which affect the quality of milk both for manufacturing and food purposes. Milk is one of the vital fluids of the animal body and is necessarily of complex composition.

2. Milk Serum. - Of the various constituents of milk, the sugar, ash, and albumin are in solution, and in the fresh milk the casein is practically in a soluble form. The fat, however, is not in solution, but is in the form of minute globules suspended in the solution which contains the sugar, ash, albumin, and casein and which is known as the milk serum. The milk serum includes all of the constituents of the milk except the fat. The term "serum solids" is applied to those substances of milk which are dissolved in the water, - the sugar, ash, albumin, and casein taken collectively. 
3. Milk Solids. - - When milk is evaporated to dryness, the water is expelled and the milk solids are obtained. Milk solids are a mechanical mixture of fat, casein, albumin, milk sugar, and \ash. Normal milk contains about 13 per cent of solid matter; some samples contain as low as 12 and a few as high as 14 per cent. The amount of milk solids varies proportionally with the fat content of the milk, the higher the per cent of fat the larger the amount of solids.

In the chemical analysis of milk, the solids are obtained by evaporating a weighed quantity of milk to dryness in a small dish which has previously been carefully weighed on a very delicate balance. The weight of the milk solids is then obtained and the percentage amounts calculated.

ExAMPLE

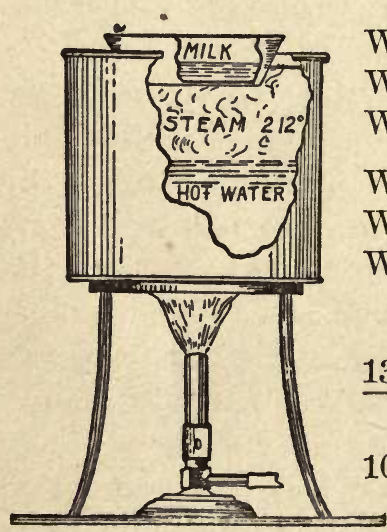

FIG. 1.-Determining the solids in milk.
Grams

23.360

12.850

$\overline{10.510}$

14.195

12.850

1.345

Weight of milk solids

$$
10.51: 1.345:: 100: x \text {. }
$$

$\frac{13.45 \times 100}{10.51}=12.80$ per cent solids. $100-12 . \dot{8} 0=87.20$ per cent water. The per cent of water in milk is obtained by subtract- 
ing the per cent of solids from 100, as the loss in weight during evaporation is the water expelled as steam. There are rarely more than 88 pounds of water in 100 pounds of milk; average milk contains about 87 per cent, while some of the richest milks contain 86 per cent or less. The milk solids, unless obtained in a specially constructed water oven, are brown in color, due to slight charring of the sugar and other compounds. The solids of milk are sometimes termed dry matter and sometimes solid matter. They are composed of fat, casein, sugar, albumin, ash, and other compounds found in smaller amounts.

4. Milk Fats. - Average milk contains about 3.5 per cent of fat; some normal samples may contain 3 per cent or less, while others may contain 5 per cent or more. Fat is the most variable constituent in milk. Cream contains ordinarily from 18 to 35 per cent of fat, and well-made butter about 85 per cent. For butter-making purposes the value of the milk is directly proportional to its fat content. Milk fat is mainly familiar as the product obtained by churning cream. Milk fat and commercial butter, however, are not synonymous terms. By milk fat is meant the pure dry fat, free from water, salt, or casein, while butter contains all of these materials in variable amounts. The determination of the fat in milk by the Babcock test is discussed in the second chapter of this work, and the composition and properties of the fats are considered in other chapters. 
As previously stated, the fat in milk is not present in solution, but in suspension in the form of minute globules. These milk fat globules are about one fivethousandth of an inch in diameter. A cubic millimeter of milk is estimated to contain from 2,000,000 to $4,000,000$ fat globules, or a single drop from $100,000,000$ to $150,000,000$. Under the microscope the fat globules appear grouped together in small colonies. The size of the fat globules varies (1) with the breed and individuality of the animal, and (2) according to the length of time the animal has been in milk. When a cow is fresh, there is a smaller number of globules, but the globules are larger; when the cow is well along in her milking period, the globules are smaller but more numerous. The milk from the Channel Island breeds is characterized by large fat globules, while the milk from the lowland breeds contains smaller globules. The fat globules must be massed together and collected when butter is made. The more completely they are recovered, the greater will be the amount of butter produced.

The fat globules are simply solid masses of fat. At one time it was believed that they were surrounded by a membrane, and in chuining it was supposed that the membrane had to be broken before the globules would mass. Recent chemical investigations have shown that there is no membrane surrounding the fat globules. The fat globules are lighter than any of the constituents of the milk 
PLATE I

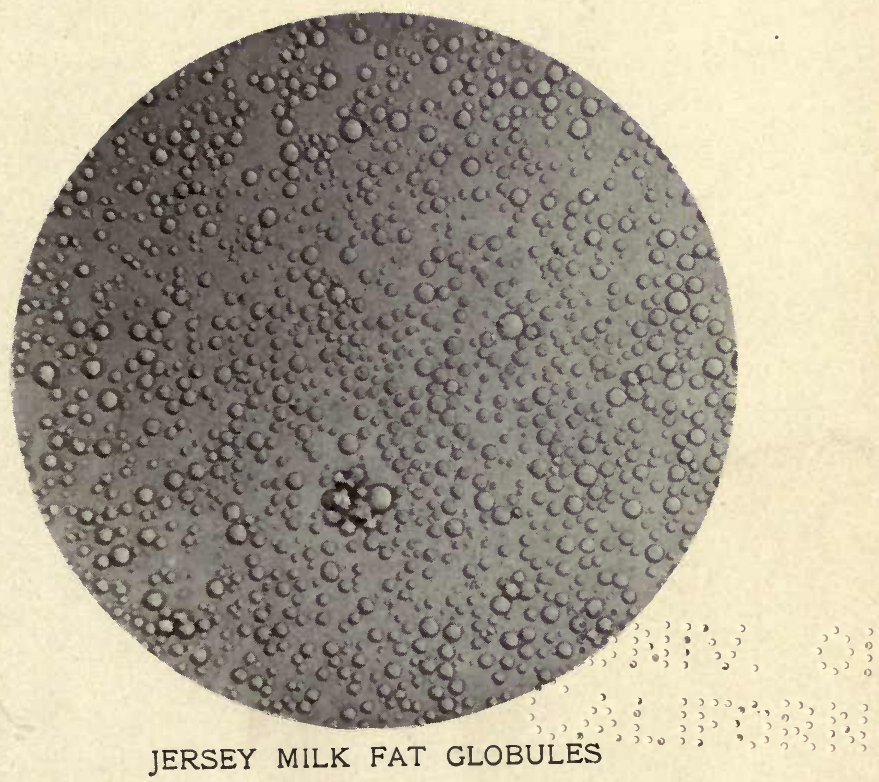





\section{PLATE II}

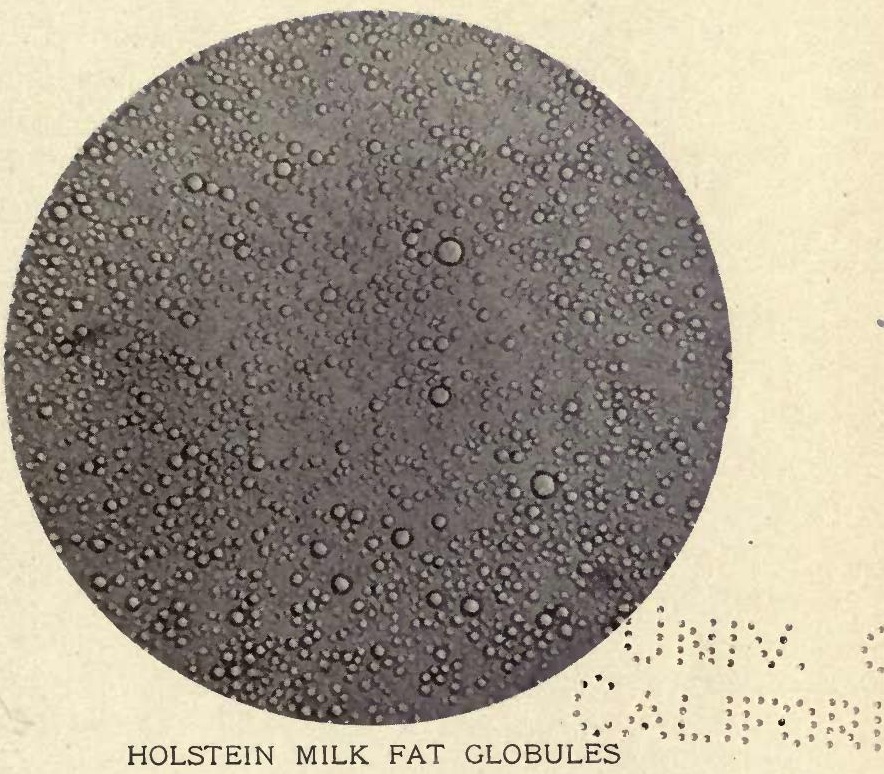



serum. They retain their form and individuality on account of surface tension, which is the pressure that is exerted on the surface of the globules and is equal on all sides, hence the spherical form of the globules.

5. Casein. - Average milk contains about 3 per cent of casein, which in fresh milk is practically in a soluble condition, but in sour milk is precipitated as curd. The per cent of casein in milk is quite constant, ranging from 2.8 to 3.5 per cent. As a general rule, normal milk contains less casein than fat. In a pure state casein is a grayish white powder. Casein takes a very important part in cheese making and other dairy operations. Its chemical and physical properties and the changes which it undergoes will be considered in other chapters.

6. Albumin. - Average milk contains about one half of one per cent of albumin, which is nearly identical with egg albumin, or the "white" of the egg. Albumin and casein have about the same general composition, but different properties; they belong to the class of bodies called proteids, and are very complex in composition, differing from fat and sugar by containing the element nitrogen, which is not found in the fats and sugars. When fresh milk is boiled, the coagulum which forms on the surface is albumin. The amount of albumin in milk is quite constant and ranges from one half to three quarters of a per cent.

7. Milk Sugar. - Lactose, or milk sugar, is present in milk to the extent of about 5 per cent. When 
obtained in the pure state, it resembles in appearance confectionery sugar, but not in taste. Milk sugar takes an important part indirectly in butter and cheese making, as it is the material from which the acid is formed that sours the milk. The amount of milk sugar or lactose in milk is quite constant, ranging from 4.6 to 5.4 per cent. In average milk it is the constituent which is present in the largest amount of any of the milk solids. The part which milk sugar takes in butter and cheese making will be considered in other chapters of this work.

8. Ash. - When the milk solids are burned, there is a small amount of grayish white ash obtained. The ash content of milk is constant and varies but little from three quarters of one per cent. Milk ash is composed of common salt, and phosphates and chlorids of potassium, calcium, and magnesium, together with small amounts of other minerals. A portion of the phosphorus is in combination with the casein.

When milk is analyzed in the laboratory, the ash is obtained by completely burning the milk solids at a low temperature. The small dish containing the milk solids (see section 3 ) is placed either over a specially regulated flame or in a low-temperature muffle furnace to completely burn the sugar, casein, albumin, and fat without volatilizing any of the mineral salts. The dish containing the milk ash is then weighed and the per cent of ash determined. 


\section{Example}

Milk taken $10.51 \mathrm{gm}$. See section 3.

Dish and milk ash

Dish

Ash

$10.51: .078:: 100: x$.

Grams

12.928

12.850

0.078

$.078 \times 100$

$10.51=.74$ per cent ash.

9. Variations in Composition of Milk. - Average milk has about the following general composition :-

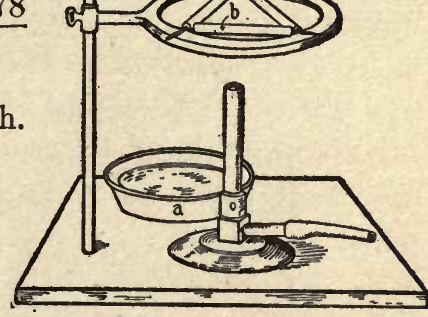

Frg. 2.-Determining the ash in milk.

\begin{tabular}{|c|c|c|c|c|c|c|c|c|}
\hline & & & & & & & Per cent & Range, Per orint \\
\hline Water & - & - & - & . & . & . . . & 87.00 & 89.6 to 82.4 \\
\hline Fat . . & . & . & - & . & . & . . . & 3.50 & 2.5 to 6.0 \\
\hline Casein . & • & . & • & - & - & . . . & 3.25 & 2.5 to 4.0 \\
\hline Albumin & . & . & . & & . & . . . & 0.50 & 0.5 to 0.8 \\
\hline Milk Sugar & & . & - & . & . & . . . & 5.00 & 4.3 to 6.0 \\
\hline \multirow[t]{2}{*}{ Ash . } & - & - & - & - & & . $\cdot$ & 0.75 & 0.6 to 0.8 \\
\hline & & & & & & Solids & 13.00 & 10.4 \\
\hline
\end{tabular}

It is seldom that the extreme limits as given for the composition of milk are met with; occasionally an individual animal may give milk of abnormally high or low solids and fat, but it is rarely the case that the milk from an entire herd will contain either the 
maximum or the minimum percentage of milk solids.

Milk varies in composition with the individuality of the animal, period of lactation, care, exhaustiveness of milking, general condition as to health, and nature of the food consumed. Individuality, as breed characteristics, influences the composition of milk to a greater extent than the other factors enumerated. The extent to which some of these factors influence the composition of milk will be discussed in other chapters of this work.

As an example of the composition of milk from different breeds, the following table taken from the New York Experiment Station, and representing one year's work, is given :-

\begin{tabular}{|c|c|c|c|c|c|}
\hline BREEDS & $\begin{array}{c}\text { Total } \\
\text { Solids } \\
\text { Per CENT }\end{array}$ & $\underset{\text { PER CENT }}{\text { FAT }}$ & $\begin{array}{c}\text { Casein } \\
\text { Per cent }\end{array}$ & $\begin{array}{c}\text { MILK } \\
\text { SugAR } \\
\text { Per CENT }\end{array}$ & $\underset{\text { PER OENT }}{\text { Ash }}$ \\
\hline Holstein-Fresian & 12.39 & 3.46 & 3.39 & 4.84 & 0.74 \\
\hline Ayrshire & 13.06 & 3.57 & 3.43 & 5.33 & 0.70 \\
\hline Jersey & 15.40 & 5.61 & 3.91 & 5.15 & 0.74 \\
\hline Am. Holderness & 12.63 & 3.55 & 3.39 & 5.01 & 0.70 \\
\hline Guernsey & 14.60 & 5.12 & 3.61 & 5.11 & 0.75 \\
\hline Devon & 13.77 & 4.15 & 3.76 & 5.07 & 0.76 \\
\hline
\end{tabular}

While these figures do not necessarily hold true for all herds, or for individual animals of any breed, they show the average composition of the milk for an entire season from a number of representative animals of different breeds. In determining the 
value of milk for butter or cheese making purposes, the yield in pounds as well as the percentage composition of the milk must be considered, as it frequently happens that the cows giving the richest milk also give the smallest yield of milk.

10. Percentage Composition and Total Yields. - In order to determine the total yield in pounds of each constituent produced by a cow or by a herd for a given period, the total weight of milk is multiplied by the percentage composition. In case it is desired to compare the yields of milk solids of two cows, giving respectively a total of 110 and 140 pounds of milk in three days, an analysis would have to be made of each milk. Suppose the milks give the following results upon analysis :-

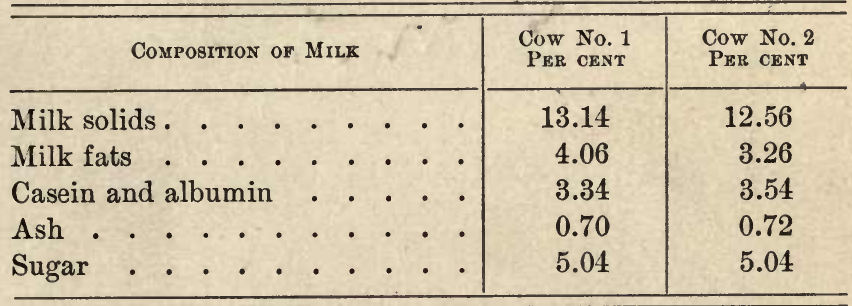

Total Yield of Milk Solids

Cow No. 1

Cow No. 2

Milk fats, $110 \times .0406=4.47$

Casein, $\quad 110 \times .0334=3.67$

Ash, $\quad 110 \times .007=0.77$

Sugar,

$110 \times .0504=\frac{5.54}{14.45}$

$140 \times .0326=4.56$

$140 \times .0354=4.95$

$140 \times .0072=1.01$

Total

$140 \times .0504=\frac{7.06}{17.58}$ 
While the difference in percentage composition of the milk is 8 of a per cent of fat in favor of cow No. 1, the total yield of fat for three days is .1 of a pound in favor of cow No. 2. Cow No. 2, however, produced a larger amount of milk solids in the form of fat than cow No. 1. In general it is to be noted that whenever a cow produces a pound of butter fat, she also produces about 1.1 of milk sugar, about a pound of casein and albumin, and about .15 of a pound of ash. When milk is paid for on the basis of its fat content for butter making purposes, the total pounds of fat are obtained by multiplying the weight of the milk by its per cent of fat, as 287 pounds of milk testing 3.6 per cent fat contain $(287 \times .036) 10.33$ pounds of fat. In dairy operations all comparisons and calculations are made on the basis of the total fat.

11. First or Fore Milk and Strippings. - As is well known, the first portion of milk given by any cow at a milking is poor in fat, while the last portion, or strippings, is very rich in fat. The per centage amounts of casein, ash, and sugar, and other ingredients, however, remain nearly constant. The difference in fat content between the first or fore milk and the strippings suggests the importance of careful and exhaustive milking, and also thorough mixing of the milk before taking a sample for analysis. The composition of the first pint and the last pint of milk from two cows is given as an illustration. 


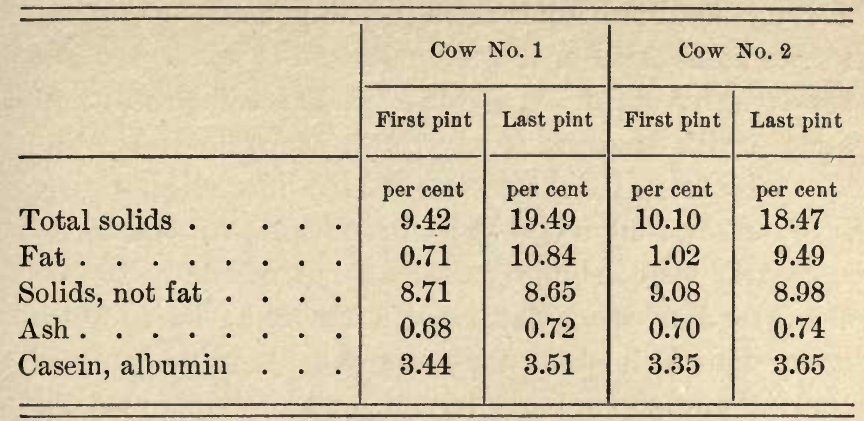

12. Milk Serum, Constancy of its Composition. The solids of the milk serum are fairly constant in composition. This is well illustrated in the example

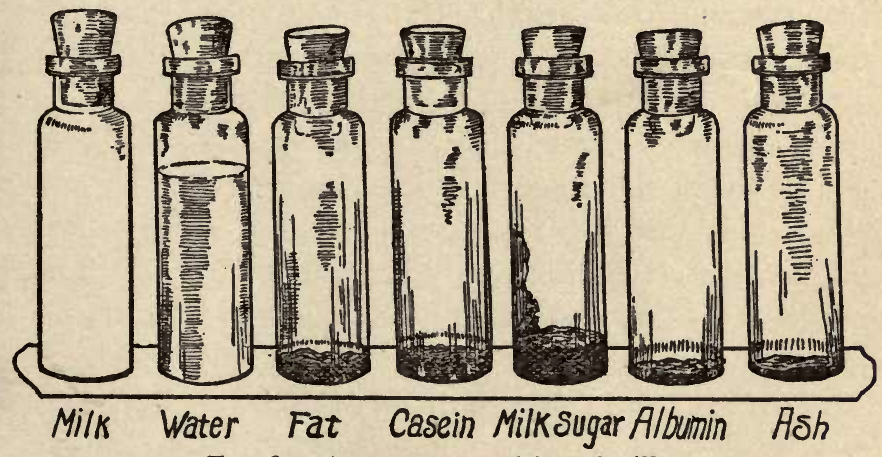

Fig. 3. - Average composition of milk.

given of the composition of first or fore milk and strippings. The solids of the milk serum, also known as the solids not fat, are never less than 8.25 per cent and rarely more than 9.75 per cent. The 
average is about 9 per cent. The greatest difference in the composition of various milks is in the fat content. Any material increase in the total solid matter of milk is due mainly to an increase of the fat. The solids not fat are subject to but slight variations compared with the fluctuations of the fat.

Nearly all of the important fluids of the body, like the blood, are normally quite constant in chemical composition. With milk the constancy of composition is confined mainly to the serum solids, or solids not fat. 


\section{CHAPTER II}

\section{MILK TESTING}

13. Importance of Milk Testing. - A knowledge of the fat content of milk is essential in order to determine (1) any unnecessary waste in the manufacture of butter and cheese, (2) the value of individual cows, (3) the cost of producing milk, (4) the value of different fodders and grains for milk-producing purposes, and (5) the commercial value of milk.

A number of simple methods have been proposed for testing milk; some of them require a more extended knowledge of chemical operations than others. The method which is in most general use on account of its accuracy, simplicity, and cheapness is the Babcock centrifugal method.

14. Reliability of the Babcock Test. - This method has been tested by many chemists, and in all cases it has been found to give reliable results. There is a tendency, however, to read the fat percentages too low. This will be considered more in detail in discussing that part of the operation. In the case of skim milk and buttermilk, when the fat is present to the extent of only two tenths of a per cent or less, the method may not give absolute results. This 
does not impair the usefulness of the test, because frequently the losses in skim milk and buttermilk are greater than this, and so far as the whole milk is concerned the method is perfectly reliable. When the Babcock test shows only a trace of fat in the skim milk or buttermilk, the losses are very small.

15. Sampling Milk. - Milk should be thoroughly mixed before sampling. The milk as it comes from the cow or when it has been standing is not in a condition to sample until it has been thoroughly mixed, either by pouring from one pail to another or by stirring with a long-handled dipper. Milk brought to the creamery in cans also requires thorough mixing before sampling. This is best accomplished by the use of a long-handled dipper. Before sampling, the milk should be weighed.

The milk should not be measured into the test bottles when it is either hot or cold. At a ligh temperature the milk is expanded and may contain an abnormal amount of dissolved air ; while at a low temperature the milk may be unduly contracted. A temperature of $70^{\circ}$ to $80^{\circ}$ is the most suitable for measuring milk. If the milk has been standing for some time in the sample bottle, it is necessary to mix it thoroughly before measuring with the pipette. To do this, turn the milk from the sample bottle into another bottle or dish, pouring it down the side to prevent the formation of foam. In case the sample bottle has been standing until the fat has separated into a layer of cream, the bottle may be placed in a 
bath of warm water, temperature $100^{\circ}$, to liquefy the fat before mixing. Milk which shows the presence of clots of cream or small particles of butter formed during the shaking of the sample bottle is not in condition to be measured with the pipette. If the sampling of the milk has not been carefully done, the work of testing is of little value, as the sample taken fails to represent the milk tested.

16. Measuring Milk with the Pipette. - The apparatus used for measuring the milk is called a pipette (see Fig. 4). In order to fill the pipette put the pointed end into the milk, apply suction with the mouth until the milk rises just above the point $a$ on the stem; then close the end with the index finger of the

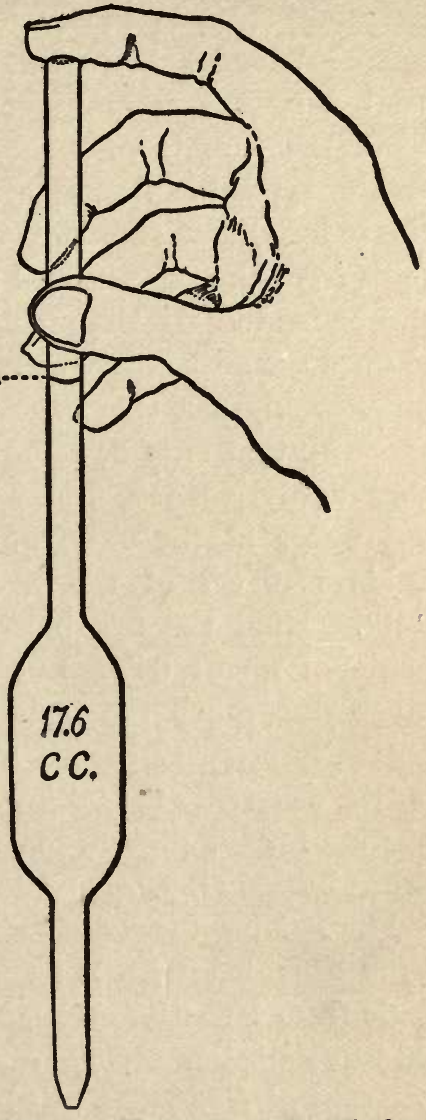

Fig. 4.-Measuring milk with the pipette. right hand, holding the pipette in the way shown 
in the cut. The second and third fingers are opposite the thumb, while the little finger rests against the stem. When held in this way, the pipette is prevented by the little finger from swaying sidewise; while the thumb, with the second and third fingers on the opposite sides, secures a good hold and leaves the index finger free to properly control the flow of milk from the pipette, and thus rapid measurements can be made. If the pipette is wet, rinse it with a little of the milk before using it. In passing from one milk to another, clean the pipette by rinsing it with the milk that is to be tested. The pipette should be thoroughly cleaned, first with cold water, then with hot water at the close of the work. The pipette holds $17.6 \mathrm{cc}$. of water, and delivers $18 \mathrm{gm}$. of milk. Hold the test bottle in the left hand at an angle of about $60^{\circ}$. Let the tip of the pipette if large just touch the inside of the neck of the test bottle, in order to permit air to pass out of the test bottle, otherwise the milk will spatter. Allow plenty of time for the pipette to drain; remove the last few drops by blowing.

17. Making the Test. - The test bottle (see Fig. 5) is provided with a neck which has a graduated scale from 1 to 10. Each larger division is divided into five smaller divisions, each representing .2 of a per cent of fat. The test bottle is usually provided with a copper collar bearing a number. Fill the acid measure, Fig. 6, up to the 17.6 cc. mark with sulphuric acid. The action of the sulphuric acid 
will be considered in another paragraph. Pour the sulphuric acid from the acid measure into the test bottle which contains the milk. The acid and the milk

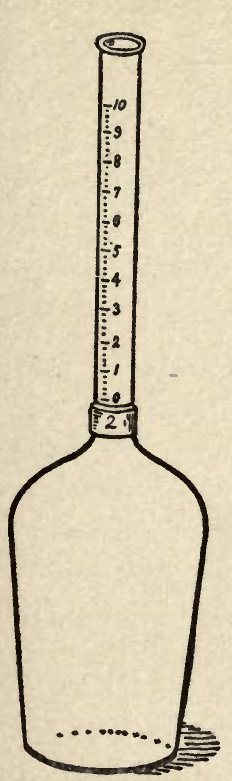

Fig. 5. - Milk test bottle. should be of nearly the same temperature, $70^{\circ} \mathrm{F}$.

While the acid is poured in, rotate the test bottle so as to wash all of the milk down from the stem. After the acid is added, take the bottle by the stem and mix the acid and the milk by rotating. The solution becomes a dark coffee color, due to the acid charring the sugar. The

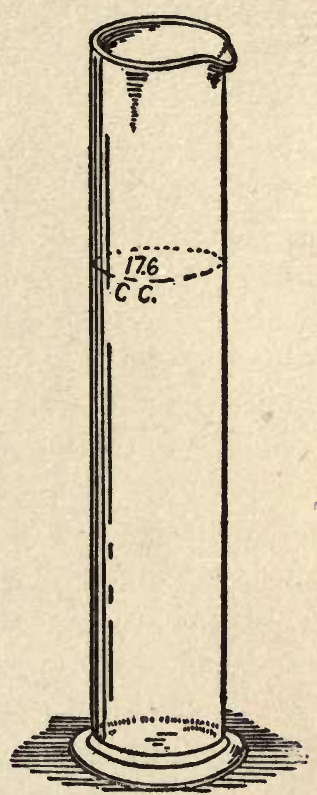

Fig. 6.-Acid measure.

acid first precipitates the casein and then dissolves it. The acid does not act on the fat.

The fat is separated from the milk serum by centrifugal action. There are a number of different kinds and sizes of centrifugal machines, but they all act on the same principle. The test bottles are placed in the pockets of the centrifugal machine. 
In case there are not enough bottles to fill the machine, arrange the bottles so there will be an even number on each side. If this is not done, the machine is unbalanced, and the bearings will soon become badly worn. The bottles are to be whirled five minutes at the rate of 900 revolutions per minute. Directions for speeding the machine will be found in another paragraph. The starting and stopping of the machine should be done gradually.

After whirling five minutes, the test bottles are to be filled with hot water up to about the eighth mark on the stem. The air bubbles which are sometimes caught in the neck should be allowed to escape. The bottles are then whirled two minutes longer in order to collect all of the fat in the graduated stem. In using the machine always put on the cover so as to prevent any accident.

None of the apparatus used in this test is patented, and a good homemade centrifugal machine will answer every purpose. The bottles and other glassware can be purchased separately.

18. Reading the Fat. - When the test is completed, the fat in the stem of the test bottle presents the appearance shown in Fig. 7. Read from the lowest point $b$ to the highest point $a$. Each large division, as 1 to 2, represents a whole per cent of fat; each of the smaller divisions one fifth or two tenths of a per cent. Suppose the top registers seven large divisions, and three small, then $a=7.6$. If $b$ registers 
two large and three small divisions, $b=2.6$. $7.6-$ $2.6=5.0$, the per cent of fat in the milk.

Do not read from other points than $a$ and $b$, otherwise the results will be too low. The bottles are made to read in just this way. The reading should be done before the fat cools and streaks down the sides. In case a number of readings are to be made, the test bottles should be set in a pan of hot water, or hot water can be run into the pan of the machine, to prevent the bottles from

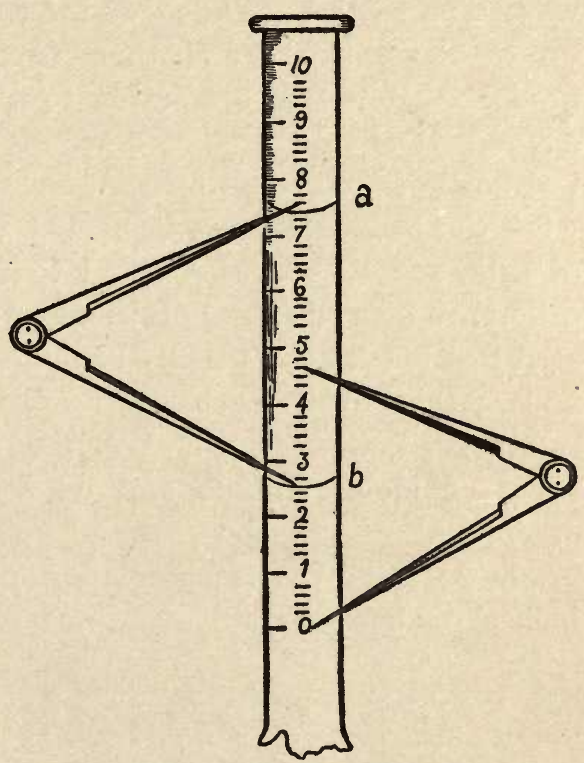

Fia. 7. - Reading the test. cooling. Dividers can be used as indicated in the figure, but should be spread from 0 to 5 .

19. Calibration of Test Bottles. - All test bottles should be rejected when inaccuracy of the divisions can be detected with the eye. In the most careful work they should be calibrated with mercury: 27.18 gm. of clean metallic mercury should just fill the 
space between the 0 and the 10 in the scale. Each small division is equal to .04 cc., or, as usually made, about one and one half millimeters. The test bottles can also be calibrated with water in the following way: The bottles are filled with pure distilled water up to the 0 mark, and then from an accurately graduated burette, graduated to $\frac{1}{20}$ cc., water is added. It should require $2 \mathrm{cc}$. of water to fill the test bottle from the 0 to the 10 mark. For ordinary work the bottles can all be tested with one sample of milk, and all bottles rejected that show a greater difference than one small division. Accurately graduated test bottles can usually be obtained from supply houses that deal in chemical apparatus. Inaceurately graduated test bottles are occasionally the cause of much trouble and dissatisfaction in the creamery.

20. Speeding the Machine. - A centrifugal of $\mathbf{1 4}$ inches' diameter should make about 900 revolutions

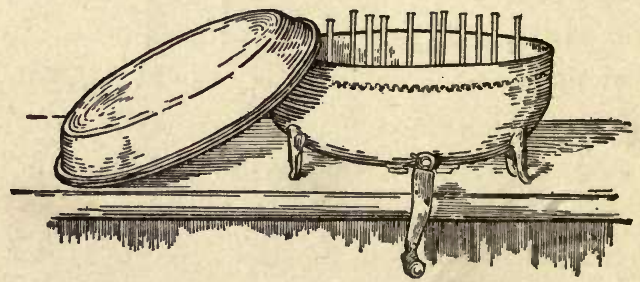

FIG. 8.-Centrifugal machine.

per minute. In order to speed the machine count the number of revolutions that the test bottles make 
for every revolution of the crank wheel. Suppose the test bottles make 12 revolutions while the crark makes one. In order that the bottles may make 900 revolutions per minute, the crank must be turned 75 times in a minute $(900 \div 12=75)$. In case the machine is less than 14 inches in diameter a greater number of revolutions is necessary.

Diameter of Centrifugal. Inohes Number of Revolutions Per Minute

10
12
14
16
18
20
1050

975

900

850

800

750

21. Centrifugal Action. - As previously stated, the fats are lighter than the milk serum, and when the milk is whirled in the test bottles, there is a separation of milk fats (lighter particles) from the milk serum (heavier portion). The serum goes to the outside of the circle of revolution, while the fats mass in the center, where they are finally collected in the graduated stem of the test bottle. The sulphuric acid, which is one and eight tenths heavier than water, also aids in the separation both by increasing the specific gravity of the milk serum and by chemical action upon the albumin and casein. The cream separator works. on this same principle. In the case of the separator, provision is made for the escape of the fat into a tube as it collects at the center. Centrifugal action is well illustrated by whirlpools, where 
all of the foam and light material, as leaves, collect in the center.

22. The Acid. - Commercial sulphuric acid (sp. gr. 1.82), about 90 per cent strength, is used. One pound of acid will make about twenty tests. When the acid is too strong, the fat presents a blackened and charred appearance; if too weak, particles of undissolved easein appear immediately below the fat line. When just right, the fat separates in a distinct and well-defined layer and looks like butter. If the acid is too strong, and chars the fat, use a smaller amount in making the test. In that case, if the test is not satisfactory, the acid should be exchanged for a new lot. Do not attempt to dilute the acid with water. If the acid is too weak, a larger amount than $17.6 \mathrm{cc}$. may give satisfactory results. The strength of the acid can be determined by using a hydrometer for heavy liquids, and noting the depth to which the spindle sinks in the acid. To obtain the best results, the acid should vary but little from 1.82 specific gravity or 90 per cent strength.

Strength of Aord
88
89
90
91
92
93
94
95

SPECIFIo Gravity

1.808

1.815

1.820

1.825

1.830

1.834

1.837

1.839 
The acid as well as the washings and contents of the test bottles can be handled only in glass or earthenware.

The acid should never come in contact with tin or a metallic dish of any kind. If acid is spilled on the floor or desks, wash it up immediately, using plenty of water. If a large quantity is spilled, absorb it with sawdust, bran, or fine clay. In case any is spilled on the clothing, rinse with water and then apply ammonia to the spots. Never throw the acid waste near a tree or where a person or animal is obliged to walk.

A convenient form of apparatus for measuring the acid where a large number of tests are to be made is shown in Fig. 9. $a$ is the acid bottle connected

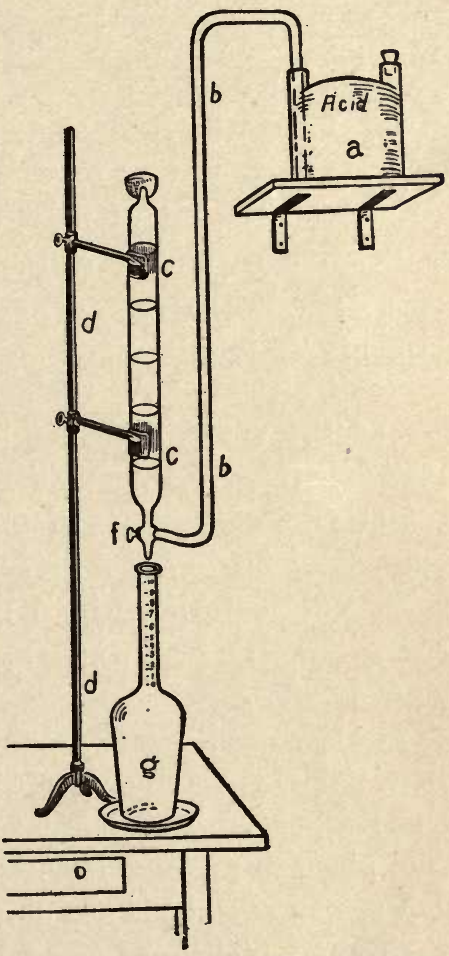

FiG. 9. - Acid measuring apparatus. with glass tube $b b$ to a pipette. The stopcock $f$ can be turned so as to allow the acid to run into the test 
bottle $g$. The automatic pipette is fastened to an iron stand $d d$, which rests upon the table. Other forms of apparatus are also in use. In ordinary practice a strong glass vessel with a good lip for pouring is the most satisfactory arrangement for handling the acid. A white tile is excellent to have on the table under the acid bottle.

23. Composite Sample. - In actual creamery practice the daily testing of each patron's milk, or in the dairy, the testing of both morning's and evening's milk from each cow is too expensive. To obviate this daily testing, a composite or compound sample is made up by saving a small sample of each milk in a pint fruit can. At the end of one week or of two weeks the compound sample is carefully mixed and tested. Inasmuch as this test represents a proportional part of each lot of milk, it gives the average amount of fat in the milk for the period. In creameries and factories, where milk is paid for by test, the composite test when properly carried out gives good results.

The composite sample should be kept covered so that the surface of the cream will not become dry and leathery. The sample should also be kept in a cool place to prevent fermentation.

Various chemicals are used to keep the milk fresh. Potassium bichromate has been found to give the best satisfaction. About one half gram of potassium bichromate will be sufficient to preserve a pint of milk. Winton and Ogden state that a .22 pistol 
shell cut one-half inch long will hold, loosely filled, approximately one-half gram of bichromate. For convenience in handling the shell can be soldered to a piece of stout wire. Put the bichromate in the sample cans when empty, and no more need be added until a new composite sample is started. The bichromate imparts its characteristic yellow color to the milk.

In case corrosive sublimate or any other poisonous material is used for preserving the composite sample, it is best to color the milk with aniline so as to prevent accidental poisoning from use of the milk.

Small four or six ounce, wide-mouthed bottles may be used for holding the composite samples. Bottles with glass stoppers are the best. Rubber stoppers may be used, but cork stoppers should never be used. They are difficult to clean, and they cause the milk to sour. When the composite sample becomes "lumpy" and is difficult to sample, a very small $(.1 \mathrm{gm}$.) piece of caustic potash may be added before mixing the milk. The potash will dissolve the lumps of curd. A few drops more than $\mathbf{1 7 . 6}$ cc. of acid should then be used.

When only a small number of tests are to be made, the following plan may be followed: Save about two ounces of each milk separately in glass bottles or cans; at the next milking add a proportional quantity. A composite sample of the day's milk is thus obtained, and while still fresh is mixed, and then by means of a small pipette, $5.9 \mathrm{cc}$. àre measured into a test bottle twice the size of those ordinarily used, or test bottles made for 35 cc. of milk. In a similar 
way the milk for six days may thus be measured directly into the test bottles, and then tested.

24. Testing Skim Milk. - In testing skim milk the special test bottle devised by Farrington, with the

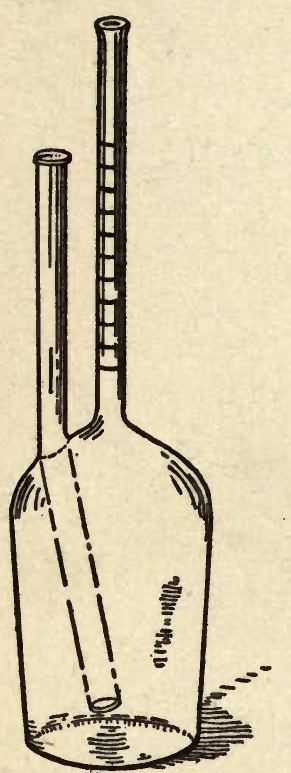
small neck and the side tube for the addition of the acid, should be used (see Fig. 10). Each division on the neck represents .05 of a per cent. In using these bottles, it must be remembered that the small amount of fat obtained in the neck is not necessarily all of the fat in the skim milk, because some of it may be present in such a fine state of division that it is not brought up into the neck. Hence the results are usually slightly lower than those obtained by chemical analysis. This, however, does not seriously impair the test. When the test shows only a trace of fat, the Fra. 10.-Skim milk test butter maker can feel satisfied that bottle. he is doing good work.

25. Sampling Frozen Milk. - When a can of milk freezes, the ice forms on the outside and there is usually a central part that does not freeze. The unfrozen part is richer in fat and solids than the frozen part. The ice in the center of a can is richer in milk solids than the ice of the outer portions. When 
frozen or partially frozen, milk is not in a condition to sample, but should be allowed to thaw and then be thoroughly mixed.

26. Cleaning Glassware. - In order to secure the best results, the test bottles and all of the glassware used in testing milk should be kept clean. The test bottles should be emptied before the fat becomes cold and hard. By shaking the test bottle, the sediment of lime sulphate or gypsum is removed with the acid mixture. The test bottles can be left to drain on the drain board placed over the acid waste jar. A drain board with holes large enough to receive the neck of the test bottle will be found very useful in handling a large number of test bottles. The test bottles should be rinsed while still hot with warm. water and after draining this should be followed by a second rinsing with hot water. A small brush will be found useful in keeping the necks of the bottles clean. Occasionally it will be necessary to give the test bottles a bath in hot water containing a little alkali, sal soda, Babbitt's potash, gold dust, or any similar material dissolved in the water in small amounts. A small copper tank large enough to receive a rack containing twelve to twenty-four test bottles so they may be completely immersed will enable the creamery or factory man to keep his test bottles in a good condition.

27. Water used in Milk Testing. - Hard waters containing large amounts of lime or alkaline salts are not suitable for use in milk testing. Rain water 
or other soft water or condensed steam is preferable. When water containing lime is used, bubbles of gas are given off, causing foam when the hot water is added to the test bottles containing the acid. The presence of foam in the graduated stem of the test bottle prevents accurate reading of the fat. Some hard waters are suitable for use provided a few drops of sulphuric acid are added before heating. If this is done, of course the water cannot be heated or used in ordinary metal boilers and receptacles. When a large number of tests are to be made, a suitable outfit should be provided for the addition of hot water to the test bottles; a pail suspended three or four feet above the tester with a rubber tube, a pinch cock, and a glass tube drawn to a point, will be found suitable for this purpose.

28. Care of Test Bottles and Apparatus. - The rims on the necks of test bottles are easily nicked and broken, and in handling bottles, care should be exercised to prevent this being done. Some bottles are provided with ground or roughened places for labeling or marking with pencil, while others have numbered copper or metal "collars." In making the test, the numbers should be carefully checked, and the proper entries made as to the sample and the fat content. Many conveniences in the way of homemade racks and devices for holding the apparatus will suggest themselves. In milk testing, cleanliness and accuracy in all the manipulations are the main essentials for securing correct results. 


\section{CHAPTER III}

\section{MILK FATS}

29. Composition of Fats. - The fat globules of milk are a mechanical mixture of several separate fats. All fats are composed of the elements carbon, hydrogen, and oxygen; but individual fats differ in the way in which these elements are combined. In all the fats, carbon, the principal element found in coal, is present to the extent of over 75 per cent. The fats as a class do not contain any nitrogen, differing in this respect from casein and albumin, which contain about 16 per cent of this element. Each fat has its own melting point, form of crystals, specific gravity, and other characteristics, and hence the physical properties of butter are largely dependent upon the proportion in which the principal fats are present. Some of the milk fats are hard, and have a high melting point, while others are liquid. The character of butter, as hard or soft, is dependent largely upon the proportion in which the various fats, as stearin, palmitin, and olein, are present.

30. Kinds of Butter Fats. - The various fats which are present in butter are butyrin, caproin, caprylin, laurin, palmitin, myristin, stearin, and olein. Of 
these fats, palmitin, stearin, and myristin make up about 50 per cent of the composition of butter fat, olein about 38 per cent, and butyrin, the characteristic fat of butter, about 6 per cent; the remaining 6 per cent being made up of laurin, capin, caproin, and caprylin. For practical purposes, butter fats may be divided into three classes: (1) hard fats, stearin, palmitin, and myristin, (2) soft fat, olein, (3) characteristic fat, butyrin.

31. Palmitin is a white, solid fat found in butter, and also obtained from palm oil. Human fat is rich in palmitin. When chemically pure, it is tasteless. Palmitin forms crystals like snowflakes. This fat has a high melting point, $145.4^{\circ} \mathrm{F}$.

32. Stearin is a white, solid fat like palmitin, and has a high melting point, $157^{\circ} \mathrm{F}$. It also crystallizes in the same way as palmitin. For a long time these two fats, palmitin and stearin, were thought to be one fat, to which was given the name margarine. Among the fats that are particularly rich in stearin are beef and mutton tallow. These melt at a much higher point than butter, and are the materials used in the adulteration of butter, forming a large part of the product known as oleomargarine, which is a mechanical mixture of the fats palmitin and stearin (margarine) with olein. The larger the proportion of either stearin or palmitin in any fat, the higher its melting point. When one butter has a higher melting point than another, it is due to the presence of a larger amount of palmitin or stearin. These 
two fats, with myristin, make up about half of the weight of the milk fats.

33. Olein is quite different from either palmitin or stearin. This fat makes up about 40 per cent of the weight of butter. Under ordinary conditions olein is a liquid. It solidifies at a temperature of $40^{\circ} \mathrm{F}$. It is liquid at the ordinary temperature of the cold deep setting of milk, that is, the setting of milk in ice water. Olein has the property of readily and copiously dissolving palmitin and stearin. The larger the per cent of olein in a butter or fat, the softer it is. Sperm oil, cod liver oil, and many of the vegetable oils are rich in olein.

34. Butyrin melts at a temperature of $77^{\circ} \mathrm{F}$. Milk fats contain from 5 to 7 per cent of butyrin. Although it forms such a small proportion of milk fat, it is the characteristic fat of butter. It is the butyrin which gives to butter its individuality, and its presence or absence is the distinguishing point between butter and oleomargarine. Butyrin, when decomposed, forms butyric acid. In rancid and stale butter, the rank odor is due to butyric acid. Butyrin is not as stable a fat as palmitin, stearin, or olein.

35. Caproin and Caprylin comprise only a small part of the fats of milk, and they do not require any special consideration.

36. Glycerine and Fatty Acid Content of Fats. When fats are broken up into simpler products, glycerine is one of the substances formed; the other 
- product is a fatty acid with an "ic" ending in place of the "in" ending of the fat.

By the action of superheated steam,

Palmitin yields palmitic acid and glycerine.

$\left.\mathrm{CON}_{2}\right)_{7} \operatorname{Cos} \mathrm{f}$ Olein yields oleic acid and glycerine.

$\mathrm{N}_{3}+\mathrm{O}_{2}$

Stearin yields stearic acid and glycerine. $\mathrm{C}_{7} \mathrm{~N}_{B_{5}}-\mathrm{COQ} \mathrm{N}$

Butyrin yields butyric acid and glycerine. $\mathrm{CN}_{3}\left(\mathrm{CN}_{2}\right)_{2}$ OO

Caproin yields caproic acid and glycerine. $\mathrm{CH}_{3}\left(\mathrm{CH}_{2}\right)_{4} \mathrm{CO}$

Caprylin yields caprylic acid and glycerine. $\mathrm{CH}_{3}\left(\mathrm{CN}_{2}\right)_{6} \mathrm{CO}$

Glycerine is alkaline in its properties, and it is the glycerol radical which unites with the fatty acids to form neutral fats. Milk fats are frequently defined as glycerides of the fatty acids. They are neutral bodies. All of the fats are lighter than water. The mixed butter fats are insoluble in water ; all are soluble in ether, chloroform, gasoline, and similar solvents. Butyrin, caproin, and caprylin, when exposed to air and light for any length of time, undergo decided changes in composition, which finally result in the production of the corresponding fatty acids which are present in rancid butter.

37. Food Value of Fats. - Fat is a concentrated form of heat-producing food, because it contains such a large amount of carbon. In very small seeds, like flax, the fat is one of the main reserve forms of food. One pound of fat when burned will produce about two and one fourth times more heat than a pound of starch. Butter, which contains about 85 per cent of fat, is valuable in a ration for the heat and energy which it produces. 
38. Saponification of Fats. - When certain chemicals, known as alkalies, such as potash and soda, are heated with fat, they form soap; the process is called saponification. When saponification takes place, part of the alkali unites with the fatty acid of the fat and forms soap, while the glycerine radical of the fat unites with the remainder of the alkali and forms glycerine.

39. Iodine Absorption of Butter Fats. - In common with other fats, butter fats have the property of absorbing a definite amount of iodine. The iodine number of butter, or the percentage of iodine absorbed by the fats, ranges from 28 to 35 , while lard, tallow, cotton-seed oil, and other commercial fats and oils generally, have a greater capacity to absorb iodine and hence have a higher iodine absorption number. The iodine absorption number is frequently used as an aid in detecting adulterated samples of butter.

40. Volatile Fatty Acids of Butter. - When butter fats are saponified and free fatty acids are liberated, about 8 per cent of the volatile fatty acids are also liberated and are volatilized in a current of steam. In the analysis of butter, the amount of volatile fatty acids obtained from $5 \mathrm{gm}$. usually requires from 27 to $28 \mathrm{cc}$. of a tenth normal solution of alkali for neutralization; this is known as the Reichert-Meissel value of butter, and is extensively used in detecting adulterated butter. Spurious samples, as oleomargarine and butterine, have a low 
value, less than 3 , because of their not containing any butyric acid.

41. Melting Point and Physical Properties of Butter. - Normal butter has a melting point of about $33^{\circ} \mathrm{C}$. Butter with an abnormal melting point is of poor quality because of an excess of some fat, as olein, stearin, or palmitin. The specific gravity of butter fat ranges from .867 to .87 when taken at a temperature of $100^{\circ} \mathrm{C}$. and compared with water at $15^{\circ} \mathrm{C}$, or when compared with water at $100^{\circ} \mathrm{C}$, .910 to .915 . The specific gravity of other fats used for adulterating butter is slightly lower than that of butter. A normal specific gravity is a definite characteristic of genuine butter. The specific gravity, melting point, and general physical properties of butter fat are different from those of any other fat. 


\section{CHAPTER IV}

\section{THE LACTOMETER AND ITS USE IN DETERMINING}

MILK ADULTERATION

42. Quevenne's Lactometer. - The lactometer is a piece of apparatus used for determining the specific gravity of milk. It consists (see Fig. 11) of a bulb weighted with mercury attached to a glass tube of cylindrical form provided with a graduated stem, which enables the operator to determine the depth to which the instrument sinks in milk. Numbers registered on the lactometer scale range from 15 to 40. These are called the lactometer degrees. If the lactometer sinks to a depth of 31 on the scale, it means that the milk has a specific gravity of 1.031 . In normal milk the lactometer shows a specific gravity of 1.029 to 1.034. Between each of the numbered divisions, as 25 to 30 , there are five subdivisions, which enable the operator to read to a .001 on the specific gravity scale, or less if care is taken in the observations.

There are other forms of lactometers in use, but the Quevenne's is generally preferred because of its greater accuracy. A lactometer should always be provided with a thermometer in order that the necessary corrections for temperature of the lactometer readings may be made. 
43. The Specific Gravity of Milk. - If a can holds 100 pounds of water, to fill it with milk would require

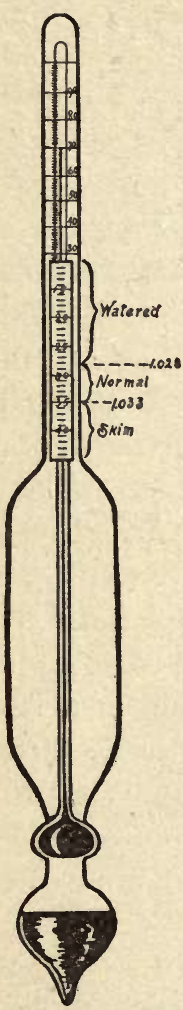

Fra. 11. - Quevenne's lactometer. about 103.2 pounds. This is because milk has a greater specific gravity than water. By the specific gravity of a material is meant the weight of a given volume compared with the weight of an equal volume of water under the same conditions. Milk has a higher specific gravity than water because it contains in solution a number of substances, as sugar, ash, casein, and albumin, which increase the weight of an equal volume of milk, causing it to have a higher specific gravity. The fat of milk, on the other hand, which is lighter than water, has a tendency to lower the specific gravity. As stated in a previous chapter, the specific gravity of milk fat is about .91. Since the amount of sugar, ash, casein, and albumin in different samples of milk is fairly constant, it follows that the specific gravity of the milk serum is quite constant. Since the variations in the fat content of milk range between 3 and 6 per cent, it follows that the variations in the gravity of milk are due largely to the variations in the fat content. Since the milk fats vary between known limits, the specific gravity of normal milk 
varies between definite limits. The lowest specific gravity of normal milk is 1.029 , while the highest specific gravity is 1.034; - The richer a sample of milk in casein, milk sugar, and ash, the greater its buoyant power and the higher specific gravity, which results in the lactometer stem not sinking to so great a depth as it would if less casein, sugar, and ash were present. Hence we find skim milk having a greater specific gravity than normal milk. On the other hand, the addition of water to milk lowers the specific gravity below 1.029 almost proportionally with the amount of water added. Milks very rich in fat have a lower specific gravity than milks which contain less fat. This is due to the additional fat in the milk lowering its specific gravity. A skilled operator can readily determine whether the increase or decrease in the specific gravity of milk is due to variation in the water or the fat content of the milk.

44. Influence of Temperature. - Whenever a lactometer reading is made, the temperature of the milk should also be recorded, because a variation of $10^{\circ}$ in temperature affects the lactometer reading to the extent of $1^{\circ}$. When milk is cold, it is contracted in volume and the lactometer does not sink to as great a depth as if the milk were warm. This results in the lactometer recording a high specific gravity. On the other hand, if the milk is too warm, it is expanded, which has the effect of diluting the milk, causing the lactometer to sink to a greater depth and a lower specific gravity to be secured. In mak- 
ing corrections for temperature, the following general rule can be applied: When the temperature is greater than $60^{\circ} \mathrm{F}$, add .1 of a lactometer degree for each degree of temperature, and when less than $60^{\circ} \mathrm{F}$., subtract .1 for each lactometer degree. This general rule will apply only for a variation of 15 degrees either above or below the temperature of $60^{\circ}$. In case more accurate corrections for variation in temperature are desired, these will be found in the tables in the appendix.

45. Other Lactometers. - The New York Board of Health lactometer is graduated into $120^{\circ}$. The 100 mark represents milk with a specific gravity of 1.029; milk with a lower gravity shows a reading of less than 100 on the lactometer scale, the percentage being somewhat proportional to the amount of water added, a reading of 75 indicating that the milk is 75 per cent pure, while a reading of more than 100 indicates that the milk is above legal standard as to fat content. These readings are, in general, proportional to the character of the milk and show whether extensive adulterations, as skimming or watering, have been practiced. But, considered alone, the lactometer results obtained by either the Quevenne or the New York Board of Health lactometer are liable to error, not on account of any imperfection in the principle or the instrument, but because of the complexity of the composition of milk. When, for purposes of comparison, it is desired to change the readings of the New York 
Board of Health lactometer, multiply the readings by .29 . In reading the lactometer, the point to which it sinks in milk should be carefully noted. Because of capillary attraction, a meniscus or curved surface is formed on the surface of the liquid. The point at which the reading should be made is on a level with the liquid and not at the top of the miscus.

46. Influence of Skimming and Watering. - Since milk has a specific gravity varying from 1.029 to 1.034 , it follows, as previously stated, that any addition of water necessarily lowers the specific gravity, and any removal of the fats necessarily raises the gravity.
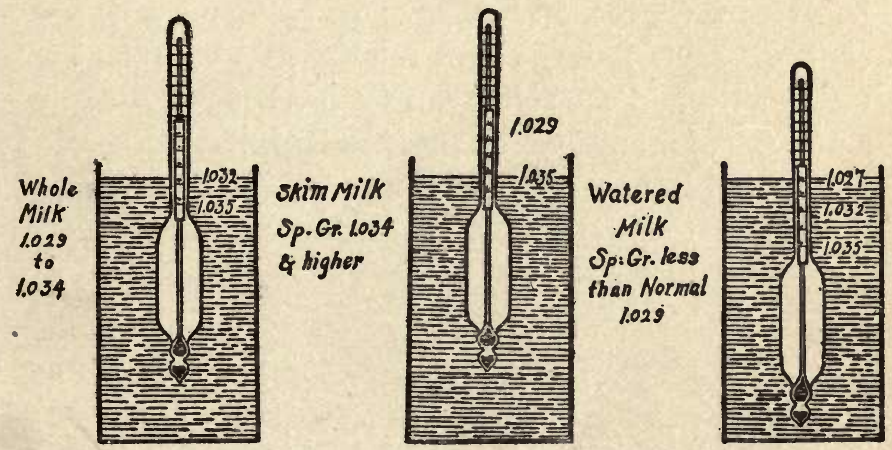

FiG. 12.-Position of lactometer in normal, skimmed, and watered milk.

Watered milk often has a specific gravity of 1.035 . When skimming alone or watering has been practiced, it is easily detected by means of the lactometer; but when milk is both skimmed and watered, the lactometer results fail to reveal the fact. The 
water lowers the gravity, and the removal of the fat raises it, so that milk which has been both skimmed and watered may have the same gravity as normal milk. This double fraud, however, is easily detected when the Babcock test is used jointly with the lactometer.

47. Calculation of Solids in Milk. - The proportion in which the various solids are present in milk directly influences both the lactometer readings and the results obtained with the Babcock test. The solids not fat (casein, albumin, sugar, and ash) increase uniformly at the rate of .25 per cent for each lactometer degree, and .02 of a per cent for each per cent of fat. This general relationship between the fat in milk and the solids not fat has been studied by a number of investigators, notably Richmond, Fleischmann, and Babcock, who have proposed various formulas for the determination of the solids in milk. Babcock's formula is as follows:-

Solids not fat $=\left(\frac{100 S-S f}{100-1.0753 S f}-1\right)(100-f) 2.5$.

When this formula is applied to a large number of observations, it will be noted that "the solids not fat increase uniformly at the rate of .25 per cent for each lactometer degree and .02 per cent for each per cent of fat." This is also practically the basis of Hehner and Richmond's formula. They found that the calculated solids were uniformly about .14 of a per cent less than those obtained by chemical 
analysis. Hehner and Richmond have proposed the following formula:-

Total solids in milk $=\frac{G}{4}+\underline{F} \times 1.2+.14$.

In order to apply the formula, divide the lactometer number or lactometer degrees by 4 . Multiply the per cent of fat found by test by 1.2. To the sum of the two results add .14 .

Example. A milk tests 4 per cent fat and has a specific gravity of 1.033 . Hence the gravity number is 33 . $4 \times 1.2=4.8 . \quad 33 \div 4=8.22 . \quad 4.8+8.22+.14=13.16$ per cent solids. This milk contains approximately 13.16 per cent solids.

48. Joint Use of Lactometer and Babcock Test. When used jointly, the quality of the milk and the extent to which any adulteration may have been practiced can be accurately determined. The following general rules will aid in determining the quality of milk: A low fat and a high specific gravity indicate skimming or removal of fats. A low fat 2 and a low specific gravity indicate the addition of water. A low fat and a normal specific gravity indidicate that the milk has been both skimmed and watered. While if there is a normal fat and a normal gravity, it is safe to conclude that the milk has been neither skimmed nor watered.

In order to determine the extent to which adulteration may have been practiced, the total solids of the milk should be calculated by Hehner and Richmond's 
formula. By deducting the percentage of fat, the solids not fat are obtained; or the solids not fat may be determined directly by multiplying the fat by .2 instead of by 1.2 , as given in the formula. The per cent of solids not fat in milk can also serve as the basis for determining the extent of adulteration. In average milk the solids not fat are about 9 per cent. If the solids not fat are found by calculation to be 7.5 , they are 1.5 less than found in normal milk, or $\frac{15}{9}$, or $16 \frac{2}{3}$ per cent, indicating that at least $16 \frac{2}{3}$ per cent of water has been added to the milk. The laws in regard to the solids and fat content of milk vary in different states. In this state (Minnesota) the legal standard of milk is 13 for solids and $3 \frac{1}{2}$ for fat. Hence the solids not fat are 9.5. On the basis of the Minnesota standard, this milk would be $\frac{20}{90}$, or about 21 per cent, below the legal standard. While the milk may not have been watered to the full extent of 21 per cent, it is 21 per cent below the legal standard for milk. 


\section{CHAPTER V}

\section{MILK SUGAR AND LACTIC ACID}

49. Physical Properties of Milk Sugar. - Milk sugar, or lactose, is present in milk to the extent of about 5 per cent. When milk sours, the sugar is converted during the process of fermentation into lactic acid, and hence the milk sugar takes an important part indirectly in all dairy operations. Milk sugar is not as soluble in water as cane sugar. It has about the same chemical composition as cane sugar, but differs from it in all of its physical and chemical properties. In butter and cheese making the main function of milk sugar is the production of lactic acid.

50. Fermentation of Milk Sugar. - Under favorable conditions milk sugar undergoes lactic acid fermentation. This change is brought about by the action of minute organisms known as the lactic acid ferments. The conditions necessary for lactic acid fermentation are: favorable temperature, $70^{\circ}$ to $90^{\circ} \mathrm{F}$., and the presence of the ferment body. The lactic acid ferments gain access to the milk through the dust particles of the air, from unclean dairy utensils, and from other sources. The spores or seeds of the lactic acid organisms readily develop in 
milk, and as a result the milk sugar undergoes a chemical change with the production of lactic acid. The milk sugar is first split up into two other sugars, dextrose and galactose, and these sugars are then changed into lactic acid. One molecule of milk sugar may produce either two or four molecules of lactic acid, depending upon the nature of the fermentation change which takes place. In addition to the lactic acid ferments, there are a great many others that may gain access to milk, develop there, and cause various changes to take place. The action of these ferments will be discussed in another chapter of this work.

51. Production of Lactic Acid in the Milk. - Fresh milk, even when first drawn from the cow, gives a slightly acid reaction, due to the acid character of the casein and to the composition of the mineral matter or ash of the milk. In a few hours, if left exposed to the air, milk readily increases its acid content until a sour taste is developed. The milk then contains from .3 to .4 of a per cent of lactic acid. If the milk contains .4 of a per cent of acid, it will curdle when boiled. The fermentation usually continues until .6 to .8 of a per cent of acid is developed, and then the lactic acid ferments become inactive. The products of the lactic acid ferments are destructive to themselves. The amount of acid in milk is directly proportional to its freshness, and for many purposes milk with more than .1 of a per cent of acid is not suitable. The rapidity with which the 
fermentation takes place is entirely dependent upon the temperature and other conditions to which the milk is subjected.

52. Determining the Acidity of Milk. - The methods employed in chemical analysis for determining the

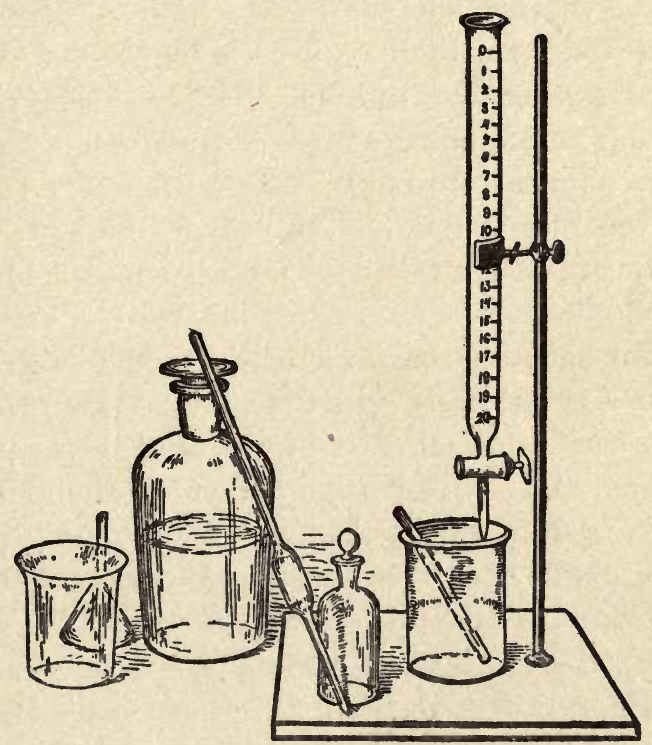

Fra. 13. - Apparatus for testing acidity of milk.

per cent of acid present in other materials are also applicable to milk. The lactic acid that is developed in the souring of milk belongs to a general class of bodies - acids - that are capable of uniting with or being neutralized by substances known as alkalies. A definite amount of an acid will always require a 
definite and known amount of an alkali for purposes of combination or neutralization. In determining the acidity of milk, it is necessary to determine simply the amount of alkali required to combine with and neutralize all of the acid present, changing it to the class of compounds known as salts. For this purpose a standard alkali solution is required. A tenth normal solution of sodium hydrate is usually employed for the purpose. The following pieces of apparatus are required: one $50 \mathrm{cc}$. burette graduated to .1 cc.; a burette holder or support; glass beakers or earthenware cups ; one 25 or 50 cc. pipette. Phenolphthalein is used as an indicator. In an acid solution phenolphthalein is colorless, while in a weak alkaline solution it gives a pink color and in a stronger alkaline solution a red color. This indicator is prepared by dissolving $10 \mathrm{gms}$. of the powder in 250 cc. of 90 per cent alcohol.

The acidity is determined in the following way: measure with the pipette $50 \mathrm{cc}$. of the milk into a glass beaker or porcelain cup. In case distilled or soft water is available, an equal amount is added to the measured milk; 5 to 7 drops of the indicator are added, and then the standard alkali from a burette a little at a time, until the color of the milk upon stirring is changed to a faint pink. Before adding the alkali the height of the liquid in the burette should be recorded, and at the close of the operation it should be read again in order to determine the number of cubic centimeters required to 
neutralize the acid in the milk. The amount of alkali used will vary directly with the amount of acid in the milk, milks of high acidity requiring a large amount of alkali. The alkali is prepared by dissolving $4 \mathrm{gm}$. of pure sodium hydrate or 5.6 $\mathrm{gm}$. of pure potassium hydrate in a liter of distilled water. This standard alkali should be prepared only by a chemist. The alkali must be kept in glassstoppered bottles protected from the air, and when used it should not be diluted.

53. Calculating the Acidity of Milk. - Each cubic centimeter of alkali neutralizes $.009 \mathrm{gm}$. of lactic acid. In case $50 \mathrm{cc}$. of milk are used and $20 \mathrm{cc}$. of alkali required to produce the pink color, the per cent of lactic acid in the milk will be found as follows :

$$
\frac{.009 \times 20}{50} \times 100=.36 \text { per cent. }
$$

In case a different quantity than 50 cc. of milk is used, then substitute the number of cubic centimeters of the sample tested for the 50 in the formula. The test can be satisfactorily made with either a 25 or a 20 cc. sample, and if desired a 17.6 cc. pipette can be used. In case a $20 \mathrm{cc}$. pipette is used for measuring the milk, then the number of cubic centimeters of alkali can be multiplied by .045 and the per cent of acid obtained directly. In making the test, the operator should cease adding the alkali as soon as a permanent pink color is obtained. When the alkali 
is first added and the milk is stirred, the color is not permanent, but after a sufficient amount of alkali is added, a point is reached when two or three drops more will produce a permanent color. In making comparative tests, the operator should always aim to secure the same degree of color in all the samples tested. Strong alkali water is not suitable for washing the milk dishes or for diluting the milk in making this test.

54. Alkaline Tablets. - Because of the difficulty in preparing and securing the tenth normal solution, Farrington and others have proposed the use of alkaline tablets. These tablets are so prepared as to contain a definite quantity of alkali mixed with the requisite indicator or coloring matter. When used, the tablets are to be dissolved in pure rain or distilled water. To prepare the ordinary tablet solution five are placed in a 100 cc. glass-stoppered cylinder filled with $97 \mathrm{cc}$. of water, and when dissolved this gives an alkali solution of the requisite strength. In making the test, 17.6 cc. of milk or cream is measured into a porcelain cup, and the alkali solution added from the cylinder until the pink color becomes permanent. The amount of the tablet solution used is found by reading the amount of solution remaining in the cylinder and subtracting it from the original quantity. The number of cubic centimeters of tablet solution used, divided by 100 , gives directly the percentage of acid in the sample. If $17.6 \mathrm{cc}$. of cream requires $40 \mathrm{cc}$. of tablet solution to produce 
the pink color, then the sample of cream contains .4 per cent lactic acid.

55. Acidity of Cream. - Cream that is suitably ripened for churning should contain about .5 of a per cent of lactic acid. If the cream contains more than .6 per cent of acid, it is liable to cause coagulation of the casein and formation of clots in the cream, and when churned, mottled butter is produced. The acid test will be found valuable in butter making as a means of producing a uniform product, which is accomplished by having the cream each day of the same degree of ripeness, and churning under uniform conditions. Any of the methods described for determining the acidity of cream will be found helpful in producing a uniform butter product. 


\section{CHAPTER VI}

\section{CREAM}

56. Composition of Cream. - Cream is characterized by containing a higher percentage of fat than milk. Average cream contains from 18 to 25 per cent of fat; some samples may contain as low as 8 per cent and others as high as 50 per cent. From 75 to 85 per cent of the solid matter of cream is fat. The percentage of ash, sugar, casein, and albumin is slightly less than in milk. The composition of average cream is about as follows :-

PER CENT

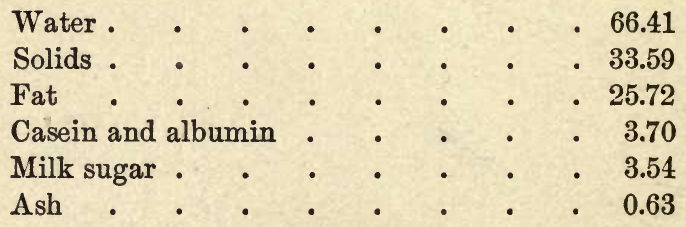

Cream is spoken of as thick, medium, or thin, according to its fat content; thin cream contains from 8 to 15 per cent of fat, and thick cream above 35 per cent. One hundred pounds of milk will produce from 15 to 22 pounds of cream, depending upon the way in which the cream is obtained, and also upon the composition of the milk. In many states and 
countries the percentage of fat which the cream should contain is designated by law. In Minnesota legal cream should contain 20 per cent of fat.

In the creaming of milk, the larger globules are more completely separated, and consequently the cream contains a higher percentage of large fat globules than milk, the smaller fat globules being present in greatest proportion in the skim milk. There is also a slight mechanical separation of the milk proteids during the creaming process, resulting in the casein and albumin being present in a different proportion in cream than in milk. When milk is creamed by gravity process, chemical changes take place, resulting in the cream containing more acid than the milk, and the proteids having a different composition.

57. Testing Cream. - Cream containing from 8 to 15 per cent of fat can be tested by the Babcock test in the same general way as milk. It will be necessary, however, to divide the 17.6 cc. of cream into two test bottles and to rinse the pipette with a small amount of warm water to completely remove all of the fat, so that each test bottle will contain about 18 cc. of liquid. The amount of fat obtained in the two bottles is added together, to give the approximate amount of fat in the cream tested. For the testing of cream special test bottles have been devised known as the Bartlett and the Winton (see Figs. 14 and 15). The Bartlett cream test bottle 
is similar to the Babcock test bottle, except that it is provided with a bulb in the stem to accommodate the additional fat from the cream. In using this bottle, care should be exercised that the right

amount of water is added

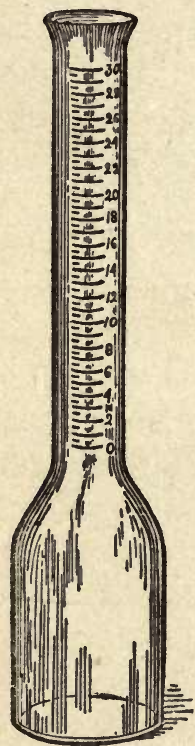

Fig. 14. - Winton cream test bottle. so as to leave a sufficient amount of fat both above and below the bulb for the purpose of reading. The Winton test bottle is provided with a larger graduated neck than the ordinary test bottle.

In the testing of cream greater care is necessary than in the testing of milk. When cream is measured with the pipette, an error is introduced into the work because cream has a lower specific gravity than milk. 17.6 cc. of cream testing 25 per cent fat weighs only about $17.2 \mathrm{gm}$. Since the test bottles are

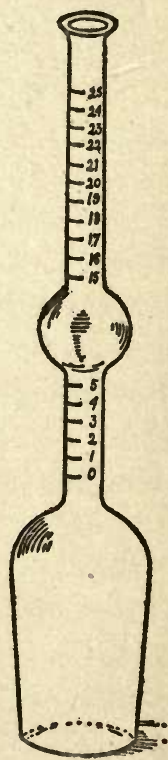

Fia.15.-Eartlett cream test bottle.

made for $18 \mathrm{gm}$. of milk, the results are necessarily low when applied to cream. Farrington and Woll, in "Testing Milk and Its Products," give the weight of cream delivered by a $17.6 \mathrm{cc}$. pipette as follows :- 


\begin{tabular}{|c|c|c|}
\hline $\begin{array}{c}\text { Pek cent of Fat in } \\
\text { Cream }\end{array}$ & $\begin{array}{c}\text { SPECIFIC Gravity } \\
\left(17.5^{\circ} \text { C. }\right)\end{array}$ & $\begin{array}{l}\text { Weigiti of Cream } \\
\text { Delivered, GMs. }\end{array}$ \\
\hline 10 & 1.023 & 17.9 \\
\hline 15 & 1.012 & 17.7 \\
\hline 20 & 1.008 & 17.3 \\
\hline 25 & 1.002 & 17.2 \\
\hline 30 & 0.996 & 17.0 \\
\hline 35 & 0.980 & 16.4 \\
\hline 40 & 0.966 & 16.3 \\
\hline 45 & 0.950 & 16.2 \\
\hline 50 & 0.947 & 15.8 \\
\hline
\end{tabular}

In the testing of cream the most satisfactory results are secured by weighing. This is done by first weighing the cream test bottle on a balance provided with a suitable beam for counterpoising, then adding with a pipette 10 cc. of cream and weighing the test bottle containing the cream to determine the weight of the cream delivered. A little warm water is then added to the test bottle in order to wash down the cream, and the test is completed in the usual way. Since the test bottle is made for $18 \mathrm{gm}$. of milk, it will be necessary to multiply the reading found in the test by 1.8 . In case more or less than $10 \mathrm{gm}$. are taken, the factor used in multiplying is obtained by dividing the 18 gm. by the weight of the cream used. If a sample of cream weighing $9.5 \mathrm{gm}$. gives a reading of 16.2 , the percentage of fat is : -

$$
\frac{18 \times 16.2}{9.5}=30.69
$$


Prior to the introduction of the Babcock test, other methods were employed for testing the value of cream for butter-making purposes. The oil test churn was one of the methods most extensively used. In operating the test the number of cubic inches of the cream sample was determined by measuring the cream in a cream pail. The cream was thoroughly mixed by stirring and a measured quantity placed in a tube which was corked. The tube with others was then placed in a specially devised churn and the

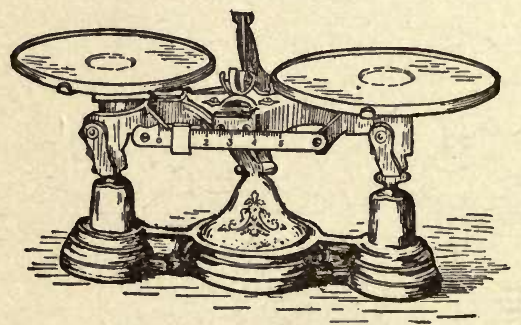

Fic. 16. - Cream scales. cream churned into butter, which was separated from the curd by melting and special manipulation. The amount of butter obtained in the tube was measured by a rule, and the butter yield of the cream was thus determined. This method of testing cream, however, has been entirely superseded by the Babcock test, the cream now being measured directly into the test bottles.

In the testing of cream, it is advisable, unless the operator has developed a high degree of skill, to make duplicate tests and then take an average.

58. Methods of Creaming. - There are three methods employed in the creaming of milk, - the gravity process, cold deep setting, and the cream 
separator. In the gravity process, the milk is usually placed in shallow pans and allowed to remain in a room at a temperature of about $60^{\circ}$ for 24 or 36 hours, until the cream is separated by gravity. When this process of creaming is followed the losses of fat are usually greater than by any other method. The losses are especially heavy when the cows are well advanced in their period of lactation. While it is possible to do reasonably effectual creaming by the gravity process, the losses of fat are frequently excessive, amounting to from 25 to 30 per cent, and more, of the total fat in the milk, the skim milk often containing from .6 to 1 per cent of fat.

In the cold deep setting process the milk is set in deep pails, which are immersed in water of a temperature of $40^{\circ}$ to $44^{\circ} \mathrm{F}$. At the end of 12 hours the process of creaming is completed and the skim milk will usually contain from .2 to .4 of a per cent fat. For the creaming of milk by the cold deep setting process, it is necessary that the water in which the milk is immersed be kept at a low temperature. The creaming commences immediately when the milk is placed in the water. The milk in the bottom of the can first becomes poorer in fat, then the middle layer is affected, and finally the upper layer. The temperature of the water at the time the milk is set is of greater importance than the temperature of the milk. A difference of $10^{\circ}$ in the temperature of the milk will not affect the efficiency of the creaming, but a difference of $5^{\circ}$ in the temperature of the 
water will seriously affect the thoroughness of the process. It is not possible by prolonging the process to make up in efficiency of creaming for the loss sustained by the want of a low temperature at the beginning. There is quite a noticeable difference in the way in which two milks may respond to creaming by the cold deep setting process. The rapidity with which the process takes place when the conditions are favorable and the effect of less favorable conditions may be observed from the following table:-

Fat in milk

Top below 4 inches, 30 minutes Middle, 30 minutes Goon Connitions TANK Water $40^{\circ}$

Poor Conditions

Tank Water $60^{\circ}$

Bottom,

Top, 30 minutes

Middle,

Bottom,

1 hour

1 hour

Top,

1 hour

Middle,

Bottom,

2 hours

Top,

2 hours

Middle,

Bottom,

Top,

Middle,

2 hours

Bottom,

$5 \frac{1}{2}$ hours

$5 \frac{1}{2}$ hours

$5 \frac{1}{2}$ hours

10 hours

10 hours

10 hours

Average fat in skim milk

\begin{tabular}{|c|c}
\hline Per cent & Per cent \\
5.00 & 4.45 \\
4.60 & 4.40 \\
4.45 & 4.40 \\
3.40 & 4.40 \\
4.00 & 4.30 \\
3.85 & 4.30 \\
1.30 & 2.92 \\
3.30 & 3.90 \\
2.10 & 3.90 \\
0.75 & 2.40 \\
1.40 & 3.00 \\
1.00 & 2.90 \\
0.35 & 2.18 \\
0.40 & 2.52 \\
0.30 & 2.40 \\
0.15 & 1.40 \\
\hline 0.25 & 1.40 \\
\hline
\end{tabular}


When milk is creamed by the separator, the losses of fat may be reduced to less than 1 of one per cent, and they are occasionally less than .05 of one per cent. The principle involved in the creaming of milk by means of the cream separator is explained in Section 21. There are a great many different kinds of separators in use. In determining the efficiency of a separator, the amount of fat left in the skim milk is the main factor to consider. In the manufacture of butter, the losses of fat in the skim milk exceed the losses in all other ways. This is because the amount of skim milk is large compared with the amount of buttermilk, and a loss of .1 of a per cent of fat in the skim milk amounts to a much greater total loss than .2 of a per cent of fat in the buttermilk. For thorough creaming at least 98 per cent of the total fat in the milk should be recovered in the cream. In the creaming of milk by the separator, the dirt, slime, and foreign matter which milk may contain are largely removed in the separator slime; this results in the production of a better quality of cream for butter making than that secured by the cold deep setting process. Cream obtained by the separator has practically the same composition as that obtained by other processes. But cream obtained by the gravity and cold deep setting processes is usually in a more advanced stage of ripeness than separator cream.

When milk is creamed by the separator, the composition of the cream can be regulated by the flow 
of the milk and the adjustment of the cream outlet. The condition of the milk as to temperature at the time of separating influences the efficiency of the creaming. If the milk is too cold, too large an amount of fat is left in the skim milk. The temperature of the milk at separation should range from $75^{\circ}$ to $90^{\circ} \mathrm{F}$., depending largely upon the individuality of the milk. It will be necessary to separate some milks at a higher temperature than others on account of the fat globules containing a larger proportion of stearin, palmitin, and hard fats. The temperature should be the lowest that will show the least loss of fat in the skim milk, so as to avoid any unnecessary heating of the milk. For data in regard to trials of different separators and the amount of fat left in the skim milk, the reader is referred to the bulletins of the various agricultural experiment stations, particularly those of the Vermont, New York, and Wisconsin Stations.

59. Adulteration of Cream. - Cream is adulterated by the addition of milk, coloring matter, preservatives, and materials to give the cream a higher viscosity. The preservatives used are formalin, boric acid, and salicylic acid. The coloring matters are similar to those used for the coloring of butter, just a sufficient amount being used to give the cream a yellow tinge suggesting a high fat content. In order to impart viscosity, the material known as viscogin, consisting of a solution of lime in cane sugar, is sometimes used. This causes the cream to appear 
to have a higher fat content by increasing its viscosity. Cream of low fat content is the most frequent form of fraud practiced.

60. The Ripening of Cream. - Before churning, cream is usually allowed to undergo the process of ripening so as to secure more complete churning of the cream and produce a better quality of butter. The cream is placed in vats and warmed to a temperature of $60^{\circ}$ to $70^{\circ} \mathrm{F}$., so as to allow the development of the lactic acid ferments. The ripening of the cream is frequently hastened by the addition of a small amount of sour milk especially prepared and known as a "starter." In the ripening of the cream, it should be the aim to allow the lactic acid ferments to develop and to prevent as far as possible other kinds of fermentation from taking place by having the milk as clean and pure as possible before creaming, so other ferment bodies cannot gain access to either the milk or the cream, and by the use of a pure culture or starter. When the cream has reached the proper degree of acidity, determined by the lactic acid test (see Sec. 52), it is in condition to churn. In the handling of cream any change of temperature should be gradual, as sudden heating or cooling may seriously affect the quality of the butter.

61. The Use of Pure Cultures. - In order to secure the best results, particular care should be given to the preparation and use of the culture. In the ripening of cream, the use of a pure culture is equally as im- 
portant as the use of good yeast in bread making. The milk from a fresh and perfectly healthy cow should be used in preparing the starter, rather than the mixed milk of an entire herd. In the preparation and use of the culture, scrupulous cleanliness should be practiced. A number of commercial cultures for the ripening of cream have been placed on the market, as Conn's bacillus No. 41 and Hanson's lactic ferment. In the use of these, or of homemade cultures, good results cannot be secured unless the cream is cared for and manipulated in the proper way. The best quality of butter cannot be made from cream that has been contaminated in any way or contains abnormal ferment bodies.

62. Influence of Delay on the Creaming of Milk. When milk is creamed by the centrifugal method, there is no loss of efficiency in creaming if the milk is not separated at once, provided the proper temperature is secured when the milk is separated. When milk is creamed by the cold deep setting process, unnecessary delay should be avoided, but undue haste in placing the milk in the tank water is not necessary. However, the milk should not be left in the barn. Experiments at the Maine and Cornell Experiment Stations have shown that with the mixed milk of an entire herd there is no appreciable loss of fat when the placing of the milk in the tank has been delayed for half or three quarters of an hour. At theWisconsin Station experiments showed that with three lots of cows there was no loss in 
creaming following a delayed setting, but with two lots a material loss of creaming power resulted.

63. Creaming of Mixed Milks. - In case milk creams with difficulty on account of the cows being far advanced in the period of lactation, the creaming is frequently improved by mixing such milk with that of fresh cows. Beneficial effects are usually obtained by creaming mixed milks. The Babcock milk test, however, is the only safe guide to follow in such cases.

64. Cream Raising by Dilution. - When either hot or cold water is added to milk, the creaming is accelerated and a larger volume of cream is obtained. When the cream is tested, however, it will be found to contain a low per cent of fat. The addition of either hot or cold water to milk produces a thin cream. The total losses of fat from cream obtained by the dilution process are greater than when the water is omitted. Experiments have shown that it is not economical to cream milk by the addition of either large or small amounts of hot or cold water. When hot water is used, the cream is often overripe before it is skimmed, and a smaller amount and a poorer quality of butter are obtained. Any interference with the normal process of creaming usually results in the production of a large volume of poor cream. 


\section{CHAPTER VII}

\section{THE CHEMISTRY OF BUTTER MAKING}

65. Churning. - When cream is agitated, the fat globules coalesce, forming granules of butter. Various theories have been advanced to explain the changes which take place during the process of churning. It is believed, however, that the change is largely physical in character and that the agitation of churning is necessary in order to overcome the resistance offered by the serum of the milk. During the process of churning, the globules lose their spherical form and become irregular masses of fat. These irregular masses more readily coalesce than spherical bodies. Various forms of churns have been devised to carry out different theories as to churning. Some churns have been provided with paddles and special devices for agitating the cream and for rupturing the membrane in which the milk fat globules were supposed to be inclosed. With change of views in regard to theories of churning, most of these devices have been discarded, and our present churns are much simpler in construction and do not have special devices for agitating the cream, this being secured largely by the concussion during the churning process.

The conditions influencing churning are (1) ripe- 
ness of cream, (2) temperature of the cream, and (3) individuality of the cream as affected by period of lactation, season of the year, nature of the fat, and breed characteristics.

Ripe cream, containing .5 of a per cent of acid, usually churns more completely than unripe cream. It is believed that this is due to the acid coagulating the casein of the cream serum, thereby reducing the surface tension of the fat globules. The ripeness of the cream is one of the most important factors in churning. If creams of different degrees of ripeness are combined and churned, there is an unevenness in the butter product due to the mixed cream not churning evenly, a part producing butter granules before the rest of the cream has completed the process of churning. If overripe, a poor quality of butter is produced, due to the presence of excessive amounts of fermentation products. It was formerly believed that an excessive amount of lactic acid caused a loss of butter fat in churning. It has been found, however, that lactic acid has no solvent action upon butter fat. It should be the object to secure the same degree of acidity for each churning, so as to produce as even a product as possible. If cream is not sufficiently ripened, butter of poor keeping quality is produced, the fermentation changes which take place in the butter eausing it to have undesirable flavors. One of the objects of the thorough ripening of cream is to prevent further and undesirable fermentation processes from taking place later in the butter. 
$+\quad$ The temperature at which cream should be churned varies from $50^{\circ}$ to $60^{\circ} \mathrm{F}$., depending upon the ripeness of the cream and its general characteristics. Sweet cream should be churned at a lower temperature $\left(50^{\circ}\right.$ to $\left.55^{\circ}\right)$ than ripened cream $\left(58^{\circ}\right.$ to $\left.66^{\circ}\right)$. It is not possible to assign a definite temperature for churning so as to secure the best results with all kinds of cream. The most suitable temperature for the conditions under which the butter is produced must be determined by trial. A preliminary churning can be made at a temperature of $60^{\circ}$, the character of the butter noted, and if it is too hard in texture and fails to churn in a reasonable time, the next churning can be made at a slightly higher temperature, $62^{\circ}$. If, however, the butter is soft in texture and churns in too short a time, the temperature has been too high. Thick cream should be churned at a lower temperature than thin cream. The right temperature for churning also depends largely upon the character of the fat globules. If the hard fats, stearin and palmitin, predominate, as is frequently the case when the cows have been long in milk and have received an excess of coarse, dry fodders with a scant amount of grain, the cream will have to be churned at a high temperature. During churning there is a rise in temperature of two or three degrees, due to the agitation of the cream, and when the churn is first started there is a slight production of gas which should be allowed to escape.

The completeness and ease with which cream is 
churned, or its churnability, is influenced by a number of factors, as season of the year, food consumed,

2 period of lactation, and individuality of the animals producing the milk. When cows have not been salted regularly, the milk is not normal in composition, and difficulties in churning frequently arise. The character of the food consumed influences the composition of the butter fats, which in turn affects the churnability of the cream. The effect of the food upon the character and composition of the milk will be discussed in another chapter of this work. When cows are advanced in their period of lactation, the globules are smaller in size, the milk is more viscous in character, and has a different composition from milk in the first stages of lactation. This affects the completeness and rapidity with which cream yields to the churning process, In churning abnormal creams, the conditions must be carefully studied and the cause of any difficulty determined; then the temperature of churning, degree of ripeness, or other conditions may be changed so as to meet the requirements of the cream in question. Occasionally abnormal conditions of the cream affecting churning are due to some form of fermentation resulting in the production of gas or rendering the milk proteids more viscous in character, which in turn affects the churnability of the cream.

The process of churning should be stopped when the butter globules are granular and about the size of wheat kernels. If the cream has been properly 
ripened, exhaustive churning has been secured when the butter is in this condition. Excessive churning may result in spoiling the grain of the butter and prevent thorough washing to remove the buttermilk. The nature and extent of the washing of butter should be regulated largely by the condition in which the butter granules are found at the close of churning. Ordinarily, butter is washed with water at a temperature of from $45^{\circ}$ to $55^{\circ}$, and the working continued until the washings which drain from the butter are clear. It is preferable to remove the buttermilk as early as possible and then continue the churning in a not too cold wash water, rather than to overchurn the cream at first. The amount of salt necessary to add at the time of working will depend largely upon the market requirements; usually three quarters to one ounce of salt per pound of butter will be sufficient. Not all of the salt added is retained in the butter; a large portion of it is removed during the process of working. From the amount of cream churned and its richness in fat, the probable butter yield can be determined; so the amount of salt required can be calculated with a good degree of accuracy.

66. Dairy Salt. - For dairy purposes salt of a high degree of purity is necessary. Many such salts are found on the market, ranging in purity from 97 to 99 per cent, the principal impurities being gypsum and small amounts of other salts. Salt should be entirely soluble in water, any residue 
being due to impurities. The salt crystals should be clear and of medium granulation. If the crystals are too large in size, overworking of the butter may be necessary in order to incorporate the salt. If the butter is worked too dry and too much fine salt is used, the salt will separate and form a crust on the surface of the butter. A pure salt will not become very moist when stored in a reasonably dry room, neither will it form hard cakes which crush with difficulty. Salts that are not pure may impart an undesirable taste and flavor to the butter.

67. Buttermilk. - Buttermilk has about the same general composition as skim milk. It is practically the skim milk of cream and varies in fat content with the exhaustiveness of churning. Buttermilk may contain a high per cent of fat, but ordinarily it contains . 2 of a per cent or less. The composition of buttermilk is generally about as follows :-

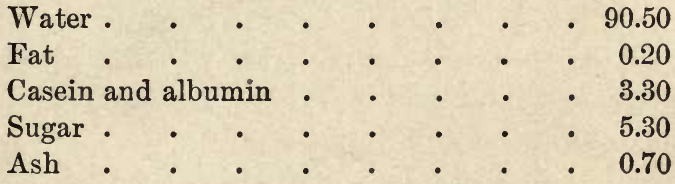

If not overdiluted with wash water, buttermilk has practically the same feeding value as skim milk.

68. Losses of Fat in Butter Making. - When 100 pounds of milk are creamed, about 80 pounds of skim milk and 20 pounds of cream are obtained. If the milk tests 4 per cent fat, and the cream is carefully churned, it will make about 4.6 pounds of 
butter. The following table shows how the various constituents of 100 pounds of milk are distributed when the milk is creamed and made into butter. With poor work, of course, a much smaller amount of fat is recovered in the butter, and more is lost in the skim milk and buttermilk.

Distribution of Milk Solids in Butter Making

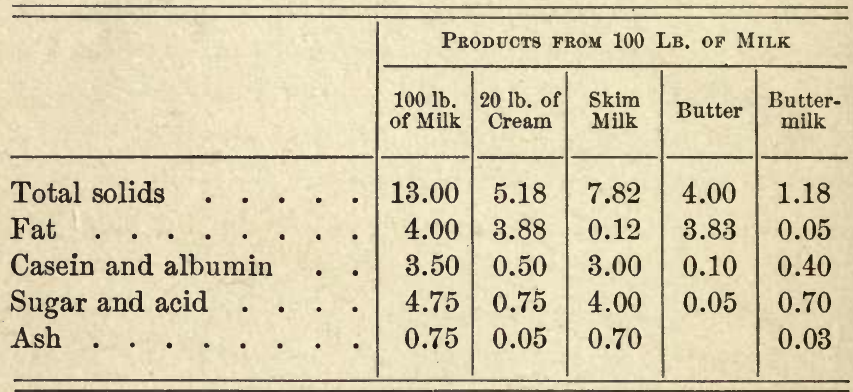

The 4 pounds of solid matter recovered in the butter, which contains 3.83 pounds of fat, together with the salt and water present, make about 4.6 pounds of marketable butter.

From 96 to 98 per cent of the total fat of the milk is recovered in the butter. About three times more fat is lost in the skim milk than in the buttermilk. Nearly 90 per cent of the casein and albumin and 85 per cent of the milk sugar finds its way into the skim milk. The buttermilk is composed of the constituents present in the cream, minus what has been removed in the butter. About 7 per cent of the ash of the 
milk goes into the cream. The buttermilk contains about 10 per cent of the original casein and albumin and about 15 per cent of the milk sugar.

69. Composition of Butter. - Average butter contains about $10 \frac{1}{2}$ per cent of water. Some samples may contain as low as 8 and others as high as 20 per cent. An excess of water in butter should be avoided, as it unfavorably influences the keeping qualities and affects the grain and other desirable characteristics. An excess of water is due either to poor methods of butter making or to intentional incorporation of water to increase weight. If a butter contains too small an amount of water, as 8 per cent, it fails to have the best physical qualities. When butter is overchurned and large lumps are formed, greater amounts of water and buttermilk are retained in the butter. The water content of butter is materially affected by the temperature of churning, washing, and working. Whenever the churning is done at a high temperature, warm wash waters are used and the butter is worked but little, an abnormal amount of water will be present; while butter that is churned at a low temperature and washed with not too cold water will have the minimum water content. If, however, the churning is continued in not too cold wash water, an additional but not excessive amount of water can be incorporated in the butter. Rich creams also have a tendency to produce butter with the maximum water content. 
The casein content of butter ranges from one half to three per cent; average butter usually contains about one per cent. An excess of casein and albumin is usually found in poor butters, causing them to retain a large amount of water and to readily undergo fermentation changes. The ash and salt content ranges from one to three and a half per cent, average butter containing about two and a quarter per cent. The amount of fat in butter ranges from 80 to 90 per cent, average butter containing about 85 per cent. The fat varies with the water content, those butters which contain the most water contain the least fat, and butters with the highest fat content contain the least water. There is only a general relationship between the quality of the butter and its percentage content of water, fat, casein, and ash. Two butters may have the same percentage of these ingredients and be widely different in taste, general physical properties, and commercial value.

70. Butter Colors. - Normal butter has a characteristic yellow color, due to the presence in milk of a distinctive nitrogenous coloring material called by Blyth lacto-chrome. The amount of this coloring matter is influenced by the food consumed and by the individuality of the animal. Milks or butters that do not contain this natural color are considered abnormal, and in order to impart the desired color to the butter, a very small amount of butter color is used. Most of the butter colors are made from harmless materials. Occasionally, how- 
ever, objectionable coloring substances are used, particularly those made from the coal-tar dyes. Some of the butter colors are made from the seed of the Bixa orellana. The use of harmless butter colors has not been regarded by courts as adulteration of butter.

71. Overruns. - One pound of butter fat will make about one and one sixth pounds of butter. During the process of butter making, the slight loss of fat in the skim milk and buttermilk is more than compensated for by the added water, casein, and salt in the butter. The additional butter made from a pound of butter fat is called the overrun; that is, the extent to which the churn overruns the test. The amount of overrun depends upon the completeness of skimming, thoroughness of churning, and the way in which the butter is handled. In some cases, the overrun amounts to .1 of a pound per pound of butter fat, and, in some cases to nearly .2 of a pound. The method in most common use for calculating the butter yield from the fat content of milk is to increase the weight of the butter fat by one sixth. This factor is the one most used, and was adopted by the Association of Agricultural Colleges and Experiment Stations as the factor for converting butter fat into butter. A butter maker can readily determine the amount of overrun by dividing the total number of pounds of butter produced for a given time by the number of pounds of fat in the milk delivered to the creamery during that period. In case the overrun amounts 
to only .1 , the butter maker can conclude that errors in the manipulation of the test or excessive losses in skimming and butter making have occurred. While, on the other hand, excessive gains in overrun are also due to errors in manipulation.

72. Dividends. - Since the value of milk for buttermaking purposes is directly proportional to its fat content, it follows that the amount of fat in the milk, as determined by the Babcock test, can be taken as the basis for making out dividends in creameries. The usual method followed is, first, to determine the total number of pounds of fat delivered by each patron; this is done by multiplying the total number of pounds of milk by the percentage of fat as obtained from the composite test. The total number of pounds of fat delivered to the creamery by all of the patrons is then determined. The expenses of manufacture, including the sinking fund, are deducted from the proceeds of the sales. These expenses depend upon the amount of butter manufactured, the amount of money reserved for the sinking fund, and all other necessary expenses incurred in the manufacture and sale of the butter. The cost of manufacture usually varies from $2 \frac{3}{4}$ to 4 cents per pound for butter. The cost of manufacture is deducted from the gross receipts and then the price per pound of the butter fat is determined. From the price per pound of the butter fat (not butter) the dividend of each patron is calculated. 
Example. Five patrons deliver to the creamery different amounts of milk which test as follows :-

\begin{tabular}{c|c|c}
\hline Patron & Pounds Milk & FAt Found By Test \\
\hline 1 & 1512 & 4.0 \\
2 & 1700 & 3.6 \\
3 & 1200 & 4.8 \\
4 & 2100 & 3.4 \\
5 & 1400 & 4.5 \\
\hline
\end{tabular}

From this milk 365 pounds of butter are made; the butter is sold for 21 cents, and 3 cents is deducted for cost of manufacture and sinking fund. The dividends are made out in the following way:-

\section{LB. FAT}

$\begin{array}{rl}1512 \times .040=60.48 & 60.48 \times .2094=\$ 12.66 \\ 1700 \times .036=61.20 & 61.20 \times .2094=12.82 \\ 1200 \times .048=57.60 & 57.60 \times .2094=12.06 \\ 2100 \times .034=71.40 & 71.40 \times .2094=14.95 \\ 1400 \times .045=63.00 & 63.00 \times .2094=\frac{13.19}{\$ 65.68} \\ \text { Total } \overline{313.68} & \end{array}$

$$
\begin{array}{r}
365 \text { lb. } \times 18 \phi=\$ 65.70 \\
\$ 65.70 \div 313.7=\$ .2094
\end{array}
$$

73. Judging Butter. - Butter is judged on the basis of flavor, texture, color, taste, and finish. If butter is unsound or abnormal in any way, it is apparent in the general physical properties. In order to accurately judge butter, a person must cultivate the 
senses of taste and smell so as to detect any objectionable flavors or odors, and the extent to which a butter may vary from a perfect sample. The scale of points usually assigned in butter judging are as follows : -

Flavor . . . . 45 Salt . . . . 10 Texture. . . . . 25 Finish . . . . 5 Color ...... 15 


\section{CHAPTER VIII}

\section{THE SANITARY CONDITION OF MILK}

74. Unwholesome Milk. - By the sanitary condition of milk is meant its condition as to wholesomeness for either food purposes direct or for manufacture into butter or cheese. Milks that are in the best sanitary condition are also those most suitable for butter and cheese making; milk that is not suitable for food should not be used for dairy purposes. Milks are most frequently unsound because of diseased conditions of the animals or because of the presence of dirt and filth of various descriptions due to lack of care of the animals or of the dairy utensils. The spread of contagious diseases is often due to unsound milk, where disease germs find lodgment, readily undergo propagation, and are then disseminated.

75. Factors influencing the Sanitary Condition of Milk. - The factors which influence the sanitary condition or wholesomeness of milk are :-

1. Condition of the animals as to health.

2. Care of the animals.

3. Care of the milk and dairy utensils.

4. Food and water which the animals receive. 
Unsanitary condition of milk may be rue to one or more of these or to other factors, the most frequent causes of contamination being lack of care of the animals, the milk, and the dairy utensils.

Condition of the Animals as to Health. - A diseased animal, as one suffering from advanced stages of tuberculosis or from other disease, does not give sound or wholesome milk. The variations in the composition of the milk when cows are suffering with disease are often slight, scarcely sufficient to change the percentage composition of the fat, casein, and albumin. A careful examination of the milk, however, will usually show the presence of abnormal bodies, products, of the disease germ many of which are toxic in character. Milk should be fairly constant in composition from day to day. When the fat content is found to vary between wide limits, it is frequently due to a diseased condition of the animal. Normal health is followed by fairly constant composition of milk; limited variations are to be expected, but not wide ones. Sound health of the animals is the first requisite in securing a milk supply of high sanitary condition. In some forms of disease, the milk will show the presence of an abnormal amount of urea, a white crystalline compound formed from disintegration of the muscular tissues of the body which have failed to be excreted and carried off by the kidneys. In normal milk, this compound is present to the extent of .001 per cent, but in diseased milk it is frequently present in much 
larger amounts. Other compounds in diseased milk are albuminous substances known as toxins, which are products of various disease germs. These toxins are poisonous in their action and are sometimes more injurious than the disease germ itself. In the case of milk from tuberculous animals, a small amount of toxic material is present. Woll, in his translation of Grotenfelt's work, "The Principles of Modern Dairy Practice," says that in the earlier stages of tuberculosis the milk often has an abnormal yellowish tinge.

The condition of the animals as to health is directly dependent upon the care they receive and the sanitary surroundings in barns, stables, and fields.

Care of the Animals. - When cows are kept in crowded and unclean stables with but little fresh air, sanitary milk cannot be expected. When under such conditions for any length of time, the animals become unhealthy, and even where they themselves are not diseased, the milk as soon as drawn absorbs the unclean atmosphere of the stable, which readily renders it unsound. Lack of cleanliness in the stables and in the care of the animals is one of the most frequent causes of unsound milk. The liquid and solid excrements of the stable are teeming with various ferment bodies, the air is filled with dust particles which contain ferments and fermentable substances, and as soon as the milk is drawn it is contaminated. In order to keep the stables in a wholesome condition, a liberal amount of bedding 
and absorbents should be used. In localities where straw cannot be procured, sawdust, shavings, peat, and other materials are employed. In addition, a small amount of land plaster, or gypsum, will be found valuable for the purpose of deodorizing the stable. Gypsum is used at the rate of about half a pound per day for each animal and is sprinkled in the stalls and trenches. Lime in any other form than the sulphate is not suitable for use in the stable. Instead of absorbing the odors, quicklime and slaked lime decompose the refuse materials, causing more odors to be produced. Lime sulphate, or land plaster, can usually be procured at about $\$ 5.00$ per ton, and is a valuable fertilizer; when added to the manure it increases its value by preventing unnecessary fermentation and loss of ammonia. Some deodorizing materials and so-called disinfectants simply mask the odors of the stable without disinfecting them. Not only the stables, but often filthy yards and fields, are direct causes of pollution of milk, and some of the diseases to which milk is subject are due to contamination from the soil. Where a large amount of manure is banked against the stable, the air which diffuses through the walls is contaminated. Undrained pasture lands are often a cause of trouble, and occasionally the output of a creamery or cheese factory is lessened in value because of such contamination. Numerous cases of this character are on record. Mr. Willard, a pioneer American cheesefactory man, found that the production of a poor 
quality of cheese was due to the milk obtained from one herd. Whenever the milk from this herd was omitted, good cheese was produced, and when the milk was added, a poor quality was obtained. An examination of the surroundings of the herd which caused the trouble showed that the cows in passing to and from the milking shed walked through a marshy place covered with green pond scum and other decomposing materials, particles of which adhered to the udders, dried, and then fell into the milk pails during milking, and fouled the milk. In the care of animals, the importance of an abundance of sunlight cannot be overestimated. Many disease germs are destroyed by the action of strong sunlight. Strong sunlight and pure air are the best disinfectants, and in many stables there is a great lack of both. Experiments made with growing animals show that there is a decided difference in general health and vigor between those reared in dark and light stables. When the stable is not properly ventilated, the carbon dioxid thrown off by the lungs as respiration products unites with the ammonia formed by the decay of the manure and produces ammonium carbonate, which is often deposited in the form of a white coating upon the stones and beams of the stable. This shows that the stable is poorly ventilated. Ammonium carbonate is an irritating alkaline compound, and when present in excessive amounts has a destructive action upon mucous membranes. It is this material which collects upon carriage tops 
and harnesses stored in poorly ventilated stables. As is well known, it causes rotting of the leather, and as could be reasonably assumed has a similar destructive action upon the mucous membranes. Animals can stand a low temperature in pure air with less discomfort than a higher temperature with impure air. However, good ventilation does not necessarily mean cold stables. Stables can be so constructed that the income and outgo of air can be regulated, rather than leaving the ventilation to faulty construction. Ventilators made of drain tiles are more sanitary than those made of wood. An old ventilating flue is often a source of pollution, due to the moist air causing decay of the wood, which then furnishes lodgment for disease germs. In order to secure the best sanitary conditions in a stable, the walls should be whitewashed at least once a year, oftener if any contagious disease has occurred.

Care of Milk and Dairy Utensils. - Milk is often rendered unsanitary by unnecessary exposure to foul air, and by handling in unclean pails, pans, and other dairy utensils. In order to improve the keeping qualities of milk, it should be cooled by exposure to clean, pure air. When not cooled at once, fermentation changes often begin immediately, causing an increase in the bacterial content of the milk. Too frequently milk is strained in the stable, in which case it becomes additionally fouled from the stable air, filled with dust particles carrying innumerable ferment bodies. The straining should be done out- 
PLATE III

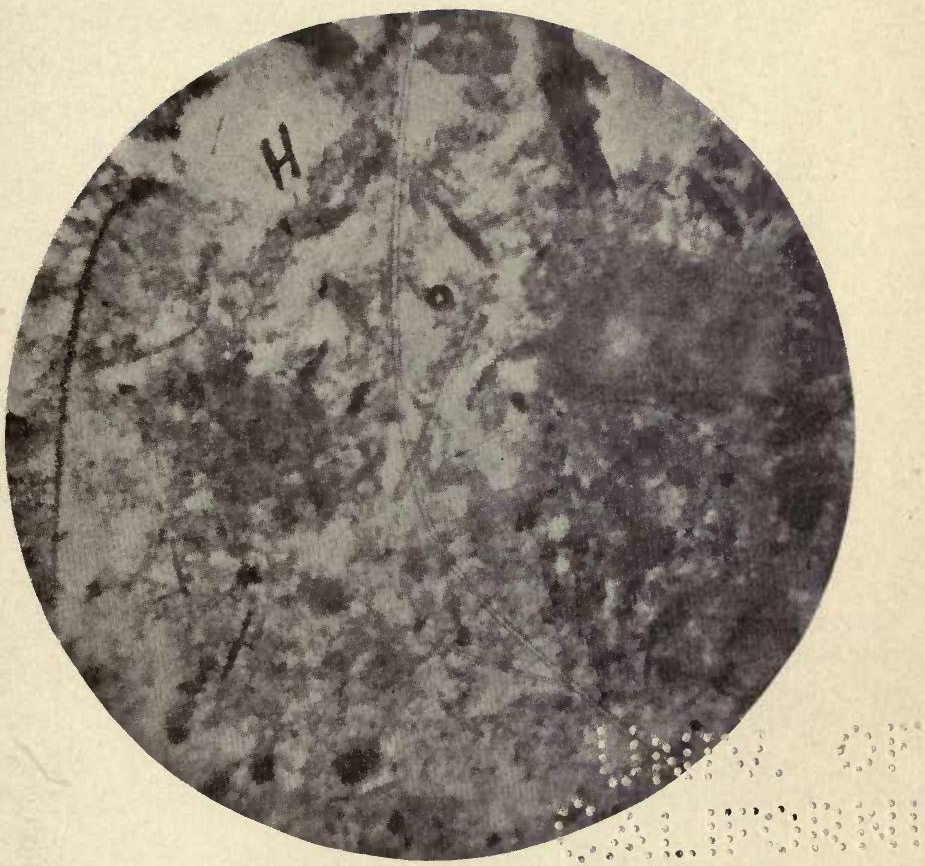

DIRT, HAIR, MANURE, ETC., IN CENTRIFUGAL SLIME FROM MILK 

side of the stable, preferably in the milk room. Metal strainers composed of 50 mesh wire gauze should be reënforced by clean cloth strainers for the removal of the finer dirt particles. Pressed tin pails which do not have seams are preferable for dairy use.

In washing pails, lukewarm water should first be used. If the water is too hot the albumin of the milk is coagulated, forming a slime over the surface of the utensil. Albumin is coagulated at a temperature of about $160^{\circ} \mathrm{F}$., and the first wash water should be below this temperature. The lukewarm water should be followed by a thorough washing with hot water and soap, and this in turn by boiling water, or preferably live steam, so that there will be thorough sterilizing. The dairy utensils should then be exposed in a clean place to bright sunlight for several hours. After being thoroughly cleaned, the utensils are sometimes contaminated by dust and dirt particles carried by the wind. Too much care cannot be bestowed upon the cleaning of the dairy utensils, particularly the straining cloths. When milk and cream are delivered at the factory where live steam is available, the factory man will save himself much trouble and annoyance by thoroughly steaming the cans.

Milk rooms are often kept in an unclean condition, and foul odors are present due to milk that has been spilled and has putrefied. Particles of the dried milk containing ferment bodies are 
given off from unclean floors, sinks, and shelves, and float about in the air of the milk room, and when fresh milk is exposed to this unclean air it is readily seeded with the spores of any ferment bodies that may be present in the dust particles. As an example of this, Soxhlet noted that when milk was placed on a particular shelf in the milk room it soon became offensive and indicated butric acid fermentation. An examination of the milk rack showed that at some time a pan of milk had been spilled on the shelf above the one causing the trouble. The lower side of the shelf had not been thoroughly cleaned, and whenever a fresh pan of milk was placed on the lower shelf, spores or seeds fell into the milk and fouled it.

There is great lack of care in the commercial handling and shipping of milk. It is often unnecessarily left exposed at small stations, and the cans are frequently reshipped without cleaning.

Food and Water which the Animal Receives. - The nature of the food which the animal receives influences the sanitary condition of the milk to a somewhat less extent than the other factors enumerated. Scant or abnormal amounts of food, or foods of unusual composition, may unfavorably affect the sanitary condition of the milk. The relation of the food to the composition and quality of the milk is discussed in another chapter of this work. Some foods, as rape, turnips, and rye fodder at the heading-out stage, impart an undesirable taste to milk. 
This is due to the presence of essential oils and other noxious compounds which pass directly into the milk without chemical change. Milk of the highest sanitary value is obtained when the animals are properly fed and the food reasonably conforms to a balanced ration. Abnormal milk will result from feeding one material to excess. Whenever cows are fed on a mixed ration, consisting of two or three grains, coarse fodders not overripe, and a small amount of roots or silage, the quality of the milk from a sanitary point of view, provided all other conditions are satisfactory, is all that could be desired.

The purity of the water supply is a very important factor in the production of sanitary milk. Impure drinking water is often the cause of unwholesome milk. Surface water collected in stagnant pools is unsuitable for animals to drink, for although it may not produce a diseased condition of the animals, it will either directly or indirectly affect the quality of the milk. No animal can do its best work in milk production if compelled to drink impure water.

None but pure water should be used for cleansing milk utensils. Numerous cases of typhoid fever are recorded which were due to milk pails and cans being washed in impure water and the typhus bacilli thus gaining access to the milk.

76. Colostrum Milk. - The milk given by a cow for the first three or four days after calving is quite different in color, taste, and appearance from milk in 
its normal condition. Such milk is called colostrum milk, and has a different chemical composition from ordinary milk. Colostrum milk is yellow in color and has a sweetish taste and a characteristic oily feeling. When boiled it coagulates on account of the large amount of albumin which is present. When hot water is poured into colostrum milk, it curdles. Colostrum milk has a higher specific gravity than normal milk, frequently reaching 1.064 .

\section{Composition of Colostrum Milk ${ }^{1}$}

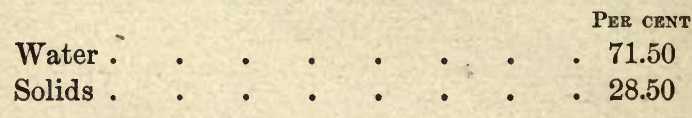

Solids contain :-

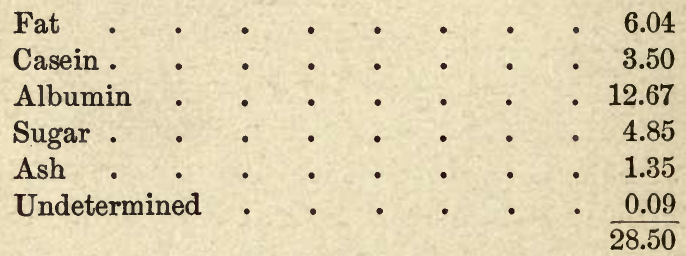

The term "colostrum" is used because of the presence in such milk of circular bodies larger than the fat globules, and known as colostrum cells. These colostrum cells are similar in structure to the white corpuscles in blood, from which it is supposed they are derived. When examined under the microscope while the milk is still warm, they show the amœboid movement of the white corpuscles.

1 Analysis made by the author. 
PLATE IV

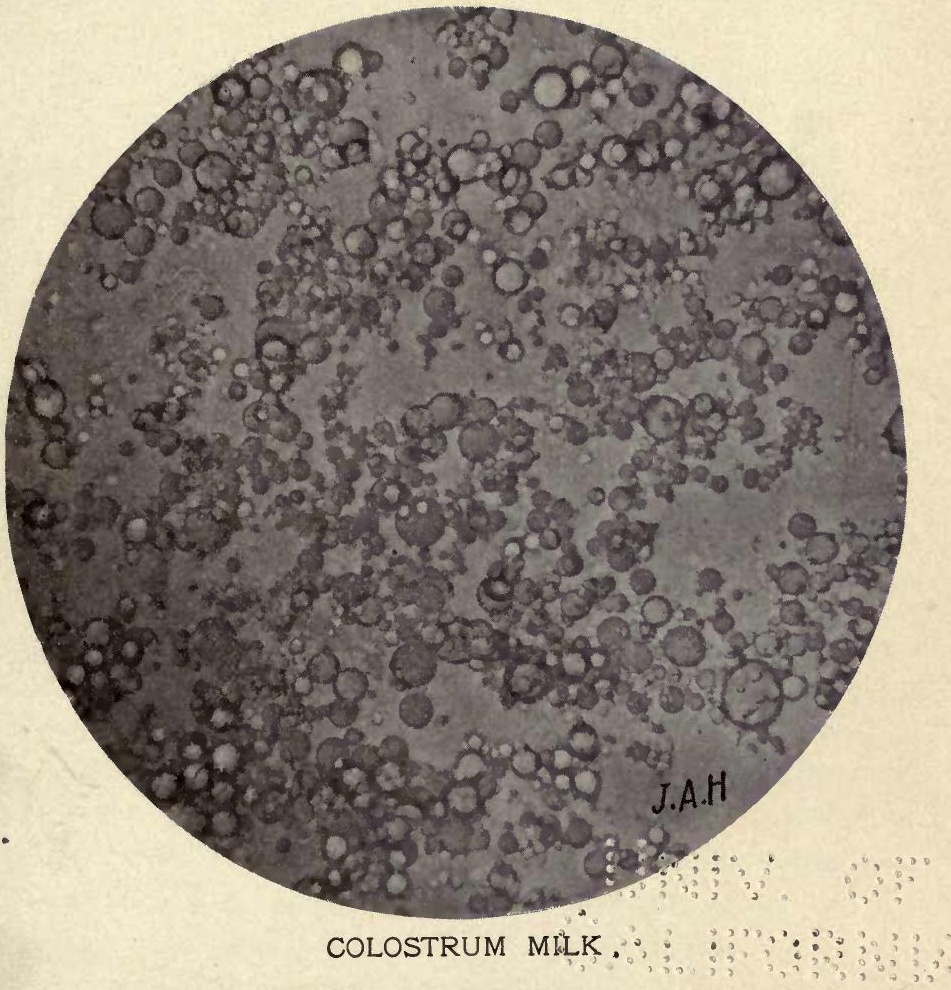



The colostrum cells begin to make their appearance in the milk about a week before the calf is born. Four or five days after calving the albumin decreases and the milk gradually reaches its normal condition. The colostrum acts as a purge upon the young calf.

The creaming of colostrum milk is very imperfect on account of the albumin present in such large quantities. Colostrum milk should never be mixed with other milk, because it will prevent creaming by the gravity process and it clogs the separator. Colostrum produces an inferior butter product, and in cheese making causes trouble as it seriously interferes with the curing and keeping qualities of the cheese. Colostrum is not as objectionable, for sanitary reasons, as it is on account of affecting the quality of the dairy products.

77. Tyrotoxicon is a poisonous chemical compound found in stale milk and old cheese. It is produced by bacteria, and is a ptomaine or poisonous nitrogenous body formed from decomposing albuminous matter. When separated and examined with the microscope, the tyrotoxicon appears in long, needleshaped crystals. When present in milk in small quantities it produces diarrhœa and symptoms similar to those of cholera. It proves fatal when injected into the veins of small animals. The tyrotoxicon is sometimes developed in ice cream made and handled in unclean ways. Inasmuch as tyrotoxicon is produced by bacteria which feed upon 
decomposing products, the utmost cleanliness should be practiced in order to prevent its formation.

78. Fibrin in Milk. - Another nitrogenous compound in milk is fibrin, which is also present in blood and forms the "clot." The best proof of the presence of fibrin in milk is the microscopic appearance of the fat globules. As previously stated, the fat globules always appear in little groups or colonies. It is supposed that they are held together by bands or meshes of fibrin which tend to prevent their coming to the surface in the gravity creaming process. The fibrin in milk is about the same in amount as the urea. Fibrin is produced by the action of the fibrin ferment. The chemical tests for its determination in milk are unsatisfactory.

79. Gases in Milk. - The gases which are dissolved in the milk as it comes from the cow are : nitrogen, oxygen, and a small amount of carbon dioxide. Nitrogen and oxygen are found in the milk in about the same proportion as in pure spring water. As milk gets older, the oxygen decreases and the carbon dioxide increases. Carbon dioxide is the gas which is given off in respired air ; in stale milk the oxygen has been used up to form carbon dioxide. At the end of four or five days, 90 per cent of the gas in milk is carbon dioxide. There is always more gas in old than in fresh milk. When the milk becomes saturated with gas, the gas is given off ; and as it escapes from the surface of cream or thick milk, it leaves small holes on the surface. 
In addition to carbon dioxide, other gases of a different character may be present in milk and in cheese making cause the curd to float: such as hydrogen, which is given off in butyric acid fermentation, and derivatives of the marsh-gas series of gases. The gases in milk are a part of the products formed by bacteria, and impure milk when made into dairy products may cause trouble, not only from the gases present, but also from subsequent action of the bacteria.

80. The Keeping Qualities of Milk are directly proportional to its germ content. Milks that have been produced from healthy animals under the most sanitary surroundings will contain but little dirt and foreign matter carrying the microörganisms which produce fermentation changes. Milks which readily become sour or undergo fermentation are unsuitable for food purposes, as they indicate previous contamination in some way. For infant feeding the wholesomeness or sanitary condition of milk is of more importance than its fat content.

The microscope is frequently employed to determine the presence of dirt and foreign materials in milk. A microscopic examination of the milk supply of large cities shows that there is much to be desired in the way of a better quality of milk for general food purposes. The health of the consumer is jeopardized by continued use of impure milk. 


\section{CHAPTER IX}

\section{THE CHEMISTRY OF CHEESE MAKING}

81. Cheese Making and Butter Making Compared. In butter making the object is to secure as much as possible of the milk fat in the form of butter. In cheese making the casein as well as the fat must be recovered. In butter making, fermentation processes are employed for ripening the cream so as to secure more exhaustive churning and to produce a better quality of butter; in cheese making, also, ferments are employed for the production of acid to coagulate the milk and to produce desirable flavors in the cheese. In cheese making the ferments take a more extended part than in butter making. The fundamental principles of cheese making are best understood by first considering the general properties of the milk proteids, particularly casein and albumin.

82. Proteids of Milk. - Milk contains \& number of proteid or nitrogenous compounds, as casein, albumin, and derivative products, as albumoses and peptoses. The nitrogenous compounds or proteids differ in composition from the sugars and fats by containing the element nitrogen in addition to the carbon, hydrogen, and oxygen that are present in the sugars and fats. The principal proteids of milk, 
casein and albumin, are alike in general composition, but differ materially in their physical properties. The proteids are the compounds to which special attention is given in human and animal nutrition, for they impart characteristic value to foods and perform functional processes which other nutrients are not capable of doing. The reader is referred to works on nutrition and the feeding of animals for the functions of protein and its value as a nutrient. The milk proteids, particularly casein, undergo numerous changes during cheese making, and the process concerns itself largely with the correct handling of these compounds.

83. Casein. - In fresh milk the casein is in nearly a soluble condition and is one of the solids of the milk serum. With the formation of lactic acid, the casein is changed from a semi-soluble to an insoluble condition, and the lactic acid unites with the casein, forming a new and insoluble compound. When sufficient acid is developed, the precipitation of the casein is complete. This is commonly spoken of as curdling of the milk. The addition of dilute acids to fresh milk will produce the same result, coagulation, and in cheese making the object of the ferment action is to produce acid to change the casein from a soluble to an insoluble condition. Dilute acids do not coagulate or precipitate the milk albumin.

84. Albumin. - When milk is allowed to sour and curdle, it separates into a coagulated mass containing 
the casein and fat, and whey which contains the albumin and milk sugar. If the clear whey is heated, a yellowish white, flakelike substance is formed. This is coagulated albumin. The albumin in milk is coagulated at temperatures ranging from $157^{\circ}$ to $161^{\circ} \mathrm{F}$., but in the ordinary processes of cheese making the temperatures reached are not sufficiently high for the coagulation of the albumin, and as a result it remains in the whey. If higher temperatures were attempted, excessive losses of fats would occur, the casein would be unfavorably affected, and a poor quality of cheese would be produced. The chief distinctions between casein and albumin are that albumin is coagulated by heat, while casein is not, and casein is coagulated by dilute acids, but the albumin is not precipitated.

85. Rennet. - In order to control the process of fermentation and the coagulation of the milk, rennet is used. Rennet is an extract prepared from the mucous membrane or lining of the fourth stomach of the calf. It contains various ferment bodies, as lactic and peptic ferments, which are the chief agents in bringing about the changes necessary for the digestion of milk. When rennet is added to ripened milk, it produces the same effect as the addition of dilute acid. A temperature of from $86^{\circ}$ to $90^{\circ}$ is favorable for the action of the rennet ferments. Prior to the addition of the rennet, the milk is ripened with a starter, as in the ripening of cream. 
It would be possible for cheese to be made by allowing the milk to sour by natural processes, but under such conditions a poor quality of cheese is produced, for the process of fermentation cannot then be controlled as when a starter is used for ripening the milk and rennet for coagulating it. The chief action of rennet in cheese making is to coagulate the milk. In the ripening of the cheese, the rennet appears to act secondary to the enzymes or soluble ferments which are normally present in all milk.

86. The Rennet Test. - The rennet test is employed in cheese making to determine when the milk is in the right condition for adding the rennet. The rennet test is made in the following way: $5 \mathrm{cc}$. of rennet extract is diluted and mixed in a flask with $45 \mathrm{cc}$. of water, 140 cc. of milk from the vat is placed in a small cup, 5 cc. of the diluted rennet solution added and thoroughly stirred, and the time required for the complete coagulation of the milk noted. In making the test, a knife is used to determine when the coagulation is completed. If more than sixty seconds are required for coagulation, the milk is not sufficiently ripened for the addition of the rennet. For ordinary purposes of Cheddar cheese making, the milk is sufficiently ripened when it coagulates in from 45 to 55 seconds. If the milk coagulates in less than 40 seconds, it is overripe and requires different manipulations for cheese-making purposes. The ripeness of the milk, as shown by the rennet test, materially 
influences the way in which the curd ripens in the vat; the rennet test also serves as a guide in subsequent manipulations.

87. Process of Cheddar Cheese Making. - In order to more intelligently discuss the principal changes that take place in cheese making, the details of the process of Cheddar cheese making are here briefly given: When the milk is received at the factory, it is weighed and its general condition as to purity noted. A small sample is retained for testing with the Babcock test, as in creamery work. Any foul or unsound milk is rejected as unsuitable for cheese-making purposes. The mixed milk is then warmed in the vat by means of steam or otherwise until a temperature of $86^{\circ}$ to $88^{\circ} \mathrm{F}$. is reached. The milk is heated gradually, and is stirred to prevent the separation of the fat. The starter is added, and when the proper degree of ripeness is thought to have been reached the rennet test is applied. If the milk is found to be in suitable condition, the rennet is then added at the rate of 3 to 5 ounces per thousand pounds of milk. If the milk contains a high percentage of fat, the maximum amount of rennet is added at the higher temperature. Ordinarily, however, the quantity of rennet required and the temperature of the milk when it is added vary with the season of the year, the condition or individuality of the milk, and the kind of cheese desired to produce. These are factors that must be thoroughly understood by the cheese 
maker, and the process of making adapted to existing conditions. After the rennet has been added and thoroughly mixed, about twenty minutes are allowed for complete coagulation of the milk. The time of coagulation, however, will vary with the conditions stated. When the curd is in a state where it readily "breaks" and maintains its form, it is cut with a curd knife into small cubes. After cutting, the mass is gently agitated for about five minutes so as to secure hardening of the curd particles and to prevent mechanical losses of fat. This agitation also prevents the curd from matting and forming large masses. The temperature of the vat is then raised gradually at the rate

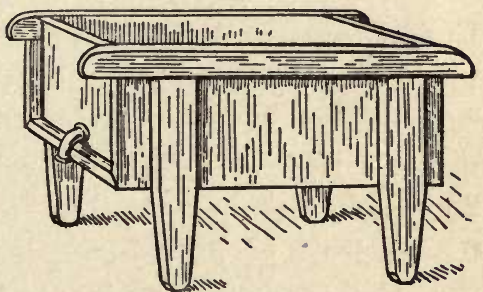

Fig. 17. - Cheese vat. of two degrees for every five minutes until a temperature of $102^{\circ} \mathrm{F}$. is reached. The stirring is continued at intervals to prevent the curd particles from matting. The heating of the curd brings about a number of important changes and results in contraction of the curd and more complete expulsion of the whey. The changes brought about by the digestive ferments present in the rennet and the milk cause a softening of the curd. The ripeness of the curd in the vat is determined by the hot-iron test. This test is made in the following way: A piece of 
cheese is pressed against a hot iron and immediately withdrawn. The length of the threads adhering to the iron are proportional to the degree of ripeness of the curd. If the threads are an eighth of an inch long, the curd is usually in a sufficiently advanced stage for the removal of the whey. In case a quickcuring cheese is desired, threads of greater length should be shown. After the whey is removed, the curd is allowed to pack and form large masses in the bottom of the vat. These masses are cut into blocks and placed in a pile so as to undergo further digestion changes and develop acid. The curd is ground when the threads shown by the hot-iron test are a fourth of an inch or more. The grinding and subsequent salting of the curd retard the fermentation process. Before grinding, the curd is kept at a temperature of $90^{\circ}$ to $95^{\circ}$; after grinding and salting, the temperature is reduced to about $80^{\circ} \mathrm{F}$. The matting of the curd particles is spoken of as cheddaring. The ground and salted curd is placed in molds and pressed in the cheese press. A gradual and uniform pressure is maintained for about 24 hours. The cheese is then ready for the curing room. As in the case of butter making, exact details for the manipulation of all kinds of milk cannot be given. The general principles of cheese making, however, should be thoroughly understood, and then the processes may be varied to meet different conditions arising in the manufacture of different kinds of milk into cheese. 
In the manufacture of cheese a record should be kept of the time required for the different operations. The following points should be noted :-

Condition of milk.

Pounds of milk in vat.

Per cent of fat in milk.

Rennet test for ripeness.

Temperature of milk when set.

Amount of rennet used.

Rate of rennet per 1000 pounds of milk.

Time cut.

Minutes in curdling.

Time heat is applied.

Time required to raise to $102^{\circ}$.

Hot-iron test when dipped.

Time dipped.

Time from cutting to dipping.

Pounds of whey.

Per cent of fat in whey.

Time ground.

Hot-iron test when ground.

Time salted.

Amount of salt in curd.

Rate of salt per 1000 pounds of milk.

Time put to press.

Time pressed.

Weight of green cheese.

Weight of milk per pound of cheese.

Weight of milk per pound of cured cheese.

Remarks. 
88. Process of Stirred Curd Cheese Making. - In cheddar cheese making, the curd is allowed to mat in the vat after the whey has been removed. In the stirred curd process, the curd is not allowed to mat or cheddar, it is kept stirred and manipulated in such a way that the whey is drained off and the curd particles are not allowed to unite. It is then salted, pressed, and cured. By this process of cheese making, a softer and milder-flavored cheese is produced. This stirred curd process results in the incorporation of a larger amount of water in the cheese, and the ripening requires less time than for cheddar cheese. These two processes, the cheddar and stirred curd, are often so varied that a sharp dividing line between the two cannot be made. For firm, longkeeping export cheese the cheddar process is followed, and for a soft, mild, quick-ripening cheese the stirred curd process is employed.

89. Distribution of Milk Solids in Cheese Making. - About one half of the milk solids are recovered in the cheese. The fat is not as completely recovered as in butter making. The whey usually contains about 5 per cent of the total fat of the milk. Of the $12 \frac{1}{2}$ or $\overline{13}$ pounds of solid mattex in milk, about 3 pounds of the casein, $3 \frac{1}{2}$ pounds of the fat, and a portion of the ash are recovered in the green cheese, while the milk sugar, albumin, and a portion of the ash are lost in the whey. The solid matter of cheese is mainly composed of fat and casein, and any increase in the amount of fat in the milk is 
followed by a corresponding increase in the fat content of the cheese. It was formerly believed that milk of high fat content could not be economically made into cheese and that only a certain percentage of the fat in milk could be recovered in cheese making. Experiments have shown this idea to have been incorrect.

90. Curing of Cheese. - New cheese is lacking in flavor and digestibility. By allowing the cheese to undergo the ripening or curing process, desirable flavors are developed, and the casein is changed into a more soluble and easily digested form. The cheese was formerly placed in a curing room at a temperature of $65^{\circ}$ to $70^{\circ}$. The curing room was kept at an even temperature and the moisture content of the air controlled as far as possible. During recent years, however, there has been a tendency to cure cheese at a lower temperature. At one time it was believed that the rennet used in making cheese was the chief agent in ripening or curing, and it was held that a temperature of from $65^{\circ}$ to $70^{\circ} \mathrm{F}$. was the most suitable for the action of the rennet ferments. Investigations by Babcock, Russell, Van Slyke, and others have shown that the soluble ferments or enzymes, which are normal products of all normal milk, can be utilized as the chief factors in the ripening of cheese, and that it is possible to ripen cheese independent of the rennet ferments.

There are two classes of ferments - the organized or insoluble ferments, and the soluble or chemical 
ferments which are also called enzymes. The insoluble or organized ferments are mainly bacterial bodies of definite form and structure propagated from a spore or seed. These organized ferments develop in milk, meat, or any other suitable material if conditions as to temperature and moisture are favorable. The chemical ferments, or enzymes, are products of living organisms capable of producing ferment changes. Chemical ferments cannot be seen with the microscope; they are simply chemical substances capable of inducing fermentation changes without entering into the composition of the material or giving up any of their own substance to the reacting bodies. Milk contains a tryptic-like ferment or enzyme, which peptonizes the casein and other proteids, forming proteoses and other soluble bodies. In the curing of cheese, it has been found that the ripening process can be carried on entirely by these soluble ferments and at a lower temperature than required by the organized ferments or bacteria. The process of cheese curing at a low temperature is akin to the curing of meat in cold storage.

Experiments on a commercial scale have shown that cheese can be cured at a temperature of less than $50^{\circ} \mathrm{F}$., resulting in the production of a better quality of cheese, less shrinkage in weight, and less loss of solid matter than by curing at a high temperature. As a result, the cold curing of cheese has gradually replaced the old process of high temperature curing. This is an advantage also in that less 
loss occurs from cheese becoming unsound during the curing process, and larger yields of cured cheese are obtained from a given amount of milk. In the cold curing of cheese the fermentation changes are brought about entirely by the action of the soluble ferments or enzymes of the milk. It is mainly a digestion process, the changes taking place being similar to those which occur in the first stages of the digestion of the proteids in the stomach. The. acids produced unite with the casein, forming more soluble and digestible products. Van Slyke, in his studies on cheese making, states that lactic acid forms with casein two compounds, paracasein and paracasein monolactate, which contains half as much acid as paracasein.

Since both the insoluble or organized ferments and the enzymes of milk take an important part in the manufacture and curing of the product, it is highly important that the milk be handled in the most cleanly way possible, so as to reduce the germ content of the milk and prevent the formation of objectionable flavors and products in the cured cheese. Attention should be given to the sanitary condition and surroundings of both the creamery and cheese factory, as any unsanitary condition may affect the quality of the product.

91. The Cheese Yield of Milk. - Since the percentage of casein to fat varies in different milks, it follows that the cheese yield of milk is not directly proportional to its fat content. Milks of the high- 
est percentage of fat are not proportionally richer in casein than milks of low fat content. When milk tests $3 \frac{1}{2}$ per cent fat, 100 pounds will make about 9.35 pounds of cheese. One pound of milk fat will make from 2.6 to 2.7 pounds of cured cheese. The relation of the fat content of milk to its cheese yield, as found by Babcock at a number of Wisconsin factories, is as follows :

\begin{tabular}{|c|c|c|c|c|c|}
\hline $\begin{array}{l}\text { No. or } \\
\text { GrouPs }\end{array}$ & $\begin{array}{c}\text { No. OF } \\
\text { REPORTB }\end{array}$ & $\begin{array}{c}\text { RANGE OF FAT } \\
\text { PER CENT }\end{array}$ & $\begin{array}{c}\text { Average } \\
\text { Per cent } \\
\text { of Fat }\end{array}$ & $\begin{array}{c}\text { Average Yield } \\
\text { OF CHEESE PER } \\
100 \text { LB. MILK }\end{array}$ & $\begin{array}{l}\text { LBS. of CURED } \\
\text { CHESE FOR } \\
1 \text { LB. FAT }\end{array}$ \\
\hline 1 & 24 & Under 3.25 & 3.126 & 9.194 & 2.941 \\
\hline 2 & 90 & $3.25-3.50$ & 3.382 & 9.285 & 2.730 \\
\hline 3 & 134 & $3.50-3.75$ & 3.600 & 9.407 & 2.613 \\
\hline 4 & 43 & $3.75-4.00$ & 3.839 & 9.806 & 2.562 \\
\hline 5 & 46 & $4.00-4.25$ & 4.090 & 10.300 & 2.512 \\
\hline 6 & 20 & Over 4.25 & 4.447 & 10.707 & 2.407 \\
\hline $\begin{array}{l}\text { All } \\
\text { groups }\end{array}$ & 347 & & 3.64 & 9.566 & 2.628 \\
\hline
\end{tabular}

\section{Testing Cheese by the Babcock Milk Test. -} The percentage of fat in cheese can be determined by the Babcock milk test in the following way: With a sharp knife and in a cool room cut the cheese into small pieces about the size of wheat grains. Weigh into a test bottle $5 \mathrm{gm}$. of this cheese sample, add about 15 cc. of hot water, and shake well so as to thoroughly disintegrate the cheese. When cool, the acid is added and the test completed in the usual way. The reading of the test bottle is multiplied by 3.6 to obtain the per cent 
of fat in the cheese. This is because the test bottles are made for $18 \mathrm{gm}$. of material, and only $5 \mathrm{gm}$. of cheese were used. A cheese made from normal milk should contain at least $30^{\circ}$ per cent, fat, and cheese of good quality shows from 32 to efer per tont.

93. Composition of Cheese. - The percentage of fat in cheese is directly proportional to the richness of the milk in fat and the amount of water left in the cheese. In average cheese the per cent of fat always exceeds the per cent of casein. This is because the milk from which the cheese is made contains more fat than casein. Any cheese containing more casein than fat has been made from skim milk. The relation of the composition of cheese to the milk from which it was made may be observed from the following tables :-

\begin{tabular}{|c|c|c|c|c|c|c|}
\hline & \multicolumn{5}{|c|}{ Composition of MiLK } \\
\hline & & Water & Fat & Ash. & $\begin{array}{c}\text { Casein and } \\
\text { Albumin }\end{array}$ & $\begin{array}{l}\text { Milk } \\
\text { Sugar }\end{array}$ \\
\hline 1. Average milk & .. & 87.52 & 3.50 & 0.80 & 3.22 & 4.80 \\
\hline 2. 4 per cent milk & - . . & 86.79 & 4.00 & 0.64 & 3.71 & 4.50 \\
\hline 3. Milk with cream & 1 added & 85.87 & 6.00 & 0.77 & 3.12 & 4.13 \\
\hline 4. Skim milk & . . . & 87.80 & 2.75 & 0.80 & 3.95 & 4.50 \\
\hline
\end{tabular}

1. Average milk . . . . . .

2. 4 per cent milk . . . . . .

3. Milk with cream added . . .

4. Skim milk. . . . . .

\begin{tabular}{|l|l|l|}
\hline \multicolumn{2}{|c|}{ Composition of CheEse } \\
\hline Water & \multicolumn{1}{|c|}{ Fat } & $\begin{array}{c}\text { Casein and } \\
\text { Albumin }\end{array}$ \\
34.29 & 33.76 & 27.47 \\
31.4 & 35.3 & 27.7 \\
32.43 & 43.55 & 20.00 \\
30.68 & 27.09 & 36.00 \\
\hline
\end{tabular}


94. Testing Whey. - In the making of cheese both the whey and the drippings from the cheese press slsould be frequently tested for fat, so as to determine whether there has been any unnecessary loss. in testing whey, the special bottles made for testing skim milk may be used. It is not necessary to use 17.6 cc. of acid, because the casein has been removed from the milk and the acid has less work to do. Use about $8 \mathrm{cc}$. of acid.

95. Making out Dividends in Cheese Factories. The dividends in cheese factories can be made out on the basis of the fat content, in the same general way as described in section 72 for making out dividends in creameries. The fat content of milk is a more satisfactory and equitable basis for making out dividends than the gross weight of the milk regardless of its composition. As previously stated (section 91), the cheese yield of milk is not always proportional to its fat content. A milk testing 6 per cent fat will not make twice as much cheese as one containing 3 per cent fat. This is because the casein does not increase proportionally with the fat. With average milk, however, testing from 3.4 to 4 per cent, the amount of cheese that can be made is practically proportional to the fat content. Inasmuch as average milk usually tests between these amounts, the fat test can be safely used as the basis for the making out of dividends. In the case of exceptionally rich milk, the quality of the cheese is materially increased by the additional fat. Experiments have 
shown that the value of the cheese is almost directly proportional to its fat content. While the richer milks make a smaller quantity of cheese, they make cheese of higher commercial value, and hence there is no injustice in paying for milks for cheese-making purposes on the basis of the fat content. Poor milks make a slightly larger amount but a poorer quality of cheese than the richer milks. In making out dividends, the total number of pounds of fat delivered by each patron is calculated from the weight of the milk and its percentage of fat. The cost of manufacture is deducted from the sales and the price per pound of the milk fat sold in the form of cheese determined, and then the amount due each patron is calculated from the pounds of fat due him and its value per pound.

96. Comparative Butter and Cheese Returns from Milk. - In case it is desired to compare the approximate gross income from the same amount of milk made either into butter or cheese, the methods for calculating the butter yields given in section 71 are used for determining the pounds of butter produced from a given quantity of milk testing a certain percentage of fat. From the data given in section 91, the estimated number of pounds of cheese produced from the same quantity of milk can also be calculated. Comparisons can then be made as to the gross sales from either the butter or cheese by taking the average market price of each. If such calculations are made, it will be found that occasionally 
larger proceeds can be obtained from cheese than from butter, and then again the sales of butter will be found to give the larger returns. In determining the net income, the cost of production and the comparative value of the by-products must also be considered. Only general comparisons can be made as to the probable income from the manufacture of butter or cheese. As to the relative advantages of butter or cheese production, much depends upon location, markets, and general conditions. In the general average, the production of one will be found to be about as profitable as the other, and it is not advisable to make frequent changes.

97. Different Kinds of Cheese. - By varying the process of cheese making so as to cause the development of specific forms of fermentation, different kinds of cheese, as Neufchâtel, Limburger, Swiss, Edam, Gouda, and Roquefort, are made.

Neufchâtel is a soft cheese, made from sweet milk by adding the rennet at $82^{\circ} \mathrm{F}$. After pressing, it is worked and kneaded, and then put up in packages and covered with tinfoil.

Limburger is a variety of cheese of characteristic odor and flavor resulting from special ferment action during the curing process.

Stilton cheese is a soft, rich cheese of mild flavor made from milk to which cream is usually added. For the curing a long time is required and a fungus with bluish green threads is developed.

Emmenthaler or Swiss cheese is made by special 
manipulation and direct pressing in the curd presses. The cheese is salted from the outside and certain forms of fermentation are induced.

Edam is a hard, dry cheese, usually made from partially skimmed milk and cured by a slow process of fermentation.

Gouda is somewhat similar to Edam, but is softer in texture.

Roquefort is a soft cheese which owes its characteristics to special forms of ferments added during the process of manufacture. When ripened a characteristic mold will be found permeating the cheese.

A number of special brands of cheese, put up in glass and porcelain packages, are made from ordinary cheese by grinding and adding fat, usually in the form of butter. The sealed package is then placed in cold storage so as to allow further fermentation changes to take place.

Cottage Cheese. - Cottage cheese can be prepared in the following way: The milk is first allowed to sour and is then heated to a temperature of $100^{\circ} \mathrm{F}$., or the coagulation of the milk can be completed, if desired, by the addition of hot water, temperature of $175^{\circ} \mathrm{F}$, at the rate of about one pint per gallon of milk. After stirring for two or three minutes, the coagulated mass is allowed to settle, the whey is drawn off and the curd collected by straining through cheese cloth. If the milk is in the right condition as to acidity, a fine, soft-grained curd is 
secured. Salt is added as desired, and the palatability and food value are increased by the addition of a small amount of cream when used. Cottage cheese, when prepared in this way, has a high food value. 


\section{CHAPTER $\mathrm{X}$}

\section{MILK BY-PRODUCTS}

98. Uses of By-products. - In the manufacture of butter and cheese the by-products are skim milk, buttermilk, and whey. These products are used mainly for animal-feeding purposes and have a high food value. Also from the by-products a number of commercial articles are prepared. From whey, milk sugar is manufactured, and from skim milk, proteids are precipitated and prepared for commercial uses.

99. Skim Milk - Composition, Value, and Use. - In the manufacture of butter, about 80 per cent of skim milk is obtained. The chief ingredients of skim milk are casein, albumin, ash, and milk sugar. Because of the removal of the fats in skimming, the solids not fat are usually present in the skim milk in slightly larger proportions than in the whole milk. Skim milk is characterized as a food of high proteid content and it is valuable in combination with other foods that are lacking in protein, particularly for the feeding of young and growing animals. Average skim milk contains about 9.75 per cent of solid matter, of which 3.7 pounds are casein and albumin, and 5.15 pounds are sugar, the remain- 
ing .9 of a pound being principally ash and a small amount of lactic acid and other compounds. The principal value of skim milk is due to the relatively large amount of casein and albumin it contains, over 36 per cent of the solid matter being in these forms.

When judiciously used, 5 pounds of skim milk will produce as much gain in the feeding of young pigs as one pound of farm grains. Professor Henry, of the Wisconsin Experiment Station, states that when corn is worth 28 cents per bushel, skim milk has a feeding value of 15 cents per hundred pounds. In order to secure the largest returns from the feeding of skim milk, it should be fed with grains at the rate of about 3 pounds of skim milk per 1 pound of grain. If fed in larger amounts than this, smaller returns are secured from the skim milk. When the nutrients in a pound of grain and 5 pounds of skim milk are compared, it will be found that 5 pounds of skim milk contain less total nutrients than the pound of grain. The unique value of skim milk lies in the fact that it is rich in protein and when combined with other feed makes a ration more palatable and also increases the digestibility of the feeds with which it is combined. When judiciously used, skim milk is valuable not only for the nutrients it contains, but also because of making the nutrients of the grains and foods with which it is combined more digestible and valuable to the body. Slim milk should be fed preferably when sweet. When partially soured it may cause digestion disorders, due 
to the presence of various ferment bodies. Skim milk that is fully soured causes less digestion trouble than when partially soured.

In the handling of skim milk the greatest care should be exercised to prevent its contamination and abnormal fermentation from taking place. The tyrotoxicon organism may develop in skim milk and cause cholera-like symptoms. The separator slime should never be added to skim milk, as it contains a large proportion of the dirt of the milk. Sheuerlen and Bank state that most of the tubercle bacilli in milk are separated in the slime of the centrifugal.

The keeping qualities and sanitary condition of skim milk are improved by pasteurizing or sterilizing it at the time the milk is separated. If the skim milk is sterilized, it should be cooled and then protected from further inoculations. Unless it is properly cared for, the sterilizing may have but little effect in improving its value. Too frequently the factoryman and farmer give but scant attention to the care of the skim milk. A little foul sour milk is. left in the skim-milk tank from day to day, and this, acting as a starter, immediately sours any fresh skim milk which is added. Some diseases, as hog cholera, have been spread through lack of care in handling the skim milk at the creamery.

Separator skim milk differs but little in compositio, from skim milk obtained by the gravity process. From the separator skim milk the fat has been quite thoroughly removed, while that obtained 
by the gravity process contains a larger amount of fat. Experiments have shown that the additional fat in the gravity skim milk produces only small additional gains over separator skim milk, the gains being of less importance than the commercial value of the butter fat. Skim milk should not be stored or handled in rusty iron pails or cans, because the small amount of acid present has a solvent action upon metals, and if too much iron zinc or tin is dissolved in the milk, it has an injurious effect when fed to animals. The handling of skim milk, buttermilk, and whey in unclean ways is frequently the cause of abnormal fermentation and the contamination of dairy products.

100. Whey - Composition, Value, and Use. - Whey differs in composition from skim milk by containing less solid matter because of the removal of the casein in cheese making. Average whey contains about 7 per cent of solid matter, the larger portion of which is milk sugar, 5.2 per cent. It also contains the albumin of the milk, which, as previously stated, is not retained in the cheese. There is less ash in whey than in skim milk, due to a portion of the mineral matter combining with the casein and being recovered in the cheese.

While whey contains less solid matter and proteids than skim milk, it nevertheless has a material feeding value. Experiments have shown that two pounds of whey are about equal in feeding value to one pound of skim milk. In general, ten pounds of whey will produce as much gain in live weight of 
growing animals as one pound of farm grains. In the handling, care, and use of whey, the same general statements made in regard to skim milk will apply.

101. Fertilizer Value of Milk By-products. - When butter is sold from the farm, there is very little fertility lost in the form of the principal plant food elements, - nitrogen, phosphorus, and potassium. The butter fats are composed of the three elements, carbon, hydrogen, and oxygen. The nitrogen and the ash or mineral elements are present in the skim milk and buttermilk, and hence when butter is sold there is practically no fertility lost. When cheese is sold, part of the fertility is lost in the form of nitrogen, which is present in the casein. In dairy farming, the crop-producing power of the soil is not lessened, provided the farm manure is judiciously cared for and used.

102. Comparative Value of Cow's Milk and the Milk of Other Domestic Animals. - In order to compare the general feeding value of cow's milk and skim milk with the milk of other domestic animals, the following table is given:-

\begin{tabular}{|c|c|c|c|c|c|c|c|c|c|}
\hline & & & & & WATER & FAT & SUGAR & AsH & $\mid \begin{array}{c}\text { CASEIN AND } \\
\text { ALBUMIN }\end{array}$ \\
\hline Mare's milk & . & . & . & & 88.49 & 2.86 & 4.75 & 0.55 & 3.35 \\
\hline Sow's milk . & . & 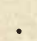 & . & & 84.00 & 4.60 & 3.15 & 1.05 & 7.25 \\
\hline Sheep's milk & . & $\bullet$ & . & - & 82.25 & 5.30 & 4.35 & 1.00 & 7.10 \\
\hline Skim milk . & $\cdot$ & $\cdot$ & . & • & 90.25 & 0.10 & 5.15 & 0.80 & 3.70 \\
\hline Cow's milk . & . & . & . & 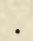 & 87.00 & 4.00 & 5.00 & 0.75 & 3.25 \\
\hline
\end{tabular}




\section{CHAPTER XI}

\section{THE ADULTERATION OF DAIRY PRODUCTS}

103. Oleomargarine.-Oleomargarine and butterine are butter substitutes made from animal fats, cottonseed oil, and other materials, and resemble butter in composition and taste. They contain about the same percentage of water, fat, salt, and nitrogenous matter as butter, but differ in not containing butyrin and other characteristic volatile fatty acids present in butter and not in butter substitutes. In the manufacture of oleomargarine, the beef fats are put through filter presses to remove a portion of the hard fats, which are used for the manufacture of candles and soap. The softer fats, with cotton-seed oil, are placed in churns together with sweet milk, and churned, salted, and worked like butter. By varying the proportion of hard and soft fats, different grades of oleomargarine can be produced, and these are sold under various trade names. These products are readily detected upon chemical analysis, as they fail to yield the requisite amount of volatile fatty acids (see section 40).

104. Simple Methods for detecting 0leomargarine.The boiling or spoon test is made in the following way: A small piece of the sample is melted in a 
large spoon with gentle heat. The process is hastened by stirring. The heat is then increased, the material is brought to the boiling point and thoroughly stirred. Oleomargarine and renovated butter boil with much sputtering and produce no foam, or very little, while genuine butter in boiling produces more foam and less noise. The Waterhouse test is conducted in the following way: "Into a small beaker pour $50 \mathrm{cc}$. of sweet milk. Heat nearly to boiling and add from 5 to $10 \mathrm{gm}$. of butter or oleomargarine. Stir with a glass rod until the fat is melted. The beaker is then placed in cold water and the milk stirred until the temperature falls sufficiently for the fat to congeal. At this point the fat, if oleomargarine, can easily be collected into one lump by means of the rod, while if butter it will granulate and cannot be collected."

105. Renovated Butter. - Low grade and rancid butters are sometimes subjected to the process known as renovation. The butter is melted and poured into cold water, so as to recrystallize the fat and remove those products which impart the undesirable flavors and odors. The butter fats are then reworked and salted, and the product is ready for the market. It is often sold as fresh butter. Renovated butter has poor keeping qualities, and so preservatives, as boric acid, are frequently added to prevent the fats from becoming rancid. When melted and recrystallized, the butter fats fail to form crystals of the same character as the original butter, which 
enables the renovated butter to be easily detected. Some of the states have laws requiring that butter treated in this way shall be stamped or labeled "Renovated Butter."

106. Adulteration of Cheese. - Cheese is adulterated (1) by removing a portion of the fat from the milk and then manufacturing the skimmed or partially skimmed milk into cheese; (2) by completely removing the milk fats and substituting other and cheaper fats, thus producing so-called " filled cheese." The foreign fats are incorporated with the skim milk while in the vats and then the process of cheese making is completed, with slight modifications, as outlined in the chapter on Cheese Making. The addition of foreign fats to the cheese can be readily detected by chemical analysis, as cotton-seed oil and other fats have different chemical and physical properties from butter fats. For the determination of the per cent of fat in cheese by the Babcock test, see section 92. Cheese with 28 per cent or less of fat can be considered as made from partially skimmed milk, and the lower the per cent of fat in the cheese, the more extensively has the skimming been practiced.

107. Adulteration of Milk. - The way in which the lactometer and Babcock test may be used for detecting skimming and watering is described in Chapter IV. In addition to skimming and watering, milk is sometimes adulterated by the addition of preservatives. The materials employed for the 
preservation of milk are principally borax, boric acid, formalin, and salicylic acid. Medical authorities object to the use of preservatives in dairy products and other foods because they interfere with the normal process of digestion. Then, too, when milk is preserved with chemicals, there is a tendency to practice unclean methods in its handling, and less care generally is taken of the milk. Abnormal amounts of preservatives have been found added to market milk to prevent its becoming sour. The producer, the wholesale milk dealer, and the retailer each adding a small amount make in the aggregate an abnormal and objectionable quantity of preservatives, which may have an unfavorable action upon the human body. In the creamery and cheese factory, the addition of formalin and other preservatives prevents the normal ripening of milk and results in the production of butter and cheese of poor quality. Not only from a sanitary but also from a financial point of view, preservatives are objectionable and should not be used in the dairy. Various trade names have been applied to the different preservatives, but they are almost invariably composed of borax, boric acid, formalin, or salicylic acid.

In addition to the Babcock test, a number of other methods have been proposed and are occasionally used for the testing of milk and detecting any adulterations. Many of these methods give accurate results, but they require more skill on the part of the operator, are more expensive, and require more time 
than the Babcock test, and hence are used but little. Some of the methods, as the Pioscope and the Lactoscope, do not give accurate results.

The Beimling method is quite similar to the Babcock test, a centrifugal being used. The test bottles, however, are smaller, and two acids instead of one are employed. Amyl alcohol is required, and this is apt to be impure and cause too high results.

The Lactocrite method has been in use in Germany and Denmark for some time. The separation of the fat is made by means of actic and sulphuric acids, combined with centrifugal action. In its workings the Lactocrite is quite like the Babcock test. The centrifugal used is in form like the Alpha separator. The method gives reliable results. It is patented and the apparatus expensive.

With Gerber's butyrometer test, the fat is separated by centrifugal action aided by sulphuric acid and amyl alcohol. This method combines the more important features of the Babcock and the Beimling methods. It gives accurate results and is quite extensively used in Europe.

Short's Method. - In this test an alkali solution is first added to the milk, which changes the fat into soap; the soap is then converted into insoluble fatty acids by adding sulphuric acid, and the fatty acids are measured in a graduated tube. The test bottles are similar to those used in the Babcock test.

In Cochrane's method the fat is separated by the combined use of sulphuric and acetic acids and 
ether. The fat is then raised into a graduated tube, where it is measured. The Cochrane fat bottles are made with two tubes, one for measuring the fat and the other for adding the reagents.

In Failyer and Willard's method an acid first is added to the milk, and then gasoline to collect the fat. The gasoline is removed by a current of air, and the fat is collected in the graduated neck of the test bottle and measured.

The Lactoscope and Feser's Pioscope were quite extensively used at one time. They are optical methods and depend upon the opacity of the milk serum. Both of these methods are totally unreliable, the results being very inaccurate.

Most of these short methods are not sufficiently accurate for scientific work, or as final evidence in court in case of adulteration.

108. Dairy Laws. - Some states and countries have passed laws prohibiting the sale of adulterated dairy products. Congress has also passed a national law prohibiting the coloring of oleomargarine to resemble butter. The injury which results from the sale of oleomargarine and filled cheese is due more to their being dishonest competitors than to their unwholesomeness. They are frequently sold for butter and cheese, and since they are made to resemble them, it is often difficult for the inexperienced person to detect the adulterated article. As to digestibility and food value, there is not a great difference between butter and oleomargarine. 
Experiments have shown that butter is slightly more digestible than oleomargarine. As long as oleomargarine is sold under its own name, there is little objection to its use; but people naturally prefer genuine butter and cheese to imitation articles, and they should be protected in securing them. It is when oleomargarine is sold as butter that the principal injury is done to the butter industry. For this reason, laws have been passed regulating the sale of dairy products and prohibiting adulteration. 


\section{CHAPTER XII}

\section{MARKET MILK AND CREAM}

109. Variable Character of Market Milk. - It is estimated that one third of the milk produced in this country is used for direct consumption by the producer or is sold as market milk. The milk supply of large cities is extremely variable in character, both in its richness in fat and its wholesomeness or sanitary condition. In those states where dairy laws have been enacted and the laws are reasonably well enforced, milk of good quality is secured, but where no legal control is exercised over the milk supply, it is often of very poor quality. To meet the requirements of the consumer, milk should be produced from animals in sound health, and the milk should be free from dirt, have good keeping qualities, and contain a reasonable amount of fat. In order to supply milk of the best quality, different methods of handling have been devised, the most satisfactory and cleanly way being to supply the milk in sterilized sealed bottles. When milk is conveyed to the consumer in this form, no opportunity presents itself for adulteration or for the milk to become contaminated by unclean methods of handling or through 
exposure in unclean streets. Usually a larger price is paid for milk prepared in this way. The sanitary condition or wholesomeness of the milk (see Chapter VIII) is of more importance than its fat content.

110. Changes in Composition of Milk during Transportation. - When milk is transported in cans and removed with a long-handled dipper, it changes but little in composition during transportation, the agitation of the can and the dipping being sufficient to prevent the separation of cream. This question has been extensively investigated in both this country and Europe. In England, one of the large dairy firms supplying milk to the London market had during the season a number of thousands of samples of milk taken from the wagons at different points on the route to prevent the watering of the milk by the drivers, and it was found that there was but little change in the solid matter of the milk. During one season over 11,000 samples were analyzed, with the following results :-

\begin{tabular}{|c|c|c|c|c|c|c|c|c|c|}
\hline & & & & & & & & MILK & Cream \\
\hline & & & & & & & & Solld Matter & Solid Matter \\
\hline Before starting & & 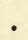 & & - & - & - & . & 12.84 & 48.3 \\
\hline During delivery & 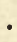 & - & • & - & - & - & - $\quad$ & 12.88 & - \\
\hline At close . & 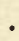 & - & - & - & - & - & - & 12.92 & 48.4 \\
\hline
\end{tabular}

At the Cornell University Experiment Station similar results were obtained, also at the Canadian Experi- 
ment Station at Guelph. The excuse sometimes offered in court that milk has lost its cream while being sold is not valid, as all the experimental evidence shows that when milk is dipped from the can with a long-handled dipper no separation of the fat takes place. While milk changes in its per cent of solid matter but little during transportation, it often becomes sour and foul through unnecessary exposure and unclean ways of handling.

111. Pasteurizing Milk and Cream. - In order to prevent milk and cream from readily fermenting, it is sometimes given the Pasteurizing treatment. This consists of heating the milk or cream to a temperature of $159^{\circ}$ or $160^{\circ} \mathrm{F}$. for a few minutes and then cooling and protecting it from further inoculations. This temperature results in rendering inactive the greater number of ferments in milk, particularly those of an objectionable nature. The destruction of the ferment bodies prevents rapid souring of the milk, especially when the milk is protected from further contamination. The Pasteurizing of milk and cream is usually done by machinery, the milk being agitated so as to secure as even an application of temperature as possible. The longer the milk is heated, the more thorough is the Pasteurizing process. Not all of the germs or ferments of milk are rendered inactive by heating to a temperature of $160^{\circ}$. To render inactive the tuberculous bacilli, a temperature of $180^{\circ}$ to $185^{\circ}$ is required. When milk is sterilized, it is heated to a higher degree than 
when it is Pasteurized. At temperatures above $185^{\circ}$, all of the bacteria are destroyed and the milk is rendered sterile. When milk is sterilized, the albumin is coagulated; when Pasteurized, the temperature is not sufficiently high to coagulate it. The Pasteurizing of milk improves its sanitary condition and often makes an unsound milk suitable for food purposes. It is preferable, however, to have a wholesome and sound milk that is not Pasteurized rather than an unsound milk that has been given this treatment. When a milk is Pasteurized, its germ content is reduced; but the products of the germs, particularly the toxins, are not removed.

The Pasteurizing of cream is often resorted to in making butter. When the cream has been contaminated in any way, Pasteurizing gives good results. When the milk has been produced under the most sanitary conditions, Pasteurizing is less necessary. The preparation and sale of Pasteurized milk and cream have become prominent features of the milk industry in a number of cities. For home use, milk can be Pasteurized in the following way: glass cans are thoroughly cleansed and then placed in the oven so as to become sterilized. When partially cooled, they are filled with fresh milk and set in water at a temperature of about $162^{\circ}$. After being in the water for from 10 to 15 minutes, with the temperature kept at $160^{\circ}$, the cans are covered, cooled, and stored at a low temperature. Not all milks are suitable for food even when Pasteurized. Digestion 
experiments indicate that perfectly sound, normal milk is more completely digested than either Pasteurized or sterilized milk; the difference in digestibility, however, between sound, fresh milk and Pasteurized milk is small, but in favor of the fresh milk. Sterilized milk is less digestible than Pasteurized.

112. Condensed Milk. - Another method of preserving milk is to remove a portion of the water by means of condensing in a vacuum pan and then sealing the condensed product while hot. Milk that is properly condensed can be kept for a long time, and in some localities it is the main source of milk supply. Whenever a can of condensed or Pasteurized milk is opened, the same care is necessary to protect it from contamination as if it were fresh milk.

113. Milk as Human Food. - There is no food that has a higher value than pure milk. Too frequently its nutritive value is impaired by its being impure. Contaminated milk, like any impure food, should not be used. Milk should form a part of the dietary, as it is easily digested, and assists in rendering other foods more digestible. Experiments have shown that at average prices milk is not a luxury, but an economical food. Milk furnishes a large amount of digestible nutrients, and, in the case of a number of diseases, it is the only food that should be allowed. Milks with either the maximum or minimum fat content are not the best for food purposes, but milk containing about 4 per cent of fat generally gives 
the most satisfactory results where it forms a large part of the diet. Milks very poor or very rich in fat have either too narrow or too wide a nutritive ratio (see section 133), while normal milk is a wellbalanced food containing proteids, carbohydrates, and fats in the right proportions for supplying the needs of the body. 


\section{CHAPTER XIII}

INFLUENCE OF DIFFERENT FOODS UPON THE QUALITY OF MILK AND DAIRY PRODUCTS

114. Food and Milk Secretion. - There is a close relationship between milk secretion and the food supply. It was formerly believed that the percentage amounts of the milk solids could be materially influenced by the character of the food consumed. In the numerous experiments that have been made, a few cases showed the composition of the milk to have been influenced, but it was not possible in most eases to materially increase or decrease the percentage of fat or other constituents of the milk. The total amount of all of the compounds present, however, can be materially increased by judicious feeding, and thus, while it is not possible for the farmer by liberal feeding to increase the per cent of fat in his milk, he practically accomplishes the same result by increasing the amount of milk.

It was formerly believed that the fat in the food was the main source of the fat in the milk. A good cow, however, will produce during a year a much larger amount of fat in the milk than she consumes in the food, showing that the fats are in part produced from other nutrients. 
115. Feeding Fat. - The investigations that have been made show that it is not possible to increase either the percentage or the total amount of fat in the milk for any appreciable time by the feeding of fats or oils. In experiments at Cornell University, the Iowa Experiment Station, and other institutions where fats have been fed to cows even at the rate of two pounds or more per day of tallow, cotton-seed oil, corn oil, or other fats, the fat content of the milk was not permanently increased. The quality of the milk fat and of all the dairy products is, however, appreciably affected by the foods consumed; and while the fats and other compounds do not pass directly from the food into the milk unchanged, the character of the fats and other nutrients materially influences the quality of the fat globules and the dairy products.

116. Production of Hard Butters. - When cottonseed meal is fed in liberal amounts and is not combined with other grains, it produces a hard and tallowlike butter having a melting point of $10^{\circ}$ higher than average butter. Chemical analysis shows that there is a larger percentage of stearin and palmitin in such butter. When cotton-seed meal is combined with other food stuffs and is fed in small amounts, it exerts but little influence on the butter product. Cotton-seed meal is a valuable nitrogenous food when properly combined and fed with other food materials.

Corn, also, if fed alone and in large amounts, will 
produce an abnormally hard butter, particularly if combined with overripe, coarse dry fodders. This tendency of some food stuffs to produce an abnormal butter is eliminated when foods are properly combined.

117. Production of Soft Butters. - While cottonseed meal produces a hard butter, linseed meal, the product obtained after removing the oil from flax-ohm seed, produces a soft butter when fed alone and in large amounts. Cotton-seed meal and linseed meal have somewhat the same general composition; both are rich in protein and fat, but when fed they have directly opposite effects upon the character of the butter.

118. Effects of Individual Foods. - There are a number of individual food stuffs that have a noticeable effect upon the quality of the milk and butter. Gluten meal, a product obtained in the manufacture of cornstarch, produces a softer butter than corn meal; oats, when fed alone and in large amounts, produce a mediumly firm but rather crumbly butter; when oats and corn are fed together, the quality of the butter is much improved. Wheat by-products, as shorts and bran, produce a mediumly firm butter of good quality; wheat and barley coarsely ground also produce normal butter.

There is but little difference in the milk-producing power of the different farm grains when fed in mixed rations. Of the coarse fodders, clover hay, corn silage, and well-cured corn fodder produce the largest flow and also milk of the best quality for butter and 
cheese making purposes. These coarse fodders, when prepared under the most favorable conditions, produce mediumly firm butter in contrast to the hard and tallow-like butter produced from overripe hay containing a large amount of fiber and but little protein. Silage has been found to be of much value in a ration, as it produces a better quality of butter than average coarse fodders. It has been objected to by some because of the silage odor of the milk. It has been found that this is due largely to lack of proper ventilation in the stable, as the silage odor gains access mainly at the time of milking rather than being transmitted through the milk. When animals are kept under the most sanitary conditions and silage forms only a part of the ration, there is no perceptible odor to the milk and it is of good quality. As previously stated (section 75), some food stuffs, as turnips, rape, and onions, affect the flavor of the milk. This is due to the volatile and essential oils passing directly from the food into the milk. There are weeds that are also responsible for bad-tasting milk, as the wild garlic, which produces a foul taste.

119. Desirable Flavors in Milk Products. - The desirable flavors in butter, cheese, and other dairy products are due to the small amount of chemical compounds formed by the workings of the bacterial ferments and the enzymes. As a result of fermentation action, definite chemical compounds, some of which have pleasant and desirable properties and 
others undesirable ones, are produced. Butyric acid fermentation is an example of the undesirable kind and results in the production of butyric acid, which gives stale butter its characteristic odor. By controlling the processes of fermentation during the manufacture of dairy products, the undesirable ferments are prevented from gaining access to the milk, and the desirable ferments are added and given every opportunity to carry on the normal processes of fermentation. Fresh, normal milk should have a pleasant taste, and when obtained and handled in a cleanly way, it will contain but few bacterial bodies.

120. Influence of Balanced Rations. - When the animal body is supplied with the necessary nutrients for the various functional purposes, the largest amount and the best quality of milk is secured. It is only when unusual food stuffs and those deficient in the requisite nutritive materials are fed that milk of abnormal character is produced. One of the objects of combining several grains and coarse fodders to form a balanced ration is to furnish the nutrients to produce the largest amount and best quality of milk. Much experimental work has been done to ascertain the relationship between the various food stuffs and milk secretion. It was believed at one time that certain foods contained special compounds which stimulated milk secretion. It has been found, however, that there are no special foods which exert an influence on milk secretion not shared alike by the common farm grains and well-prepared 
fodders. There are no stock foods that possess properties for increasing the secretion or flow of milk. The best results are secured by supplying a variety of food stuffs containing a liberal amount of nutritive materials. Milk produced under the best sanitary conditions from healthy and well-fed animals has an individuality, and such milk is specially valuable for food and for the manufacture of butter and cheese.

121. Milk Secretion. - The materials of which milk is composed are abstracted from the blood, and in order to keep up a good flow of milk suitable food should be supplied, which may be later elaborated into milk. Some animals are so constituted that the food supply is used for the production of fat and increase in weight rather than for milk production. Such animals are not profitable for dairy purposes.

There are a number of factors that influence milk secretion, as regularity of milking and feeding, manipulation of the udder, exhaustive milking, protection of the animals from sudden changes in temperature and adverse climatic conditions, and good sanitary surroundings. These factors all influence the secretion of milk, because the process is largely the result of the working of individual cells which compose the ultimate follicles, and in case the cells are injured or are not given the best conditions for doing their work, milk secretion is decreased and the quality of the product lowered. 


\section{CHAPTER XIV}

\section{THE RATIONAL FEEDING OF DAIRY STOCK}

122. Uses of Food. - Food is used by the animal body for three purposes: (1) for production of heat and energy; (2) for growth and to furnish materials to renew the worn-out tissues of the body; and (3) for the production of animal products, as milk, meat, and wool. When the animal body has been supplied with food for heat, energy, and growth, the excess is then available for the production of meat and milk. The different nutrients or compounds of which foods are composed serve different functions in the body, and in the rational feeding of farm animals it is the object to combine various food stuffs so that the nutrients will be present in the right amounts and proportions for the various functions of the body.

123. Nutrients and their Functions. - The compounds of which foods are composed are divided into two main classes, the nitrogen-containing or nitrogenous compounds, and those containing no nitrogen or the non-nitrogenous compounds. The nitrogenous compounds are spoken of collectively as the crude protein of food stuffs; the non-nitrogenous compounds are mainly starch, sugar, fat, and 
cellulose. The two classes of compounds, nitrogenous and non-nitrogenous, serve different functional purposes in the body. The nitrogenous compounds, or proteids, are the more expensive and are present in much smaller amounts than the non-nitrogenous compounds. Starch, sugar, fiber or cellulose, and allied bodies, are spoken of collectively as the carbohydrates, and in connection with feeding stuffs only, the three general terms, "crude protein," "carbohydrates," and "crude fat" or "ether extract," are employed. Food stuffs are composed of a great many other compounds besides these general classes.

124. Dry Matter. - When a substance is dried at a temperature of $212^{\circ} \mathrm{F}$, all of the water is removed, and what is left is called dry matter. All food stuffs contain some water. Grains and mill products contain from 10 to 15 per cent of water, dry hay from 12 to 18 per cent, and roots and tubers from 75 to 90 per cent. Some green crops and vegetables contain as high as 95 per cent of water. The dry matter of a food is simply a mechanical mixture of the different compounds of which the material is composed, as ash or mineral matter, crude protein, and nonnitrogenous compounds, including carbohydrates and crude fats.

125. Ash. - When the dry matter of a food is burned at the lowest temperature necessary for complete combustion, the ash or mineral matter is obtained. In most agricultural plants the ash is less than 10 per cent of the dry matter, and in the grain 
crops it ranges from 2 to 4 per cent. The ash is composed of lime, potash, phosphates, and other mineral substances. All of the coarse fodders, grains, and mill products contain a sufficient amount of mineral matter for purposes of nutrition, including phosphates for bone formation and for the production of milk.

126. The Organic Matter. - That portion of the dry matter which is burned and converted into volatile products is called the organic matter. It is obtained by subtracting the per cent of ash from 100, which represents the total amount of-dry substance.

127. Proteids. - These compounds, which are found in variable amounts in all food stuffs, are similar in general composition to the milk proteids described in section 82. The proteids as a class are characterized by containing the element nitrogen in addition to carbon, hydrogen, and oxygen, which are present in all the other nutrients of food stuffs. It is the proteids which serve the special purpose of supplying the materials for repairing the body waste. Proteids are the principal materials out of which the muscles are formed, and they also enter largely into the composition of all the tissues of the body. All the vital fluids of the body, as the blood, contain large amounts of this class of compounds. The proteids of the body can be formed only from the proteids of the food; hence the importance of the requisite supply of this nutrient in the food. An excessive 
amount, however, in a ration is unnecessary. After the functions of the body are served, the surplus protein is used for producing heat and energy, and it quite frequently happens that a ration is unnecessarily expensive because of containing an excess of protein, which is used for the production of heat where cheaper nutrients, as the carbohydrates, would serve the same purpose. Neither is a ration that contains too scant an amount economical, as a full milk flow cannot be maintained on a scant supply of protein. The rational feeding of animals is largely a regulation of the supply in the food of proteids and carbohydrates for milk production and other purposes. There are a great many different kinds of proteids in food stuffs. Casein and albumin in milk are proteids; egg albumin is also a proteid. The glutens of wheat and other grains are among the most common proteids found in food stuffs.

128. Carbohydrates. - With the exception of fat, all the non-nitrogenous compounds, as sugar, starch, and cellulose, taken collectively, are called carbohydrates. By far the largest part of the nutrients in food stuffs are carbohydrates. Those carbohydrates which are easily rendered soluble, as sugar and starch, are called the nitrogen-free-extract compounds. Carbohydrates are a complex group of substances composed of three elements, - carbon, hydrogen, and oxygen. The chief function of the carbohydrates is to produce heat and energy, and, when properly combined with the proteids, they may 
serve for the production of fat in the body. The carbohydrates from different food stuffs vary widely in character. In the potato, starch is the main carbohydrate; in beets, it is sugar ; in apples, pectose or jellylike substances; and in hay and coarse fodders, pentosans predominate, or bodies that can be converted into sugarlike substances containing five atoms of carbon in the molecule.

129. CrudeFiber.-The term "crudefiber" is applied to the cellular tissues of which the framework of plants is composed. A portion of the fiber is digestible and capable of serving the same functions as the soluble carbohydrates. Foods with excessive amounts of fiber are objectionable, but on the other hand some fiber is desirable in order to give the necessary bulk to a ration.

130. Crude Fat. - All food stuffs contain some fatty compounds. In farm grains from 2 to 5 per cent of ether extract or crude fat is present; in coarse fodders from $1 \frac{1}{2}$ to 2.25 per cent; while in some of the specially prepared mill products, as oil meal, 10 per cent or more of fat may be present. The fat in food stuffs is extracted with ether, and hence the term "ether extract" is used. In addition to the fats, ether extract contains small amounts of other substances, as chlorophyll and resin. Hence the ether extract is not pure fat. From grains and mill products, however, the ether extract is nearly pure fat, while in that from coarse fodders there is only from 50 to 75 per cent of pure fat. Fats are character- 
ized by containing a larger amount of carbon than either starch or sugar, and hence, when burned or digested in the body, they produce a larger amount of heat and energy. A pound of fat will produce 2.25 times as much heat as a pound of starch.

131. Digestible Nutrients. - Only a portion of the compounds of which foods are composed is digested, absorbed by the body, and used for some functional purpose. In average food stuffs from 15 to 45 per cent of the nutrients are indigestible and unavailable to the body. That portion of a compound which is digested and utilized is called a digestible nutrient. Foods contain digestible protein, digestible fats, and digestible carbohydrates. The total nutrients are only in part digestible. The digestible nutrients of a food stuff are determined by means of digestion experiments, in which the income and outgo of the nutrients of the food, including the amount which fails to digest, are accurately determined. As a result of numerous digestion experiments, the digestion coefficients or the percentage of the nutrients that are digested are determined. The digestion coefficients are used for the construction of tables of digestible nutrients in foods. In using these tables in rational feeding, it is only the digestible nutrients that are to be considered, as the indigestible portion of the food furnishes no material for functional purposes.

132. Caloric Value or Heat Units of a Ration. When food is digested, heat is produced and the 
amount of heat is directly proportional to the percentage of fat, carbohydrates, and proteids present. A balanced ration produces about 32,000 calories, or heat units. A calory is the unit of heat, or the amount of heat required to raise $1 \mathrm{~kg}$. of water $1^{\circ}$ on the centigrade scale, or one pound of water about $4^{\circ}$ on the Fahrenheit scale. A pound of digestible fat produces 4225 calories, and a pound of digestible carbohydrates or protein produces 1860 calories.

133. Nutritive Ratio. - The term "nutritive ratio" is used to express the ratio which exists between the digestible protein and the digestible carbohydrates. A nutritive ratio of 1 to 6.5 means that there is one part of digestible protein to 6.5 parts of digestible, non-nitrogenous compounds. A wide ration means a large proportional amount of carbohydrates to protein, while a narrow ration means a comparatively small amount of digestible carbohydrates to protein. In calculating the nutritive ratio, the crude fat or ether extract is multiplied by 2.25 , because the fats are 2.25 times more concentrated than the carbohydrates.

134. Selection of Foods for Rations. - In the feeding of dairy animals the selection of the food materials is of equal importance with the amount of nutrients they contain, because, as stated in a preceding chapter, the amount and quality of the milk and products are dependent largely upon the character of the foods consumed. To give the best results, a ration should contain grains, mill products, coarse 
fodders, and roots blended in such a way as to meet all the requirements of the body. A ration should have the requisite bulk, be palatable, and contain a variety of food materials with sufficient digestible nutrients. The coarse fodders most satisfactory for dairy feeding are clover hay, alfalfa, corn fodder, corn silage, oat hay, and the best grades of timothy, upland, and prairie hay. Common farm grains, as barley, oats, and corn are equally as valuable for milk production as the common mill products, - bran and shorts. Farm grains, however, are not quite as valuable pound for pound as the more concentrated mill products, such as oil meal and cotton-seed meal. The quantity of food an animal receives should vary with the amount of milk produced. When an animal is giving a full flow of milk, the maximum amount of food should be supplied. A standard ration or one for a cow giving 25 to 30 pounds of milk should contain from 1.7 to 2 pounds of digestible protein and about 14 pounds of digestible carbohydrates per day. Such a ration will produce about 32,000 calories or heat units. A ration that is well suited for dairy purposes will return from 10 to 12 per cent of the dry matter of the food in the milk. About one quarter of the protein in the food of a milk cow is used for maintenance purposes, about one half for the production of the milk, and about one quarter is voided as indigestible. It is not possible to formulate definite standards in the feeding of dairy stock that are alike applicable to all animals 
and all conditions. The quantity of food that can be consumed to the best advantage must be determined experimentally by the feeder and should be varied as occasion demands in order to give the best results. Ordinarily a ration of from 7 to 10 pounds of farm grains and mill feeds, with 18 to 25 pounds of mixed coarse fodders, will supply approximately the requisite amount of nutrients for the production of milk. There is but little difference in the milkproducing value of the different farm grains when fed in mixed rations. For economical production, as much of the digestible protein as possible should be supplied in the coarse fodders, so as to reduce the quantity of grains that are required for feeding purposes.

135. How to calculate a Ration. - The foods that are to be combined to form the ration should be selected on the basis of cost and composition. In case corn fodder, clover hay, oats, corn, and mangels are raised on the farm, these foods can be combined to form a balanced ration either with or without any commercial foods. In case it is desired to make a ration of these foods with bran, the general statements given in paragraph 134 as to quantities of food should be noted. About 20 pounds of coarse fodder, 10 to 12 pounds of grains, and 10 pounds of mangels will form the roughage of a reasonably wellbalanced ration for a cow giving from 25 to 30 pounds of milk per day. The digestible nutrients in 100 pounds of the foods combined are first noted. 
As given in the table in the Appendix, they contain the following amounts of digestible nutrients :-

Corn fodder . . . . Clover hay . . . . . . Oats . . . . . . Corn . . . . . . Bran ........ Mangels . . . . . .

Digestible Nutrients in 100 LB. of Food Materials

\begin{tabular}{|c|c|c|c|c|c|c|}
\hline & \\
\hline & & & & Proteln & Carbohydrates & Fats \\
\hline Corn fodder & . . & & . & 2.5 & 34.6 & 1.2 \\
\hline Clover hay . & . . & . . & . . . & 6.8 & 35.8 & 1.7 \\
\hline Oats . . & . . & . . & . . . & 9.2 & 47.3 & 4.2 \\
\hline Corn . . & . . & . . & . . . & 7.9 & 66.7 & 4.3 \\
\hline Bran . . & . . & . . & . . . & 12.9 & 40.1 & 3.4 \\
\hline Mangels . & . . & . . & . . & 1.1 & 5.4 & 0.1 \\
\hline
\end{tabular}

Since the figures represent the amounts of digestible protein, carbohydrates, and fats in 100 pounds of the foods, the amount of digestible nutrients in 1 pound is obtained by moving the decimal point two places to the left. A trial ration is first made with 10 pounds each of corn fodder, clover hay, and mangels, and 7 pounds of oats, 3 of corn, and 2 of bran. The pounds of digestible protein, carbohydrates, and fats in 10 pounds of the corn fodder, clover hay, and mangels are obtained by moving the decimal point one place to the left. The pounds of digestible protein in the 7 pounds of oats are obtained by multiplying .092 by 7 , and the pounds of digestible carbohydrates by multiplying .473 by 7 , and the fat by multiplying .042 by 7 . In like manner, the digestible nutrients in the 3 pounds of corn and the 
2 pounds of bran are obtained by multiplying the per cent of each digestible nutrient by the weight of the material used. The pounds of digestible protein, carbohydrates, and fat in the several foods are as follows:

\begin{tabular}{|c|c|c|c|c|c|c|}
\hline & & & & \multicolumn{3}{|c|}{ Total Digestible Nutrifnts } \\
\hline & & & & Protein & Carbohydrates & Crude Fats \\
\hline Corn fodder, & $10 \mathrm{lb}$ & - & -. & 0.25 & 3.50 & 0.12 \\
\hline Clover hay, & $10 \mathrm{lb}$ & - $\quad$. & - $\quad$ & 0.68 & 3.58 & 0.17 \\
\hline Mangels, & $10 \mathrm{lb}$ & - $\quad$ & - & 0.01 & 0.05 & - \\
\hline Oats, & 7 lb. & . $\quad$. & . & 0.65 & 3.31 & 0.29 \\
\hline Corn, & $3 \mathrm{lb}$ & - & - & 0.24 & 1.99 & 0.12 \\
\hline Bran, & $2 \mathrm{lb}$. & - $\quad$. & - $\cdot$ & 0.25 & 0.80 & 0.06 \\
\hline Total & .. & .. & . & 2.08 & 13.23 & 0.76 \\
\hline
\end{tabular}

$.76 \times 2.25=1.71 ; \frac{13.23+1.71}{2.08}=7$ nutritive ratio.

Heat units : $(13.23+2.08) \times 1860=28,476.6$

$$
\begin{aligned}
& .76 \times 4225 \\
& \text { Total }
\end{aligned}=\frac{3,211.0}{31,687.6}
$$

This ration contains 2.08 pounds of digestible protein, 13.23 pounds of digestible carbohydrates, and .76 pound of digestible fats. The nutritive ratio is 1 to 7 , and the ration yields a total of $31,687.6$ calories. Compared with the requirements of a standard ration for a cow giving 25 to 30 pounds of milk, it will be found that these amounts conform suffieiently to the standard to warrant this ration being used. It is to be noted that the pro- 
tein is largely supplied by the clover hay and oats, and the carbohydrates in nearly equal amounts by the corn fodder, clover hay, and oats. Corn and bran are used in smaller quantities, but add appreciable amounts of digestible nutrients to the ration. While the mangels do not supply a large amount of nutrients, they are very valuable in the ration in other ways. They impart palatability and promote secretion of the gastric and digestive fluids. In case a smaller amount of milk is produced, the quantity of grain should be reduced. If more than 30 pounds of milk are given, the grain part of the ration should be proportionally increased. The ration contains a sufficient variety of food materials, and the foods are combined in such a way as to produce a good quality of milk. It is not necessary that a ration should conform absolutely with the tables. A variation of .1 to .2 of a pound of protein in a ration, provided there is a corresponding increase in the other nutrients, will not seriously affect the milk-producing power of the ration.

The figures given in the Appendix represent the average composition of feeding stuffs, as found by a number of experiment stations. Individual samples of coarse fodders may vary appreciably from the average that is given. For example, it is possible for corn fodder to contain as low as $\mathbf{1 . 5}$ pounds of digestible protein per 100 , or as high as 3.5 pounds. When the coarse fodders are raised on rich soil and prepared under the best conditions and cut when not overripe, 
they will contain the maximum amount of nutritive materials, and such fodders can be used in appreciably less amounts than fodders grown under less favorable conditions and which contain more fiber and less digestible protein and carbohydrates. Because of differences in the quality of the same class of fodders, it is possible for two farmers to feed the same kinds of feeding stuffs and grains and yet secure widely different return in milk yields.

While it is not necessary to conform too closely to the standards in the feeding of dairy stock, a wide variation is not desirable, as milk cannot be produced economically when the stock is not fed on reasonably well-balanced rations, and the quality of the product is often abnormal. Numerous experiments have been made to determine the rations that are most suitable for milk production. It has been found that a comparatively narrow ration of 1 to 5.5 will produce a larger flow of milk than a wider ration of 1 to 8 . But if the narrow ration is fed in large amounts, the milk is not produced as economically as when the wider ration is fed. Maximum returns are secured when a ration is fed which has a nutritive ratio of from 1 to 6.5 or 7.5. It frequently happens in the feeding of dairy stock that heavy grain rations are not economical because the excess of protein is not used for vital purposes, but serves a purpose which would be as well served by the use of the cheaper carbohydrates. In the case of young stock it is advantageous to feed a liberal ration, as this will have 
a tendency to encourage a larger flow of milk during later periods of lactation.

In the feeding of dairy stock, sudden changes in the ration should be avoided. In case it is necessary to make a change in the coarse fodder or grains, it should be done gradually. A good feeder can tell from the appearance of the stock and the avidity with which the ration is consumed whether the grains and coarse fodders are being fed to advantage. In many of the feeding trials that have been made, the experimental periods have been too short to give reliable results.

136. Comparative Cost and Value of Grains. - The market and feeding value of grains often vary between wide extremes, and it is frequently found that a given sum of money, if invested in one food, will procure a larger amount of digestible nutrients than if invested in other foods. In general, it can be said that there is but little difference in the milk-producing value of grains when fed in a mixed ration, and hence the price per pound can be taken as the deciding factor as to what shall constitute the main part of the ration. In case it is desired to compare the amount of nutrients that can be procured for a given sum of money, it can be done in the following way: Determine the number of pounds of food material that can be purchased for $\$ 1.00$, and then calculate the number of pounds of digestible nutrients in this quantity of food. For example; if oats are 30 cents per bushel, a dollar will purchase 107 pounds. Since 100 pounds of 
oats contain 9.2 pounds of digestible protein, 4.2 pounds of fat and 47.3 pounds of digestible carbohydrates, 107 pounds will be found to contain 9.84 pounds of protein, 4.5 pounds of fat, and 50.6 pounds of carbohydrates. In case it is desired to compare the nutrients in oats at 30 cents per bushel with the nutrients in corn at 50 cents per bushel, the same process of calculation is carried on. One dollar will purchase 112 pounds of corn, and since 100 pounds contain protein, fat, and carbohydrates in the proportion given in section 135,112 pounds will contain 8.85 pounds of protein, 4.83 pounds of fat, and 74.7 pounds of carbohydrates. The 107 pounds of oats contain about a pound more digestible protein than the 112 pounds of corn, but on the other hand the corn contains about 24 pounds more digestible carbohydrates. For ordinary purposes of feeding, a larger return will be secured from 24 pounds of carbohydrates than from 1 pound of protein. If, however, the ration contains a scant amount of protein, then preference should be given to the protein. But at the price stated, corn could be used more economically than the oats. In determining the comparative value of two grains, preference should always be given to the protein; but in case the difference in the amount of digestible protein that can be purchased for $\$ 1.00$ is not large, while the difference in digestible carbohydrates is quite large, then the food that contains the smaller amount of protein, but larger amount of carbohydrates, would be the cheaper food. 
In the combination of foods to form balanced rations there are a number of factors that should receive consideration. The foods should be in the best mechanical condition. In the case of some grains, coarse grinding should be practiced. Seeds with hard seed coats, as wheat and barley, should be coarsely ground, particularly if the animals are giving large amounts of milk. If the animals are giving a smaller quantity of milk, grinding is not so necessary, as more energy can then be profitably expended in the mastication of the food. In order to meet with success in feeding, practical experience in the handling of stock is necessary. Too frequently the foods are portioned out by volume rather than by weight, and the feeder has but little knowledge as to the weight of the food he is feeding. Since the weight per bushel of grains varies so widely, volume or measure is a very unsafe basis for portioning out food. For example, a quart of corn will weigh much more than a quart of oats, although a pound of oats will contain more digestible protein than a pound of corn. It makes a great difference in the amount of digestible nutrients which the animals receive when the foods are portioned out by volume instead of by weight.

In the feeding of dairy stock, the sanitary conditions discussed in Chapter VIII must be taken into consideration, because the best returns cannot be secured from foods when the animals are not cared for under the most sanitary conditions. 


\section{APPENDIX}

\section{DIGESTIBLE NUTRIENTS IN FODDERS}

\begin{tabular}{|c|c|c|c|c|c|c|c|}
\hline \multirow{2}{*}{\multicolumn{4}{|c|}{$N_{\triangle M E}$ OF FEED }} & \multirow{2}{*}{\begin{tabular}{|c} 
DRY \\
MATTER \\
IN \\
$100 \mathrm{LB}$.
\end{tabular}} & \multicolumn{3}{|c|}{$\begin{array}{l}\text { Diagetible Nutrients } \\
\text { IN } 100 \mathrm{LB} . \\
\end{array}$} \\
\hline & & & & & Protein & 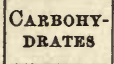 & $\mid \begin{aligned} \text { ETHER } \\
\text { EXTRACT }\end{aligned}$ \\
\hline alyses). & & - & & 89.1 & & 66. & 4.3 \\
\hline . & & & & & & & ש. \\
\hline Flint corn . . . & & . & & & & 2.2 & 4.3 \\
\hline Sweet corn. . . & & & & & 8 & t & 7.0 \\
\hline Corn cob . . . & & & & 89 & & 5 & .3 \\
\hline Corn and cob meal. & & & & 84 & & & 2.9 \\
\hline Corn bran . . . & & & & 90.9 & & & .6 \\
\hline Gluten meal . & . & . & & 91.8 & 25. & 3.3 & 11.0 \\
\hline Germ meal & & & & 89. & 9. & 1. & 2 \\
\hline Iominy chops & & & & 88. & & b. & 6.8 \\
\hline Whe & & & & & 1 & & 1.7 \\
\hline bran & & & & & & & 7 \\
\hline Wheat bran (spring & wh & lea & & 8 & 1 & & 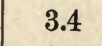 \\
\hline an (winter & wh & reat & & & 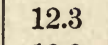 & 3 & 2.6 \\
\hline lorts . . & & ${ }^{\circ}$ & & 88.2 & 2.2 & 0 & 3.8 \\
\hline Vheat middlings & & & & & 2.8 & & , \\
\hline Vheat screenings & & & & & & & .2 \\
\hline Rye... . & & & & 88.4 & 9.9 & & 1 \\
\hline ye bran . & & & & 8 & 11 & 0.3 & .0 \\
\hline Rye shorts. . & & & . & 90 & 11. & 45.1 & 6 \\
\hline Barley . • & & & & 89.1 & 8 & 65.6 & 6 \\
\hline Malt sprouts . & & & & 89.8 & 18.6 & 3 & 1.7 \\
\hline Brewer's grains (wet) & & • & $\bullet^{\circ}$ & 24.3 & 3.9 & 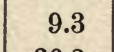 & 1.4 \\
\hline Brewer's grains (driec & & & & 91.8 & 15.7 & 36.3 & 5.1 \\
\hline$\cdot \cdot \cdot \cdot$ & & $\cdot$ & & 89.0 & 9.2 & 47.3 & 4.2 \\
\hline Jat feed or shorts & & & & 92.3 & 12.5 & 46.9 & 2.8 \\
\hline
\end{tabular}




\section{DIGESTIBLE NUTRIENTS IN FODDERS-Continued}

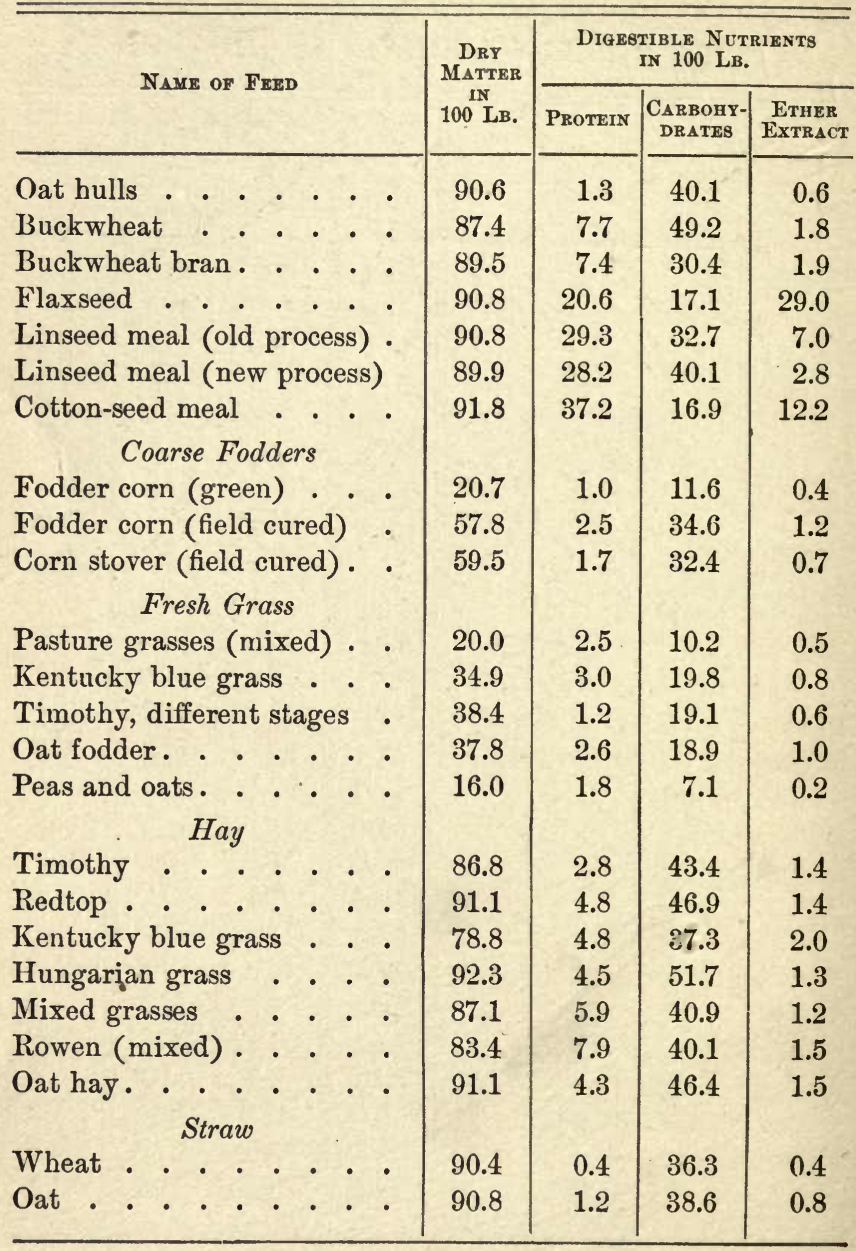


DIGESTIBLE NUTRIEN'TS IN FODDERS - Concluded

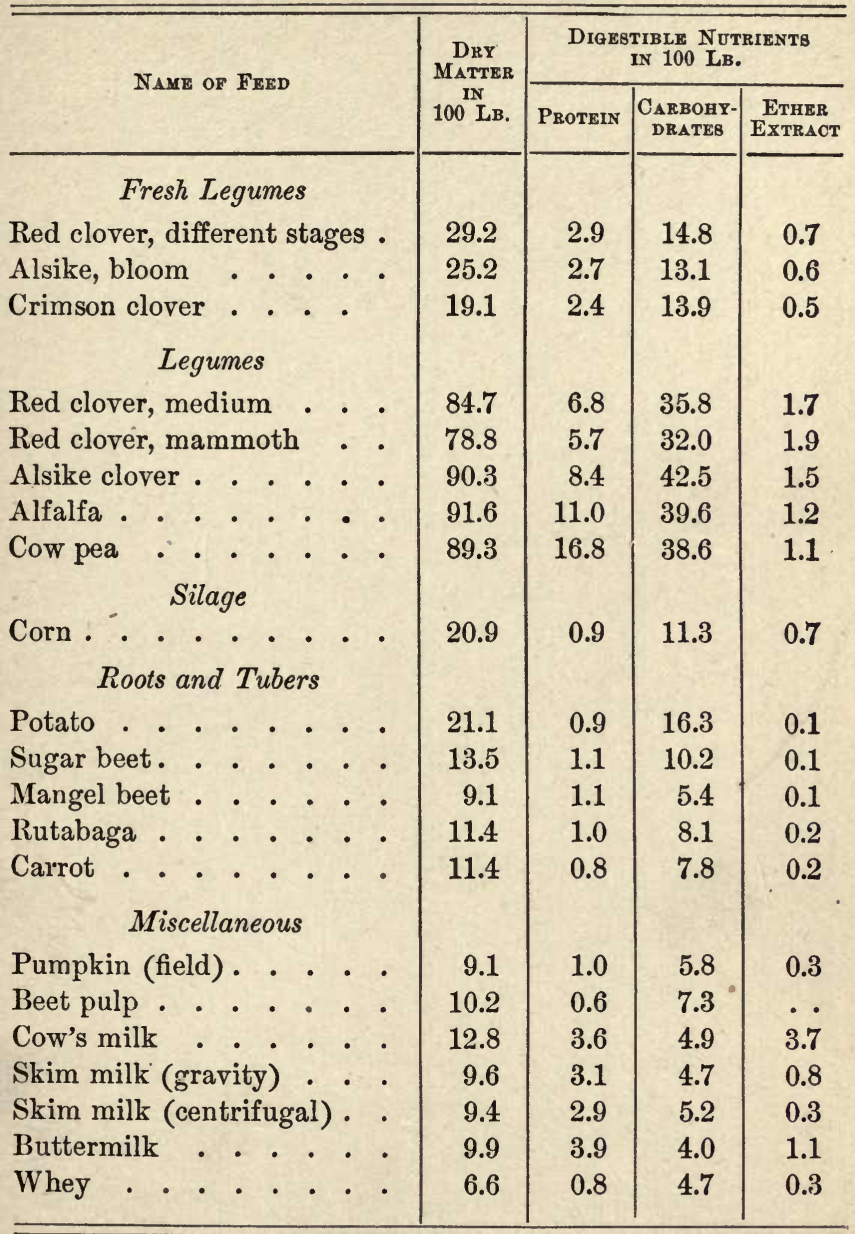




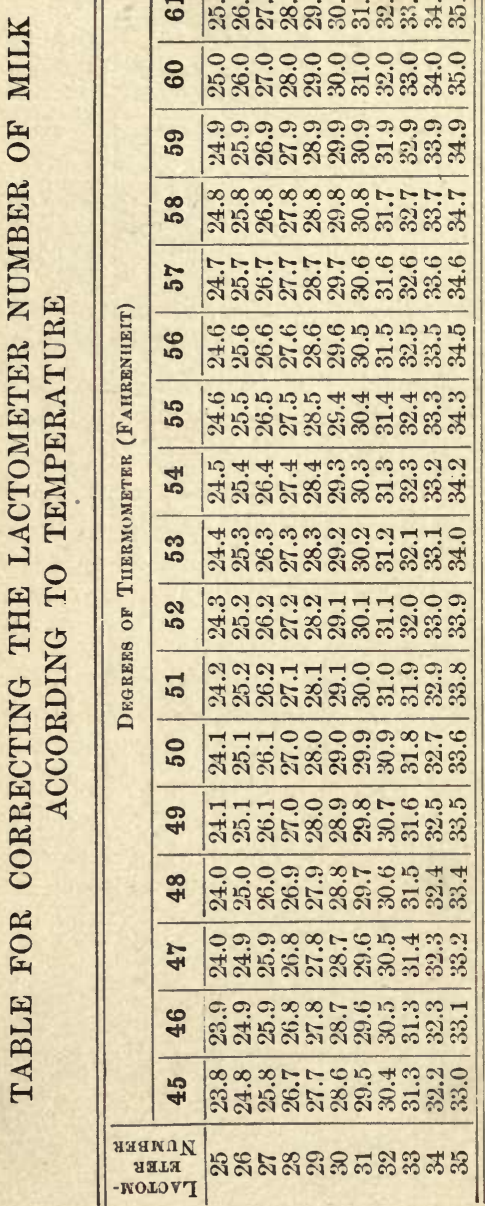

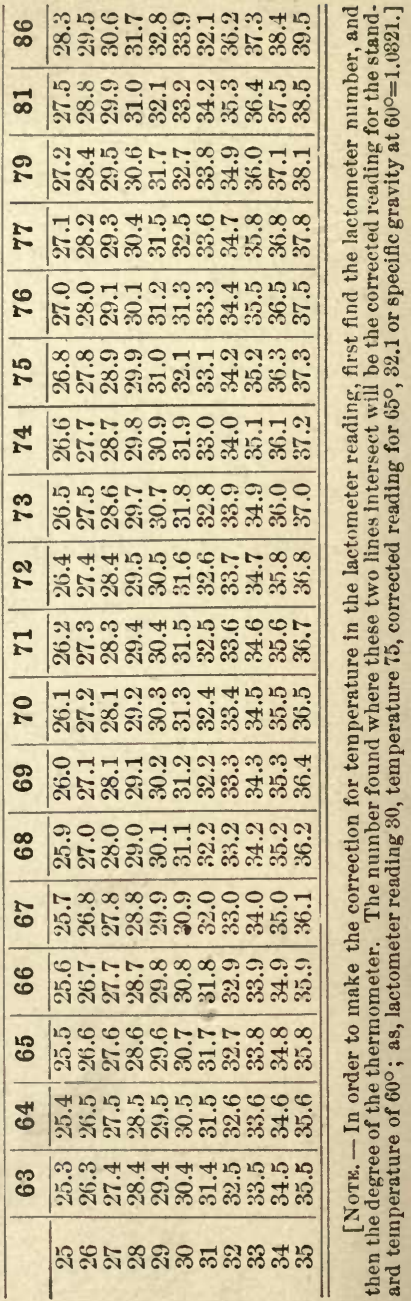




\section{REVIEW QUESTIONS}

\section{CHAPTER I}

1. What are the milk solids, and how are they obtained? 2. Of what compounds are the milk solids composed? 3. Give the approximate percentage amounts in which these compounds are present. 4. What is milk serum? 5. To what extent does the solid matter in milk vary? 6 . How much water does average milk contain? 7. What are the fat globules of milk? 8. Why are they globular in form? 9. To what extent do the globules in milk vary in size and number? 10. Are the fat globules surrounded by a membrane? 11. What breeds produce milk containing the largest fat globules? 12. What is casein? 13. In what dairy operations does it take the most important part? 14. What is albumin, and how can it be obtained from milk? 15. What is milk sugar? 16. How does it resemble and how does it differ from ordinary sugar? 17. What is the ash of milk? 18. Of what is it composed? 19. How is the ash of milk obtained? 20. To what extent do different milks vary in composition? 21. What is the most variable ingredient in milk? 22. Why should the quantity of milk be considered jointly with its percentage composition? 23. How can the total yield of fat and other compounds of milk be determined? 24. How does the first or fore milk differ from the strippings? 25. What are the solids not fat? 26. To what extent do they vary in different milks?

\section{CHAPTER II}

27. What is the object of testing milks? 28. What method is most generally used in milk testing? 29. What can you say of the reliability of this method? 30. How should a sample of milk be taken from a can or pail? 31. What treatment should milk in the sample bottle receive before measuring with the pipette? 32. Why is careful sampling of the milk neces- 
sary? 33. What is the pipette? 34. How is milk measured with the pipette? 35. How much milk does the pipette deliver? 36. What is the test bottle? 37. How is the scale made to read? 38. How would you measure acid and pour it into the test bottle? 39. After adding the acid, what is the next step in the test? 41. How is the fat read? 40. How is the test completed? taken in reading the fat? 43. What causes some tests to show particles of casein below the fat in the test bottle? 44 . Why are some tests black or charred? 45. How would you determine whether a test bottle is correctly graduated or not? 46. Why is it necessary to have accurately graduated test bottles? 47. What causes the separation of the fat in the test? 48. In the handling of the acid what precautions are to be observed? 49. How can the machine be speeded? 50. Why should the number of revolutions per minute vary with the diameter of the machine? $/ 51$. What is a composite sample? 52. What material is used for its preservation? 53. How long should the composite sample be kept? 54. What is a convenient way for handling and measuring the preservative? 55. What kind of bottles should be used for the composite sample? 56. How is skim milk tested? 57. How is the fat content in skim milk read? 58. What effect does partial freezing have upon the composition of milk? 59. How should the glassware used in making the test be cleaned? 60. What kind of water should be used in making the test? 61. Why are some waters objectionable? 62. What are some of the necessary precautions to take in milk testing?

\section{CHAPTER III}

63. Of what are the fat globules of milk composed? 64 . What are the three elements of which fats are composed? 65. Name the different fats of which butter is composed. 66. To what extent are these fats present? 67. Name the three classes into which these fats may be divided. 68. Give 
the characteristics of the principal fats of butter. 69. Why does butter differ in composition from all other fats? 70 . What is meant by the glycerine and fatty acid content of fats? 71. What is meant by saponification of fats? 72. What are the volatile fatty acids of butter? 73. Why do butters produced from different creams vary in hardness and other physical properties?

\section{CHAPTER IV}

74. What is the lactometer and for what is it used? 75 . What are the lactometer degrees? 76. How is the specific gravity of milk determined? 77. Why does milk have a higher specific gravity than water? 78. What influence does the removal of the fat have upon the specific gravity of milk? 79. What influence does the addition of water have upon the specific gravity of milk? 80. To what extent do changes of temperature influence the lactometer readings? 81. How is skimming or watering of milk detected? 82 . How can the Babcock test and the lactometer be used jointly in milk testing? 83. How are the milk solids calculated from the fat content and the specific gravity? 84. How would you determine the extent to which milks have been either watered or skimmed?

\section{CHAPTER V}

85. Give the physical properties of milk sugar. 86. What changes does milk sugar undergo when milk sours? 87. What is produced? 88. Name the conditions necessary for fermentation of milk. 89. What causes the fermentation to take place? 90. To what extent may lactic acid form in milk? 91. What causes milk to sour and curdle? 92. How can the amount of lactic acid in milk be determined? 93. Describe the test employed for obtaining the acidity of milk. 94. How is the amount of acid in the milk calculated? 95. Of what value is this test in butter making? 96. What per cent of acidity should well-ripened cream show? 


\section{CHAPTER VI}

97. What is cream? 98. To what extent does it vary in fat content? 99. Give the three ways in which milks are creamed. 100. How is cream tested? 101. Why is it more accurate to weigh instead of measure the cream used in testing? 102. What is creaming by gravity? 103. To what extent do losses of butter fat occur in gravity creaming? 104. How is milk creamed by the cold deep-setting process? 105. What are the essential conditions for efficient creaming by this process? 106. To what extent do losses of fat occur when milks are creamed by the separator? 107. How can the composition of separator cream be regulated? 108. What should be the temperature of milk when separated? 109. Why should different milks be separated at different temperatures? 110. In what ways is cream adulterated? 111. Explain the ripening process of cream. 112. What is the object of the ripening of cream? 113. Explain the workings of the culture or starter. 114. What influence does delay have in the gravity creaming of milk? 115. Is there any advantage in gravity creaming of mixed milk? 116. What is cream raising by dilution? 117. Is it a desirable process? 118. Why?

\section{CHAPTER VII}

119. What is churning? 120. What changes take place in the form of the fat globules during churning? 121. What are the conditions necessary for exhaustive churning? 122. Does the ripeness of the cream affect churning? 123. Does the fat content of cream affect churning? 124. Why should unripened mixed creams first be ripened before churning? 125. Why should the temperature of churning vary with different creams? 126. How would you determine the best temperature for churning? 127. What are some of the factors influencing the churmability of cream? 128. At what stage should churning be stopped? 129. To what extent should the butter be washed 
and worked? 130. How can the water content of butter be influenced by working? 131. What are the characteristics of a good dairy salt? 132. What is buttermilk, and how does it compare in composition with skim milk? 133. What becomes of the casein in butter making? 134. Of the milk sugar? 135. Of the albumin? 136. To what extent do butters vary in water content? 137. How much fat does average butter contain? 138. How much casein? 139. Of what are butter colors composed? 140. Why does one hundred pounds of fat make more than one hundred pounds of butter? 141. How is the butter yield estimated from the fat content of milk? 142. How would you make out a dividend in a creamery on the basis of the weight of the milks and their fat content?

\section{CHAPTER VIII}

143. Define sanitary condition of milk. 144. Name the factors which influence the sanitary condition of milk. 145. Why is milk from diseased animals unsanitary? 146. To what extent do diseases affect the composition of the milk? 147. How does the care of the animals influence the sanitary condition of the milk? 148. Why should the utmost cleanliness be practiced in the handling of milk? 149. What are the most frequent causes of contaninated milk? 150. Why should milk not be left in stables? 151. What causes the difference in the bacterial content of milk? 152. Why should stables be well ventilated? 153. How do unclean dairy utensils foul milk? 154. How should pails and cans be washed? 155. What effect does the storing of milk in unclean milk rooms have upon its wholesomeness? 156. In what ways does the water supply influence the quality of the milk? 157. What is colostrum milk, and how does it differ in composition from other milk? 158. What is tyrotoxicon? 159. How is it produced in milk? 160. What is fibrin? 161. What gases are present in milk? 162. To what is the color of milk due? 163. How would you pick out milks of the highest sanitary value? 
164. How may milks be the cause of the spread of contagious diseases?

\section{CHAPTER IX}

165. What milk solids are recovered in cheese making? 166. What are the proteids of milk? 167. How do the proteids differ in composition from the fats? 168. In what condition is the casein in milk? 169. What causes coagulation of the casein? 170. Is milk albumin recovered in ordinary cheese making? 171. What is rennet? 172. How is it obtained? 173. For what is it used? 174. What action does it have upon milk? 175. What is the rennet test and how is it made? 176. What is the object of this test? 177. Describe briefly the process of cheddar cheese making. 178. Why is it called the cheddar process? 179. How does it differ from the stirred curd process? 180. To what is the curing of cheese due? 181. What are the enzymes ? 182. What part do they take in cheese ripening? 183. What is the cold curing process? 184. What is gained by this process of curing cheese? 185. What relationship exists between the fat content and the cheese yield of milk? 186. How can the fat content of cheese be determined? 187. How much fat should cheese contain? 188. How much casein? 189. How are dividends made out in a cheese factory on the basis of the fat content? 190. Is this an equitable basis for making out dividends? 191. How may the approximate cheese and butter yield of milks be determined? 192. What are some of the kinds of cheese occasionally manufactured? 193. How is a long-keeping export cheese made? 194. How is a quick-ripening or home-market cheese made? 195. What is the hot-iron test, and how is it used in cheese making? 196. How do the losses of fat in cheese making compare with the losses in butter making? 197. Can rich milks be made into cheese economically? 198. How does the fat content of milk affect the quality of cheese? 199. When milk curdles, what becomes of part of the lactic acid that is formed? 


\section{CHAPTER $\mathrm{X}$}

200. What are the by-products of milk? 201. What are the principal compounds in skim milk? 202. To what does skim milk owe its feeding value? 203. How does skim milk compare in feeding value with corn and other grains? 204. What is the best proportion to feed skim milk with grain? 205. Why should separator slime be kept out of skim milk? 206. What is the difference between separator skim milk and skim milk obtained by the gravity process? 207. How does whey differ in composition from skim milk? 208. How does whey compare in feeding value with skim milk and grains? 209. What fertilizer value do the milk byproducts possess? 210. Why is there but little loss of fertility from the farm in dairying? 211. Why should skim milk, buttermilk, and whey be handled in the most cleanly way?

\section{CHAPTER XI}

212. What is oleomargarine? 213. Butterine? 214. How are these materials made? 215. To what extent do they resemble butter? 216. How do they differ from butter? 217. What simple methods can be employed for detecting oleomargarine? 218. What is renovated butter and how is it made? 219. How does it differ from other butter? 220. In what ways may cheese be adulterated? 221. In addition to skimming and watering in what other ways may milks be adulterated? 222. Why do medical authorities object to the use of preservatives in milk? 223. What other methods are sometimes used in testing milks? 224. Which of these methods are unreliable? 225. Why are dairy laws enacted? 226. What is gained by inspection of dairy products?

\section{CHAPTER XII}

227. Why are market milks so variable in character? 228. To what extent does milk or cream vary in composition 
during transportation? 229. What is Pasteurized milk? 230. How is milk Pasteurized? 231. What is sterilized milk, and how does it differ from Pasteurized milk? 232. Could cream used for butter-making purposes be Pasteurized to advantage? 233. How could milk be Pasteurized on a small scale for home use? 234. What is condensed milk?

\section{CHAPTER XIII}

235. What relationship exists between milk secretion and food supply? 236. To what extent can the per cent of fat in milk be increased by the food? 237. What is the result of the tests where fats were fed in large amounts to dairy cows? 238. How does feed affect the total yield of milk? 239. Is the fat in milk formed from other nutrients than the fat in the food? 240. What effect on the quality of butter does cottonseed meal have when fed to cows in large amounts? 241. What influence does corn alone and in large amounts have upon the quality of the butter? 242. When corn or cotton-seed meal are combined with other grains, what is the effect on the quality of the butter? 243. When cows are fed large amounts of linseed meal, what quality of butter is produced? 244. What effect does gluten meal have upon the quality of the butter? 245. When oats are fed, what kind of butter is produced? 246. What effect do the wheat by-products have upon the butter? 247. To what extent do farm grains differ in milkproducing power in mixed rations? 248. What coarse fodders produce the best quality of milk? 249. What effect do overripe and fibrous fodders have upon the quality of the milk and butter? 250. Does silage exert a favorable influence upon the character of the butter? 251. To what is silage odor in milk largely due? 252. How do turnips, rape, and onions affect the flavor of milk? 253. To what are the desirable flavors in milk due? 254. What causes the undesirable flavors? 255. Why does a balanced ration produce dairy products of the best quality? 256. Under what conditions 
are abnormal milks and dairy products produced? 257. Are there any foods that exert a marked ability to cause an increase in milk secretion? 258. How do so-called stock foods affect milk yield? 259. Under what conditions of feeding are the best returns in milk yield and quality of product secured? 260. Why is liberal feeding necessary to produce prolonged milk secretion? 261. To what extent do individual animals differ in their ability to utilize foods for milk production? 262. What factors influence milk secretion? 263. To what extent can the secretion of milk be influenced?

\section{CHAPTER XIV}

264. What uses are made of the food by the body? 265. Do all the nutrients of the food serve the same purpose? 266. What is a nutrient? 267. Into what two classes of nutrients are the compounds of foods divided? 268. What is the difference in composition between these two classes of nutrients? 269. Which class of nutrients is found in smaller amounts in food stuffs? 270. Which class is the more expensive? 271. Give an example of each class. 272. What is the crude protein? 273. What are the carbohydrates? 274. What is dry matter? 275. How is it obtained? 276. To what extent does the water content of foods vary? 277. Define ash or mineral matter. 278. To what extent is ash present in grains? 279. What compounds are present in plant ash? 280. What is organic matter, and how is it obtained? 281. What functions do the proteids of food serve? 282. Why should foods contain a fairly. liberal supply of proteids? 283. What is the result when the food contains too scant an amount of proteids? 284. Why are abnormal amounts of proteids in foods objectionable? 285. What is the object of the rational feeding of animals? 286. What functions do the carbohydrates of foods serve? 287. Do carbohydrates found in different food materials have the same general composition? 288. What are some of the carbohydrates found 
in food stuffs? 289. What is crude fiber, and how is it obtained? 290. To which of the two large classes of compounds found in food stuffs does crude fiber belong? 291. What is crude fat, and why is it sometimes called ether extract? 292. How does fat as a nutrient compare with starch in heat-producing power? 293. What are digestible nutrients? 294. How are they obtained? 295. What is the caloric value of a ration? 296. What is the nutritive ratio? 297. What is a wide ration? 298. What is a narrow ration? 299. On what basis should the foods for the dairy be selected? 300. How do farm grains compare in milkproducing power with average mill products other than oilseed products? 301. Name the coarse fodders most suitable for dairy feeding. 302. How should the amount of grain which an animal receives be regulated? 303. How much coarse fodder should a cow receive? 304. How much grain should a cow yielding twenty-eight pounds of milk receive? 305. Give the amount of nutrients which should be present in the ration of a dairy cow. 306. How is a ration for a dairy animal calculated? 307. How would you determine whether a ration conformed sufficiently to a standard ration? 308. How would you determine when it is desirable to use one grain in a ration in large amounts in preference to another? 309. How would you calculate the amount of digestible nutrients which can be purchased for $\$ 1.00$ when grains are at different prices? 310. In selecting grains, to what nutrient should the preference be given? 311. In case there is only a small difference in the amount of this nutrient which can be purchased for $\$ 1.00$, then what nutrient should be taken as the basis? 312. Why is it possible for two farmers to feed the same kinds of grains and coarse fodders and yet secure entirely different returns in milk yields? 313. In order to secure the best returns in milk yields from the food consumed, why should the animals be cared for under the most sanitary conditions? 314. Why should grains be weighed when fed? 315. To what extent do grains and mill products vary in bulk and weight? 


\section{REFERENCES}

THE references given in the following pages are not intended to represent a complete bibliography of the subject. The student is advised to consult some of the bulletins and articles referred to so as to obtain more information upon many of the topics that are only briefly discussed in this work. It has not been possible to give the references and authorities for each statement that has been made in this book, or in those cases where different and conflicting views are held, to enter into discussion of questions. The literature of dairying is very extensive, and there are a number of works that treat of special topics, as: Testing Milk and its Products, by Woll and Farrington; Dairy Chemistry, by Richmond; Dairy Bacteriology; by Russell; Milk and its Prodúcts, by Wing; Feeds and Feeding, by Henry ; and Feeding of Farm Animals, by Jordan. These should be frequently consulted in studying the subject. The student should early acquire the habit of consulting different works, as many topics are presented more clearly in one than in another.

\section{REFERENCES TO CHAPTER I}

1. The Composition of Milk. König: Chemie der Menschlichen Nahrungs- und Genussmittal.

2. The Composition of Cow's Milk. Blyth: Food Analysis.

3. The Physical Composition of Milk. Duclaux: Le Lait, Études Chemiques et Microbiologiques.

4. The Composition of Milk. Wisconsin Experiment Station, Bulletin No. 19.

5. The Constitution of Milk. Wisconsin Experiment Station, Bulletin No. 18.

6. The Composition of Milk and its Products. Richmond: Analyst, August, 1894.

7. The Composition of Milk as affected by Change of Milkers 
and Change of Quarters. Wisconsin Experiment Station Report, 1889.

8. Variations in the Fat Content of Milk. Weilandt: Milch Zeitung, 24 (1895).

9. The Average Composition of Milk. Vieth: Analyst, 18, $192,193$.

10. Historical Article regarding Milk. Blyth : Food Analysis.

11. The Composition of Milk from Different Breeds. Michigan Experiment Station, Bulletin No. 68.

12. The Composition of Milk from Different Breeds. New York State Station Report, 1891.

13. The Composition of Milk. Maine Experiment Station Reports, 1890, 1893.

14. Variations in Milk during the Period of Lactation. Vermont Experiment Station, Sixth Annual Report.

15. Composition of Milk. Wisconsin Experiment Station Report, 1889 ; also Bulletins Nos. 15 and 16; also Fifth Annual Report.

16. Composition of Milk. New Jersey Experiment Station, Bulletins Nos. 61, 65, 68, 77.

17. Composition of Milk. Massachusetts State Station Reports, 1888, 1889, 1890, 1891, 1892.

18. The Number and Size of Fat Globules in Milk. Wisconsin Experiment Station Report, 1890.

19. The Fat Globules of Milk. Maine Experiment Station, Annual Report, 1890.

20. Conditions influencing the Number and Size of the Fat Globules. Milch Zeitung, 24 (1895).

21. On the Variation in the Number and Size of Fat Globules. Pennsylvania Experiment Station Report, 1895.

22. The Size of Fat Globules in Milk. Vermont Experiment Station, Fourth Annual Report.

23. Size of Fat Globules in the First and Last Half of Milking. Indiana Experiment Station, Bulletin No. 24.

24. The Size of Fat Globules in Milk of Cows of Different Breeds. New York State Experiment Station Reports, 1891, 1592. 
25. Composition of First Milk and Strippings. Connecticut State Experiment Station Report, 1886.

26. Fore Milk and Strippings. Blyth : Food Analysis.

27. Relation of Fat and Casein in Milk. Vermont Experiment Station, Fourth Annual Report.

28. Liquid Condition of the Fat. Soxhlet: Landwirtschaftlischen Versuchs-Stationen, 1876.

29. No Membrane about Milk Fat Globules. Martiny: Die Milch.

30. Artificial Emulsions representing Milk. Duclaux: Annales de l'Institut Nat. agronomique, 1882.

31. The Membrane of the Milk Fat Globule. Jurstenburg : Die Milch drusen die Kuh.

32. The Membrane of the Fat Globule. Bechamp: Comptes Rendus, 1888.

33. Composition of the Ash of Milk. Maine Experiment Station Report, 1890.

34. Milk Ash Analysis. New Hampshire Experiment Station Report, 1888.

35. Average Composition of Milk Ash. König: Chemische der menschlichen Nahrungs- und Genussmittel. Band II.

36. The Phosphates of Milk. Duclaux: Annals Pasteur Institute, 1893.

37. Calcium Phosphate and the Casein. Söldner : Die Landwirtschaftlichen Versuchs-Stationen, 1888, 35.

38. Yield of Front and Rear Udder of Cow. Wis. Rept., 1898.

39. The Milk Yield of Quarters on Same Side of Udder.

40. The Composition of Frozen Milk. Wisconsin Station, Twentieth Annual Report.

41. The Fat Globules of Cows' Milk. Wisconsin Station, Twentieth Annual Report.

42. On the Average Composition of Milk of Pure-bred Cows of Different Breeds. Wisconsin Station, Twentieth Annual Report. 43. On the Average Composition of Milk of Pure-bred Cows of Different Breeds. Wisconsin Station, Eighteenth Annual Report. 
44. Variations in Milk and Milk Production. Illinois Experiment Station, Bulletin No. 51.

\section{REFERENCES TO CHAPTER II}

1. The Babcock Test. A New Method for the Estimation of Fat in Milk, especially adapted to Creameries and Cheese Factories. Wisconsin Experiment Station, Bulletin No. 24; also Annual Report, 1890.

2. Babcock Test. Notes on its Use and the Lactometer. Wisconsin Experiment Station, Bulletin No. 31.

3. Application of Dr. Babcock's Centrifugal Method to the Analysis of Milk, Skim-milk, etc. Cornell University Experiment Station, Bulletin No. 29.

4. New Points in Manipulation of the Babcock Test. Illinois Experiment Station, Bulletin No. 27.

5. The Babcock Test. Association of Official Agricultural Chemists' Report, 1890.

6. The Babcock Method of finding the Amount of Butter-fat in Milk. Connecticut State Experiment Station, Bulletin No. 106 ; also Reports, 1891, 1894.

7. Directions for using the Babcock Milk Test. Pennsylvania Experiment Station, Bulletin No. 33, Report, 1895.

8. The Babcock Method of Milk Analysis. F. T. Shutt: Analyst, 17, 200; Chemical News, 64, 4.

9. Accuracy of the Babcock Milk Test. Cornell University Experiment Station, Bulletin No. 25.

10. Accuracy of the Babcock Milk Test. Illinois Experiment Station, Bulletin No. 14.

11. Comparative Trials of the Babcock Milk Test. Heinrich: Molkerei Zeitung, 1893, No. 4.

12. The Babcock Test. Wiley: Agricultural Analysis, Vol.III.

13. Marking Test-bottles. Illinois Agricultural Experiment Station, Bulletin No. 18.

14. Milk Sampling. Delaware Experiment Station, Bulletin No. 31 . 
15. The Testing of Milk. North Carolina Experiment Station, Bulletin No. 113.

16. Composite Milk Samples. Patrick: Journal of Analytical and Applied Chemistry, 5, 8.

17. The Composite Test. Wisconsin Experiment Station, Bulletin No. 36.

18. Composite Sampling of Milk. Iowa Experiment Station, Bulletins Nos. 9, 14, and 22.

19. Composite Method of Milk Sampling. Illinois Experiment Station, Bulletins Nos. 16 and 18.

20. Method of Sampling Milk for Analysis. Pennsylvania Experiment Station, Annual Report, 1892.

21. Preservatives for Milk Samples. Iowa Experiment Station, Bulletin No. 11.

22. Milk Sampler. Wiley: Agricultural Analysis, Vol. III.

23. The Trowbridge Method of Calibrating Babcock Testbottles. Wisconsin Experiment Station, Eighteenth Annual Report.

24. Methods and Apparatus for testing Milk and Milk Products. Wisconsin Experiment Station, Twentieth Annual Report.

25. Examination of Babcock Apparatus. Connecticut Experiment Station, Report 1901, Part IV.

26. Testing Dairy Products by the Babcock Test. Maine Experiment Station, Report of 1897.

27. The Babcock Test. New Hampshire Experiment Station, Bulletin No. 114.

28. Inspection of Babcock Milk Test-bottles. New York Experiment Station, Bulletin No. 178.

\section{REFERENCES TO CHAPTER IV}

1. Table for Corrections of the Temperature in Lactometry (Centigrade Scale). König: Untersuchungen in landwirtschaftlich und gewerblich Wichtiger Stoffe. 
2. A Simple Formula for calculating the Solids not Fat. Babcock: Wisconsin Experiment Station, Bulletin No. 34.

3. The Adulteration of Milk. Blyth: Foods; Composition and Analysis.

4. Comparison of Results by the Use of the Formulas of Hehner and Richmond, Fleischmann, and Babcock, with the Gravimetric Method. Report of the Eighteenth Annual Convention of the Association of Official Agricultural Chemists, 1894.

5. Effect upon the Specific Gravity of Milk by allowing the Milk to stand after Milking. Richmond: Report of Eighteenth Annual Convention of Association of Official Agricultural Chemists, 1894.

6. Lactodensimeter. Quevenne-Müller: Grandeau, Analyse des Matéries Agricoles.

7. The Adulteration of Milk. Various articles in the current numbers of the Analyst.

8. Legal Cases relating to the Adulteration of Milk. Various and numerous articles in the current numbers of the Milch Zeitung.

\section{REFERENCES TO CHAPTER V}

1. Influence of Sugar on the Nature of the Fermentation occurring in Milk and Cheese. Wisconsin Experiment Station, Eighteenth Annual Report.

2. Galactase, the Inherent Digestive Enzyme of Milk. Wisconsin Experiment Station, Twentieth Annual Report.

3. Milk Fermentations. United States Department of Agriculture, Farmers' Bulletins Nos. 9 and 29, also current numbers.

4. Dairy Bacteriology. United States Department of Agriculture, Office of Experiment Stations, Bulletin No. 25.

5. The Number of Bacteria in Milk. (Storrs) Connecticut Experiment Station, Seventh Annual Report.

6. Bacteria in their Relation to the Dairy. Lugger: Minnesota Experiment Station, Annual Report, 1893.

7. Ripening of Cream and Milk Fermentations. Article in Handbook of Experiment Station Work. 
8. The Action of Different Classes of Bacteria on Milk. Adametz: Monatsschrifte für Thierheilkunde, 1890.

9. Bacteria in the Dairy. Conn: (Storrs) Connecticut Experiment Station, Third, Fourth, Fifth, Sixth, Seventh, and Eighth Annual Reports.

10. Milk Sugar. Remsen: Organic Chemistry.

11. An Acid Test of Cream. Illinois Experiment Station, Bulletin No. 32.

12. The Alkaline Tablet Test of Acidity in Milk or Cream. Wisconsin Experiment Station, Bulletin No. 52.

13. Lactic Acid Ferments. Pasteur: Studies on Fermentation.

14. Outlines of Dairy Bacteriology. Russell.

15. Le Lait, Études Chemiques et Microbiologiques. Duclaux.

16. Determining the Acid in Milk. Hopkins and Powers : Report of the Association of Official Agricultural Chemists, 1895.

\section{REFERENCES TO CHAPTER VI}

1. Ripening Cream with Pure Cultures. Conn: (Storrs) Connecticut Experiment Station, Fifth, Sixth, and Seventh Annual Reports.

2. Ripening of Cream with Artificial Cultures. Adametz: Landwirtschaftlichen Versuchs-Stationen, 1892.

3. Artificial Butter Cultures. Storch: Milch Zeitung, 1890.

4. Artificial Butter Cultures. Weigmann: Milch Zeitung, 1890.

5. Experiments with Cream : Ripening, Flavor, Aroma, Acid. Conn: (Storrs) Connecticut Experiment Station, Bulletin No. 16.

6. Experiments in the Ripening of Cream by Means of Pure Cultures. F. Fries and H. P. Lunde: reported in Experiment Station Record, 7, No. 3.

7. Abnormal Ripening of Cream due to Faulty Character of Milk. L. Adametz: Milch Zeitung, 1893, No. 18. 
8. Cream Ripening with Pure Cultures. Milch Zeitung. Experiment Station Record, 7, No. 1.

9. The Composition of Cream. Massachusetts Experiment Station Reports, 1889, 1890, 1892, 1893.

10. On the Raising of Cream on the Milk Route. Bergmann : Milch Zeitung, 1893.

11. Effects of Transportation upon the Fat Content of Milk. Klein: Chemisches Centralblatt, 89, 397.

12. Variations in Fat Content in Milk served from Cans to Customers. Legal Case. Analyst, 17, 189.

13. Variations in Fat of Milk served to Customers in Dipping from Cans. Cornell University Experiment Station, Bulletin No. 20.

14. Variations in the Fat of Milk served to Customers from Milk Cans. Ontario Agricultural College, Bulletin No. 16.

15. Effects of Delay in Creaming Milk. Maine Experiment Station Report, 1890.

16. Effects of Delayed Setting. Wisconsin Experiment Station, Bulletin No. 29.

17. Delay in Setting. See Creaming Article in Handbook of Experiment Station Work.

18. Effects of Delay in Creaming Milk. Cornell University Experiment Station, Bulletin No. 29.

19. Cream Raising by Dilution. Cornell University Experiment Station, Bulletins Nos. 20 and 29.

20. Cream Raising by Dilution. Illinois Experiment Station, Bulletins Nos. 12 and 18.

21. Cream Raising by Dilution. Vermont Experiment Station, Fourth and Fifth Annual Reports.

22. Cream Raising by Dilution. Indiana Experiment Station, Bulletin No. 44.

23. Cream Raising by Dilution. Article, Creaming of Milk, in Handbook of Experiment Station Work.

24. Testing Cream and Milk. Maine Experiment Station, Bulletin No. 4. 
25. Testing Cream by the Babcock Test. Connecticut Experiment Station (New Haven), Eighteenth Annual Report.

26. The Babcock Test as a Basis for Payment in Creamgathering Creameries. Connecticut Experiment Station (New Haven), Bulletin No. 119.

27. The Composition of Cream. König: Chemie der Menschlichen und Genussmittel, Band II.

28. Test of Cream Separators. Cornell University Experiment Station, Bulletins Nos. 66 and 105.

29. Test of Cream Separators. Pennsylvania Experiment Station, Bulletins Nos. 20 and 21, Annual Report, 1895.

30. Report on Separators, Gravity, Creaming, etc. Iowa Experiment Station, Bulletin No. 25.

31. Tests of Dairy Implements. North Carolina Experiment Station, Bulletin No. 114.

32. Hand Power Cream Separators. Delaware Experiment Station, Bulletin No. 27, Fifth Annual Report.

33. Cream Raising by the Cold Deep-setting Process. Minnesota Experiment Station, Bulletin No. 19.

34. Creaming of Milk. Article in Handbook of Experiment Station Work.

35. Creaming Experiments. Babcock: Wisconsin Experiment Station, Bulletin No. 29.

36. The Ripening of Cream. Conn: (Storrs) Connecticut Experiment Station, Report, 1900.

37. Commercial Butter Cultures. Pennsylvania Experiment Station, Bulletin No. 44.

38. Variations in Cream and Milk Tests. South Dakota Experiment Station, Bulletin No. 73.

39. Cream Testing. Iowa Experiment Station, Bulletin No. 52.

40. A Modified Cream Test Bottle. Wisconsin Experiment Station, Nineteenth Annual Report.

REFERENCES TO CHAPTER VII

1. Loss of Fat in Butter-making. Iowa Experiment Station, Bulletin No. 11. 
2. Loss of Fat in Butter-making, with increase in Lactation Period. New York State Experiment Station Report, 1891.

3. Butter Production from Milk at Different Periods of Lactation. Maine Experiment Station Report, 1889.

4. Loss of Fat in Butter-making. Article on Butter-making in Handbook of Experiment Station Work.

5. Composition of the Slime from the Centrifugal Bowl. Fleischmann: Lehrbuch der Milchwirtschaft.

6. Butter-making. Fleischmann: Lehrbuch der Milchwirtschaft.

7. Churning and Butter-making. Gurler: American Dairying.

8. Churning. Article in Handbook of Experiment Station Work.

9. Churning Experiments. Iowa Experiment Station, Bulletin No. 22.

10. On the Churning Process and the Formation of Butter. A. Jscher Kasserd: Milch Zeitung, No. 23, 1894.

11. The Churning Temperature of Sweet and Sour Cream. New York State Experiment Station Report, 1889.

12. Tests of Box and Barrel Churns. Vermont Experiment Station, Bulletin No. 27.

13. The Acidity of the Cream and the Yield of Butter. Illinois Experiment Station, Bulletin No. 9.

14. Churning the Cream from Cows at Different Periods in Lactation. Haecker: Hoard's Dairyman, 1894.

15. Butter-making. Powrian : La laitière: Art de traiter le lait, de fabrique le beurre et les principaux fromages.

16. The Composition of Butter. Minnesota Experiment Station, Bulletin No. 19.

17. Composition of Butter. Wisconsin Experiment Station, Annual Report, 1889.

18. Composition of Butter. Massachusetts State Station, Annual Report, 1889.

19. Composition of Butter. Pennsylvania Experiment Station, Annual Report, 1893. 
20. The Composition of Butter. Connecticut State Station, Annual Report, 1892.

21. Composition of Sweet Cream Butter. West Virginia Experiment Station, Annual Report, 1890.

22. Composition of Sweet and Sour Cream Butter. Iowa Experiment Station, Bulletin No. 18.

23. The Composition of Butter from Different Countries. König: See reference No. 6.

24. Abnormal Amounts of Water in Butter-Legal Cases. Current numbers of the Analyst.

25. The Yellow Coloring Matter of Milk. Blyth: Foods, their Composition and Analysis.

26. The Proteids of Butter in Relation to Mottled Butter. New York Experiment Station (Geneva), Bulletin No. 263.

27. Heated Milk for Butter-making. Pennsylvania Experiment Station, Bulletin No. 45.

28. Paying for Separator Cream at the Creamery. Vermont Experiment Station, Bulletin No. 100.

29. Salt in Butter. Iowa Experiment Station, Bulletin No. 80 .

30. Moisture Content of Butter and Methods of controlling it. Iowa Experiment Station, Bulletin No. 76.

31. Keeping Qualities of Butter. Iowa Experiment Station, Bulletin No. 71.

32. Influence of Certain Conditions in Churning on the Amount of Water in Butter. Iowa Experiment Station, Bulletin No. 52.

33. Effect of Salt and the Size of Butter Granules on the Water Content of Butter. Wisconsin Experiment Station, Twentieth Annual Report.

34. Salt Crystals on the Surface of Butter. Wisconsin Experiment Station, Twentieth Annual Report.

35. Score of Butter, as affected by the Size of Package. Wisconsin Experiment Station, Twentieth Annual Report.

36. Composition of Dairy Salt. Wisconsin Experiment Station, Twentieth Annual Report. 
37. Calculating Dividends for Milk and for Cream at the Same Factory. Wisconsin Experiment Station, Seventeenth Annual Report.

\section{REFERENCES TO CHAPTER VIII}

1. The Behavior of Anthrax Bacilli in Milk. O. Caro: Chemisches Centralblatt, 1894, 1, 164.

2. Behavior of Cholera Germs in Milk. Heim: Milch Zeitung, 21, 1892.

3. Vitality of Tuberculosis Bacilli. Forster and Mann: Milch Zeitung, 22, 1894.

4. Tuberculosis and Public Health, etc., Law. New York Experiment Station, Bulletin No. 65.

5. Typhoid Fever disseminated through the Milk Supply. Russell: Science, November 15, 1895.

6. Diseases conveyed by Milk. B. Lee : Agriculture of Pennsylvania, 1894.

7. Milk as a Source of an Epidemic of Typhoid Fever. Schmidt: Milch Zeitung, 23, 1894.

8. Danger from consuming the Milk of Sick Cows. F. Baum: Archiv wissech und praktische Thierheilkunde, 18, Heft 384.

9. On Ptomaines in Milk. V. Malenchini : Zeitschrift Nahrungsmittel Untersuchen und Hygiene.

10. The Care of Milk for Cheese Factories and Creameries. Ontario Agricultural College, Bulletin No. 44.

11. Cleanliness in Handling Milk. North Dakota Experiment Station, Bulletin No. 21.

12. Poisonous Milk and Milk Panics. Wanklyn : Milk Analysis.

13. Milk Inspection affecting Death Rate of Children. Milch Zeitung, 9, 24, and 349.

14. Citric Acid as a Normal Constituent of Cow's Milk. Henkel : Die Landwirtschaftlichen Versuchs-Stationen, 39.

15. Citric Acid in Milk. Abstract. Sixth Annual Convention (1889), Association of Official Agricultural Chemists. 
16. The Composition, Creaming, and Churning of Colostrum. Vermont Experiment Station, Fifth Annual Report.

17. Composition of Colostrum Milk. Kruger: Molkerei Zeitung, 1892.

18. The Chemical Composition of Cow's Colostrum. Blyth : Foods, their Composition and Analysis.

19. Nature of the Colostrum Cells. Heidenhain: Handbuch der Physiologie.

20. Tyrotoxicon. Vaughan: Michigan State Board of Health Report, 1886.

21. The Chemistry of Tyrotoxicon, and its Action on Lower Animals. Vaughan: Analyst, 13, 141.

22. Fibrin in Milk. Proceedings of the Society for the Pro, motion of Agricultural Science, 1888.

23. Fibrin in Milk, and its Effects upon Creaming. Wisconsin Experiment Station, Bulletin No. 18.

24. Gases in Milk. Kirchner: Handbuch der Milchwirtschaft.

25. Gases in Milk. Blyth : Foods, their Composition and Analysis.

26. Gas-producing Organism. Baumann: Molkerei Zeitung, 7, 1893.

27. Blue Milk, Red Milk, Brownish Red Milk, Bitter-milk. Lugger: Minnesota Experiment Station, Annual Report, 1893.

28. Creaming and Aërating Milk. Cornell University Experiment Station, Bulletin No. 39.

29. Aëration of Milk. Vermont Experiment Station, Sixth Annual Report.

30. Aëration of Milk for Butter Production. Indiana Experiment Station, Bulletin No. 44.

31. "Soapy" Milk, and the Sources of Bacteria in Milk. Weigmann and Zirn: Milch Zeitung, 23, 1893.

32. The Care and Handling of Milk. Michigan Experiment Station, Bulletin No. 221.

33. Aëration of Milk. Michigan Experiment Station, Special Bulletin No. 16. 
34. Ropiness in Milk. Michigan Experiment Station, Bulletin No. 140.

35. Economical Methods for improving the Keeping Qualities of Milk. Maryland Experiment Station, Bulletin No. 88 .

36. Classification of Dairy Bacteria. (Storrs) Connecticut Experiment Station Report, 1899.

37. The Comparative Growth of Different Species of Bacteria in Normal Milk. (Storrs) Connecticut Experiment Station Report, 1901.

38. Efficiency of a Covered Pail in excluding Filth and Bacteria from Milk. (Storrs) Connecticut Experiment Station Report, 1901.

39. Dairy Conditions and Suggestions for their Improvement. Illinois Experiment Station, Bulletin No. 84 .

40. Methods of controlling Contamination of Milk during Milking. Nebraska Experiment Station, Bulletin No. 87.

41. Ropiness in Milk and Cream. New York (Cornell) Experiment Station, Bulletins Nos. 165 and 195.

42. Investigations concerning the Germicidal Action in Cow's Milk. New York (Cornell) Experiment Station, Bulletin No. 197.

43. The Care and Handling of Milk. New York (Cornell) Experiment Station, Bulletin No. 203.

44. Stagnant Water Germs in Milk. Oregon Experiment Station, Bulletin No. 71.

45. Investigations of Methods of Milking. Wisconsin Experiment Station, Twentieth Annual Report.

46. Thermal Death Point of Tubercle Bacilli under Commercial Conditions. Wisconsin Experiment Station, Seventeenth Annual Report.

47. Outbreak of Anthrax Fever traceable to Tannery Refuse. Wisconsin Experiment Station, Seventeenth Annual Report.

48. The Effect of Different Stable Temperatures upon the Milk Yield of Dairy Cows. Wisconsin Experiment Station, Twenty-first Annual Report.

49. Infectiousness of Milk from Tubercular Cows. Wisconsin Experiment Station, Twenty-first Annual Report. 
50. Effect of Short Periods of Exposure to Heat on Tubercle Bacilli in Milk. Wisconsin Experiment Station, Twenty-first Annual Report.

\section{REFERENCES TO CHAPTER IX}

1. The Content of Pepton in Milk. Schmidt and Muilheim : Reported in König, Chemie der Menschlichen Nahrungs- und Genussmittel, Band II.

2. The Proteids of Milk. Halliburton: Journal of Physiology, 2, 459.

3. The Chemistry of Casein and the Theory of the Curdling Action of Rennet. G. Courant: Abstract in Experiment Station Record, 5.

4. Three Forms of the Casein in Milk. Struve: Journal für practische Chemie, 1884.

5. The Action of Rennet on Milk. Hammarsten: Popular Form given in Milk, its Nature and Composition by Aikman.

6. The Curdling of Milk by Ferments which render the Milk Alkaline. Warrington: Journal of the Chemical Society (England), 1888.

7. A Study of the Coagulating Power of Commercial Rennets. Patrick: Abstract in Experiment Station Record, 5, 100.

8. The Isolation of Rennet from Bacteria Cultures. Conn : (Storrs) Connecticut Experiment Station, Fifth Annual Report.

9. The Nature of Rennet. Russell: Outlines of Dairy Bacteriology.

10. Beiträge zur Erfarschung der Käserifange. Baumann : Die Landwirtschaftlichen Versuchs-Stationen, 42, et seq.

11. Cheese-making, Directions for. Iowa Experiment Station, Bulletins Nos. 19 and 21.

12. Cheese Factory Notes. Wisconsin Experiment Station, Annual Report, 1892.

13. Cheese-making. Article relating to Recent Work on Dairying. Allen: Experiment Station Record, 5. Nos. 10 and 11.

14. Cheddar Cheese-making. Decker. 
15. A, B, C in Cheese-making. Monrad.

16. Cheese-making in Switzerland. Monrad.

17. The Manufacture and Production of Cheese. Alvord: United States Department of Agriculture, Year Book, 1895.

18. The Manufacture of Some Fancy Brands of Cheese. Luschinger: Report Sixteenth Annual Convention of the Minnesota Dairy Association.

19. The Changes during the Ripening of Cheese. Iowa Experiment Station, Bulletin No. 24.

20. Salt and its Preventing the Swelling of Cheese. Von Freudenreich : Abstract in Experiment Station Record, Vol. V, p. 921.

21. The Forms of the Nitrogen Compounds in Cheese. Stutzer: Reported in Wiley's Agricultural Analysis, Vol. III.

22. Manufacture of Sweet Curd Cheese. Haecker: Minnesota Experiment Station, Bulletin No. 35.

23. Experiments in Cheese-making. Minnesota Experiment Station, Bulletin No. 19.

24. Cheese-making, Distribution of Ingredients, and Losses of Fat. Handbook of Experiment Station Work.

25. Losses in Cheese-making. Vermont Experiment Station, Fifth Annual Report.

26. Experiments in Cheese-making. Ontario Agricultural College Report, 1894.

27. Losses of Milk Solids in Cheese-making, and the Addition of Cream to the Milk. Minnesota Experiment Station, Bulletin No. 19.

28. Determining the Amount of Fat in Cheese by the Babcock Test. Wisconsin Experiment Station, Bulletin No. 36.

29. Composition of Different Kinds of Cheese made in Different Countries. König: Chemie der Menschlichen Nahrungs- und Genussmittel, Band II.

30. The Composition of English Cream Cheese. (Cream added to the Milk.) P. Vieth: Milch Zeitung, 1887, 120.

31. The Composition of Milk, Cheese, and Whey, in Relation to One Another. Ontario Agricultural College Report, 1894. 
32. The Composition of Cheese made from Cream. Hassall: Foods, Adulterations and the Methods for their Detection.

33. The Composition of Cheese. Connecticut State Experiment Station Report, 1892.

34. Ripening of Cheese. Adametz : Berlin. Landwirtschaftlicher Jahrbücher, 1889.

35. The Abnormal Ripening of Cheese. Adametz: Milch Zeitung, Nos. 21 and 22, 1892 and 1893.

36. An Aromatic Bacillus in Cheese. Iowa Experiment Station, Bulletin No. 21.

37. Influence of Cold Curing on the Quality of Cheddar Cheese (Second Paper). Wisconsin Experiment Station, Nineteenth Annual Report.

38. Influence of Temperatures approximating $60^{\circ} \mathrm{F}$. on the Development of Flavor in Cold-cured Cheese. Wisconsin Experiment Station, Nineteenth Annual Report.

39. Investigations relating to the Manufacture, Curing, and Handling of Cheese. See Wisconsin Experiment Station, Seventeenth, Eighteenth, Nineteenth, Twentieth, and Twenty-first Annual Reports.

40. Investigations relating to the Manufacture, Curing, and Handling of Cheese. See New York State Agricultural Experiment Station, Bulletins Nos. $37,43,45,46,56,65,68,110$, $184,203,207,214,215,219,231,233,234,236,237,245$, and 261.

\section{REFERENCES TO CHAPTER $\mathrm{X}$.}

1. The Composition of the Milk of the Mare, Ewe, Goat, Sow, etc. König: Chemie der Menschlichen Nahrungs-und Genussmittel, Band II.

2. Composition of Mule's Milk. Aubert and Colby: Journal of Analytical and Applied Chemistry, 7, No. 6.

3. Analyses of Skim-milks. Wisconsin Experiment Station, Annual Report for 1889.

4. The Composition of Whey. New York State Experiment Station, Bulletins Nos. 37, 43, 45, 46, 47. 
5. The Composition of Buttermilk. Maine Experiment Station, Annual Report for 1890 .

6. The Composition of Skim-milk and Whey. C. B.Cochran : Journal of the American Chemical Society, 15, No. 6.

7. The Feeding Value of Skim-milk. Massachusetts State Experiment Station, Annual Reports for 1884, 1885, 1886, 1887, 1888,1889 , etc.

8. The Effects of Skim-milk in a Ration for Pigs. Maine Experiment Station, Annual Report for 1889.

9. The Feeding Value of Skim-milk. Vermont Experiment Station, Bulletin No. 18.

10. The Effects of Skim-milk in a Ration for Pigs. New Hampshire Experiment Station, Bulletin No. 11.

11. The Comparative Feeding Value of Skim-milk and Buttermilk. Wisconsin Experiment Station, Annual Report for 1886.

12. The Comparative Feeding Value of Buttermilk and Skimmilk. Massachusetts State Experiment Station, Annual Reports for 1884,1885 .

13. The Comparative Value of Sweet and Sour Skim-milk. Vermont Experiment Station, Annual Report for 1891.

14. The Feeding Value of Whey. Wisconsin Experiment Station, Bulletin No. 27.

15. The Average Composition of Skim-milk, Buttermilk, and Whey. König: Chemie der Menschlichen Nahrungs- und Genussmittel, Band II.

16. Influence of Temperature on Skim-milk Tests. Wisconsin Experiment Station, Seventeenth Annual Report.

\section{REFERENCES TO CHAPTER XI}

1. A New Milk Test (Beimling's). Vermont Experiment Station, Bulletin No. 24.

2. Determining the Fat in Milk. Leffmann and Beam: Analyst, 18, 193.

3. Acid Butyrometer. Gerber: Chemiker Zeitung, 16, 839. 
4. The Lactocrite. United States Department of Agriculture, Division of Chemistry, Bulletin No. 13.

5. The Lactocrite. Biedermann's Centralblatt, 17, 627.

6. A New Method for detecting the Fat in Milk. Short: Wisconsin Experiment Station, Bulletin No. 16.

7. The Determining of Fat in Milk by Short's Method. Journal of Analytical Chemistry, 2, Part 4.

8. Cochran's Method for determining the Fat in Milk. Journal of Analytical Chemistry, 3, Part 4.

9. A Description of Cochran's Method for determining the Fat in Milk. Cornell University Experiment Station, Bulletin No. 17.

10. Methods of manufacturing Butter Substitutes; Wholesomeness of Artificial Butter; The Adulteration of Butter, including References and Methods of Analysis. Wiley: United States Department of Agriculture, Division of Chemistry: Foods and Food Adulterants, Part First, Dairy Products.

11. Extent and Character of Food Adulterations. Wedderburn: United States Department of Agriculture, Division of Chemistry, Bulletins Nos. 25 and 32.

12. The Analysis and Adulteration of Foods. Part III. James Bell.

13. The Adulteration of Butter and Cheese. Blyth: Foods. Their Composition and Analysis.

14. Influence of Preservatives upon the Food Value of Milk. Maryland Experiment Station, Bulletin No. 86.

15. State and Municipal Milk Legislation. Delaware Experiment Station, Bulletin No. 43.

16. Butter, its Composition, Artificial Imitation, and Adulterants. North Carolina Experiment Station, Bulletin No.166.

17. Process Butter. A Dairy Fraud. Utah Experiment Station, Bulletin No. 79.

18. Inspection of Milk Tests and Feeding Stuffs. Vermont Experiment Station, Bulletin No. 68.

19. Official Tests of Dairy Cows, 1903-4. Wisconsin Experiment Station, Twenty-first Annual Report. 
20. Reports of the following State Dairy and Food Commissioners : Minnesota, Michigan, Illinois, North Dakota, Connecticut, Kentucky, and other states.

21. Dairy and Milk Inspection. Alabama Experiment Station, Bulletin No. 97.

\section{REFERENCES TO CHAPTER XII}

1. The Action of Heat on Milk. Richmond: Analyst, June, 1893.

2. The Sterilization of Milk on a Large Scale. Hesse : Zeitschrift für Hygiene, 1890, 85.

3. The Chemical and Physical Changes attendant upon the Sterilization of Milk. Leeds : Journal of the American Chemical Society, 13, No. 1.

4. Methods of Milk Preservation. Weigmann.

5. The Pasteurization of Skim-milk. Lunde: Abstract in Experiment Station Record, 4, 383.

6. Methods of Sterilizing and Pasteurizing Milk. Review of Kinds of Apparatus Used. Allen: Article in Recent Work on Dairying. Experiment Station Record, 5, 1051.

7. Pasteurization and Milk Preservation, with a Chapter on Selling Milk. Monrad.

8. Preservation of Milk. Blyth : Foods.

9. Experiments in preserving Milk Samples. Newmann: Milch Zeitung, 22, 93.

10. Preservatives and their Importance in Dairying. Kruger : Molkerei Zeitung, 1892, No. 34.

11. The Composition of, and Objections to the Use of, Preservatives in Milk. Current numbers of the Analyst, 1890-91, etc.

12. Compilation of Analyses of Condensed Milks. König: Chemie der Menschlichen Nahrungs- und Genussmittel, Band II.

13. Variations in the Composition of Milk during Delivery. Vieth : Analyst, 1891 and 1892.

14. Standard Milk. New Hampshire Experiment Station, Bulletin No. 103. 
15. The Value of a Pound of Milk Solids in Milk Poor and Rich in Fat Content. (Storrs) Connecticut Report, 1904.

16. The Comparative Digestibility of Raw, Pasteurized, and Cooked Milk. Maryland Experiment Station, Bulletin No. 77.

17. Standard Milk and Cream. Illinois Experiment Station, Bulletin No. 74.

18. City Milk Supply. Illinois Experiment Station, Bulletin No. 92.

19. Domestic Pasteurizing Methods and the Care of Milk in the Home. New Jersey Experiment Station, Bulletin No. 152.

20. The Efficiency of a Continuous Pasteurizer at Different Temperatures.

21. Pasteurization of Skim Milk. Wisconsin Experiment Station, Twentieth Annual Report.

22. Pasteurization as applied to Butter-making. Wisconsin Experiment Station, Twentieth Annual Report.

23. Preservation of Milk for Direct Use by Pasteurization. Wisconsin Experiment Station, Twentieth Annual Report.

24. On the Increased Resistance of Bacteria in Milk Pasteurized in Contact with the Air. Wisconsin Experiment Station, Eighteenth Annual Report.

25. Estimation of Fat in Sweetened Condensed Milk by the Babcock Test. Wisconsin Experiment Station, Seventeenth Annual Report.

26. Effect of Pasteurization and Sterilization on the Viscosity and Fat Globules of Milk and Cream. Wisconsin Experiment Station, Twentieth Annual Report.

27. Restoration of the Consistency of Pasteurized Milk and Cream. Wisconsin Experiment Station, Twentieth Annual Report.

\section{REFERENCES TO CHAPTER XIII}

1. The Composition of Butter-fat as affected by Food. New Hampshire Experiment Station, Bulletins Nos. 16 and 18.

2. Effect of Food upon the Quality of Butter. Article on 
Butter-making in Handbook of Experiment Station Work. United States Department of Agriculture.

3. Effect of Cotton-seed Meal on the Composition of Butter. Texas Experiment Station, Bulletins Nos. 11 and 14.

4. Effect of Cotton-seed Meal on Butter. Alabama (College) Experiment Station, Bulletin No. 25.

5. Injurious Effects of Certain Plants on Milk and its Products. Milch Zeitung, 1892, 46.

6. The Effect of Peanut Cake and Cotton-seed Cake on the Fat Content of Milk. Backaus: Journal für Landwirtschaft, 41,4 .

7. Effects of Different Kinds of Food upon Butter. A. Mayer: Die Landwirtschaftlichen Versuchs-Stationen, 41.

8. Influence of Food upon the Qualities of Butter Fat. Frear: Agricultural Science, 1833, 7.

9. Transmission of Nitrates to Milk. Richmond: Analyst, 1893, 279.

10. On the Effect of feeding Fat to Cows. Wing: Cornell University Experiment Station, Bulletin No. 92.

11. Recovery of the Food Ingredients in the Milk. New York State Experiment Station Report, 1891.

12. Effects of Rye Pasture on the Taste of Milk. Breeder's Gazette, 26, 203, 220, 239.

13. Transmission of Substances from Food to Milk. Fröhner: Zeitschrift für Fleisch und Milch Hygiene, 10, 1.

14. Influence of the Quality of Food upon the Economy of Milk and Butter Production. Pennsylvania Experiment Station, Annual Report for 1895.

15. Quality of Butter as influenced by Food. Pennsylvania Experiment Station, Bulletin No. 17.

16. Influence of Roots and Silage on the Composition of Milk. Pennsylvania Experiment Station Report, 1890.

17. The Quality of Butter as affected by Food. Maine Experiment Station Report, 1891.

18. Simple Methods of determining Milk Fat (Short's and Cochran's). Pennsylvania Experiment Station, Bulletin No. 12. 
19. Failyer and Willard's Method for determining the Fat in Milk. Journal of Analytical Chemistry, 3, Part 3.

20. Parsons' Method for determining the Fat in Milk. Journal of Analytical Chemistry, 3, Part 3.

21. The Oil Test for Cream. Wis. Ex. Sta:, Bul. 12.

22. Patrick's Method of testing Milk. Iowa Experiment Station, Bulletins Nos. 8 and 11.

23. Milk Tests, Comparison of Simple Methods. Illinois Experiment Station, Bulletins Nos. 10 and 14.

24. Comparison of Various Methods for testing Milk. West Virginia Experiment Station, Third Annual Report.

25. Milk Tests. Handbook of Experiment Station Work, United States Department of Agriculture.

26. Feser's Lactoscope. Die Lands. Vers.-Stat., 27, 2, 135.

27. The Lactoscope. Biedermann's Centralblatt, 9, 302.

28. Effects of Feed upon the Quality of Milk. Iowa Experiment Station, Bulletins Nos. 13, 14, 16, 17.

29. A Study of Milk Secretion. (Storrs) Connecticut Experiment Station Report, 1904.

30. The Effect of Silage on the Acidity of Milk. (Storrs) Connecticut Experiment Station Report, 1904.

31. Weedy Flavors in Butter. California Experiment Star tion, Annual Report, 1903.

32. Studies in Milk Secretion. New York (Cornell) Experiment Station, Bulletins Nos. 152 and 169.

33. The Relation of Food to Milk Fat. New York (Cornell) Experiment Station, Bulletin No. 173.

34. Methods of Milking. New York (Cornell) Experiment Station, Bulletin No. 213.

35. Record of an Attempt to increase the Fat in Milk by Means of Liberal Feeding. New York (Cornell) Experiment Station, Bulletin No. 222.

36. The Source of Milk Fat. New York State Experiment Station, Bulletin No. 132.

37. Flavors in Milk and its Products. New York State Experiment Station, Bulletin No. 183. 
38. Fat in Milk from Starch in Food. New York State Experiment Station, Bulletin No. 197.

39. The Immediate Effect on Milk Production of Changes in the Ration. New York State Experiment Station, Bulletin No. 210.

40. The Effect of Food on Economic Dairy Production. Texas Experiment Station, Bulletin No. 47.

41. A Study of Butter Increasers. Iowa Experiment Station, Bulletin No. 52 .

\section{REFERENCES TO CHAPTER XIV}

[NotE. - The literature on this subject is so extensive that only a few typical references are given. For references to special topics, as the characteristic value of any food for milk production, the student is referred to the card catalogue index issued by the United States Department of Agriculture, Office of Experiment Stations. In calculating rations, it is best to use the figures given for the average composition of American feeding stuffs, except in those cases where extended special investigations have been made of the fodders of a state by an Experiment Station.]

1. Manual of Cattle Feeding. Armsby.

2. Landwirtschaftliche Fütterungslehre. Emil Wolff.

3. Feeding Farm Animals. Allen: Office of Experiment Stations, United States Department of Agriculture, Farmer's Bulletin No. 22.

4. A Compilation of Analyses of American Feeding Stuffs. Jenkins and Winton: Office of Experiment Stations, United States Department of Agriculture, Bulletin No. 38.

5. One Hundred American Rations for Dairy Cows. Woll: Wisconsin Experiment Station, Bulletin No. 38.

6. Investigation in Milk Production; Feeding Dairy Cows. Minnesota Experiment Station, Bulletins Nos. 71 and 79.

7. Feeding Experiments with Dairy Cows. Alabama Experiment Station, Bulletin No. 114.

8. Feed and Care of the Dairy Cow. Kansas Experiment Station, Bulletin No. 81. 
9. Ration Tests for Dairy Cows; the Best Week in a Cow's Lactation Period. Nebraska Experiment Station, Bulletin No. 76.

10. Discussion of the Amount of Protein required in the Ration for Dairy Cows. (Storrs) Connecticut Experiment Station Report, 1904.

11. A Study of Rations fed to Milch Cows in Connecticut. (Storrs) Connecticut Experiment Station Report, 1900.

12. A Study of Rations fed to Milch Cows. (Storrs) Connecticut Experiment Station Report, 1901.

13. Economic Feeding of Milch Cows. (Hatch) Massachusetts Experiment Station, Bulletin No. 39.

14. Rations for Milch Cows. Rhode Island Experiment Station, Bulletin No. 77.

15. Individuality of Cows. Rhode Island Experiment Station, Bulletin No. 80.

16. Feeding Dairy Cows. Michigan Experiment Station, Bulletin No. 149. 



\section{INDEX}

Abnormal creams, churning of, 65. Absorption of odors by milk, 78 . Acid, adding of, to milk, 16; butyric, 31 ; disposal of, waste, 23 ; handling of, 23; lactic, production of, 44 ; measure, 17 ; strong, 22 ; weak, 22.

Acidity, calculation of, in milk, 47 ; of cream, 49 ; of milk, 47. Acids, fatty, 31; volatile fatty, 33. Adulteration of butter, 112; of cream, 58 ; of milk, 41 .

Aerating milk, 86 .

Albumin, 5, 89; coagulation of, 5 . Alkali, standard, 47.

Alkaline tablets, 48.

Apparatus, care of, 28.

Ash, 6.

Ash of foods, 132.

Babcock's formula, 40.

Babcock test, 13-28; reliability of, 13.

Balanced rations, influence of, 129.

Bartlett test bottle, 51 .

Boric acid in milk, 113.

Butter, adulterations of, 112 ; color, 70 ; composition of, 69 ; fats, 29 ; hard, 29; judging, 73; melting point, 34 ; renovated, 113 ; soft, 29 ; working of, 66 .

Buttermilk, composition of, 67 .

Butters, hard, production of, 126 ; soft, production of, 127.

Butyric acid, 31.

Butyrin, 31.

By-products of milk, 107.

Calculation of acidity in milk, 47 ; of rations, 139.
Calibration of test bottles, 19.

Caloric value of foods. 136 .

Carbohydrates, of foods, 134.

Care of dairy utensils, 80 ; of milk rooms, 81 ; of test bottles and apparatus, 28.

Casein, 5, 89.

Centrifugal action, 21.

Centrifuge, 17 ; action of, 21 ; speeding of, 20.

Cheddar cheese, 92.

Cheese, composition of, 101 ; different kinds of, 104; filled, 114 ; making, 88-106; quick-ripening, 97 ; slow-curing, 97 ; skim milk, 114 ; testing of, 100 ; yield of milk, 99.

Churning, 62; abnormal creams, 65 ; exhaustive, 65 ; and grain of butter, 65; influence of food on, 64 ; influence of ripeness of cream on, 63 ; influence of season on, 64 ; influence of temperature on, 64 ; thick and thin cream, 64.

Cleaning glassware, 27 .

Coarse fodders, influence of, in rations, 127.

Cochrane, method of, 117.

Cold curing of cheese, 98.

Cold deep setting, 55 .

Color of milk, 70 .

Colostrum milk, 83.

Composite sample, 24.

Composition of butter, 69 ; of buttermilk, 67 ; of fats, 29 ; of fodders, 148-149; of grains, 147; of milk, 1-12; of milk, individual cows, 8,9 .

Condensed milk, 123.

Corn, influence of, on butter, 126. 
Cost and value of foods, 144 .

Cottage cheese, 105.

Cotton-seed meal, influence of, on butter, 126.

Cream, 49-61; acidity of, 49 ; adulteration of, 59 ; amount of, from milk, 50; composition of, 50 ; heating of, 59; raising by dilution, 61 ; ripening of, 59 ; separators, 54 ; test bottle, 51 ; testing, 51 ; thick, 50 ; thin, 50 ; viscosity, 58 ; weighing of, for testing, 53.

Creaming, gravity process, 54 ; influence of delay, 60 ; methods of, 54 ; milk, temperature of, 58 ; of mixed milks, 61 .

Crude fat, 135.

Crude fiber, 135 .

Cultures, 59.

Curd, grinding of, 94 .

Curd knife, 93.

Curing of cheese, 97.

Dairy laws, 117.

Dairy salt, 66.

Dairy utensils, care of, 80 .

Delay in creaming, 60 .

Detection of the skimming of milk, 39 ; of the watering of milk, 69.

Determination of lactic acid, 45.

Digestible nutrients of foods, 138.

Dilution, cream raising by, 61 .

Disease and foul air, 79 .

Dividends, 72.

Dry matter, 132 .

Edam cheese, 105.

Enzymes and cheese ripening, 97. Exhaustive churning, 65.

Fat, feeding of, in ration, 126 ; globules, 4 ; size of globules, 4 ; losses of, in skim milk, 57; losses of, in butter making, 67 ; reading of, in test, 18.
Fats, composition of, 29; food value, 32 ; melting point, 34 ; milk, 3 ; preseut in butter, 29 ; properties of, 29-34; saponification of, 33 ; specific gravity, 34 .

Fatty acids, 31 .

Feeding of dairy stock, 144; skim milk, 107; value of whey, 100 .

Fermentation of milk sugar, 43.

Ferments, lactic acid, 43.

Fibrin, 86.

Filled cheese, 114.

First milk, 10.

Flavors imparted by foods, 128.

Fodders, coarse, influence of, in rations, 127.

Food value of milk, 123 .

Foods, caloric value of, 136 ; carbohydrates, 134; crude fat of, 135 ; crude fiber of, 135 ; influence of, on butter, 127, 128; selection of, for ration, 137; uses of, by body, 131.

Fore milk, 10.

Formalin in milk, 115.

Formula, Babcock's, 40; Hehner \& Richmond's, 41.

Foul air and disease, 79.

Frozen milk, sampling of, 26.

Gases in milk, 86.

Gerber's Butyrometer, 116.

Germ content of milk, 77.

Glassware, cleaning of, 27.

Globules, fat, 4.

Gluten meal, influence of, on butter, 127.

Glycerine, 31.

Gouda cheese, 105.

Grain of butter, influenced by churning, 65 .

Gravity creaming, 54.

Hard butters, production of, 126.

Heating of cream, 59 .

Hehner \& Richmond's formula, 41. 
Illegal milk, 41.

Indicator, 46.

Influeuce of foods on quality of butter, 127, 128; of water on milk supply, 83.

Iodine absorption, 33.

Judging butter, 73.

Lactic acid, determination of, 45 ; ferments, 43; production of, 44.

Lac tocrite, 116.

Lactometer, its use, 35-42.

Lactose, 5 .

Laws, Dairy, 117.

Limburger cheese, 104.

Loss of fat in skim milk, 57 .

Losses of fat in butter making, 67 .

Maintenance ration, 131.

Mare's milk, 111.

Market milk, 119-130.

Measuring acid, 16 ; milk, 15.

Melting point of fats, 34 .

Method of cheese making, 93-94.

Methods of creaming, 54 .

Milk, absorption of odors by, 78; acidity of, 47 ; ash, 6 ; as human food, 123; by-products, 107; changes during transportation, 120 ; cheese, yield of, 99 ; color of, 70 ; complexity of composition, 1 ; composition of, 1-10; composition of, individual cows, $8-9$; condensed, 123 ; contaminated by soil, 78 ; fats, 3 ; from diseased animals, 76; gases in, 86 ; germ content, 77 ; illegal, 41 ; influence of storage in stables on, 77; mixing of samples, 14 ; pails, washing of, 80; pasteurizing of, 121 ; pipette, 15 ; proteids, 88 ; rooms, care of, 81; sanitary condition of, 75-87; secretion, 125 ; serum, 1 ; solids, 2 ; solids, calculation of, 40 ; spe- cific gravity, 36 ; sterilized, 121 ; sugar, 7 ; sugar, fermentation of, 43 ; supply, influence of tuberculosis, 76; testing, 13-28; testing, importance of, 13 ; water in, 2 ; yields, 9 ; urea in, 76.

Nutrients, 131.

Nutritive ratio, 137.

Oats, influence of, on butter, 127. Oleomargarine, 112; tests for, 112. Organic matter of foods, 133.

Overruns, 71.

Palmitin, 31.

Pasteurizing milk, 121.

Pipette, milk, 15.

Potassium bichromate, 24.

Preservatives in milk, 113.

Proteids of foods, 133; of milk, 88.

Quick ripening of cheese, 97.

Ratio, nutritive, 137.

Ration, calculation of, 139 .

Rational feeding, 131-146.

References, 161-185.

Rennet, 90 ; test, 91.

Renovated butter, 113.

Review questions, 151-160.

Ripening of cream, 59.

Roots, value of, in ration, 142.

Roquefort cheese, 105.

Salt, dairy, 66.

Samples, mixing of milk, 14 .

Sampling frozen milk, 26 ; milk, 14.

Sanitary condition of milk, 75-87.

Saponification of fats, 33.

Secretion of milk, 125 .

Selection of foods for ration, 137.

Separators, efficiency of, 57.

Separator slime, 57.

Serum, milk, 1. 
Serum solids, 11.

Sheep's milk, 111.

Short, method of, 116.

Silage, influence of, on butter, 128.

Skim-milk cheese, 114; feeding of, 107.

Skimming, detection of, 39 .

Skim milk, testing of, 26.

Slow-curing cheese, 97.

Soft butters, production of, 127 .

Soil contamination of milk, 78 .

Solids, milk, 2 ; in milk, calculation of, 40 ; not fat, 11.

Sow's milk, 111.

Specific gravity of fats, 34 ; of milk, 36 ; of skim milk, 37 .

Stables, sanitary condition of, 77; storing milk in, 77 ; ventilation of, 79 .

Standard alkali, 47; ration, 138.

Stearin, 31.

Sterilizing mailk, 121.

Stilton cheese, 104.

Strippings, 10.

Sugar, 7 .

Sulphuric acid, 22.

Sweet and sour cream, churning of, 64.

Swiss cheese, 104.

Tables of composition of foods, 147-149; for correcting lactometer readings, 150 .

Tablets, alkaline, 48.

Temperature of creaming milk, 58; of churning, 64 ; influence of, on lactometer, 37.

Test, rennet, 91.

'Test bottles, 17; calibration of, Yields, milk, 9.
19 ; care of, 28 ; for cream, 51 ; for skim milk, 26 ; whirling of, 18.

Testing cheese, 100; cream, 51; milk, 12-28; importance of milk, 13 ; skim milk, 26 ; whey, 102.

Tests for oleomargarine, 112.

Thick and thin cream, churning of, 64.

Transportation of milk, changes during, 120.

Tuberculosis and milk supply, 76 . Tyrotoxicon, 85.

Urea in milk, 76.

Use of pipette, 15.

Uses of food by body, 131.

Value and cost of foods, 144.

Ventilation of stables, 79.

Viscosity of cream, 58.

Volatile fatty acids, 33.

Water, addition of, to test bottles, - 18; in butter, 69 ; influence of, on milk supply, 83 ; in milk, 2.

Watering of milk, detection of, 39.

Weighing cream for testing, 52.

Wheat by-products, influence of, on butter, 127.

Whey, testing of, 102 ; value for feeding, 100.

Whirling test bottles, 18.

Winton test bottle, 51 .

Working butter, 66 . 


\section{The Chemistry of Plant and Animal Life}

\section{BY HARRY SNYDER}

Professor of Agricultural Chemistry, University of Minnesota

Cloth

I2mo

$\$ 1.25$ net

"This work was originally outlined as agricultural chemistry, but as special features have been developed and published, as the 'Chemistry of Soils and Fertilizers,' and 'The Chemistry of Dairying,' this part of the subject has gradually developed into 'The Chemistry of Plant and Animal Life,' and includes the composition of plant and animal bodies, the chemistry of the plant and of its food and growth, the chemistry of human foods and animal nutrition, the digestibility and value of foods, and the laws governing their economic use. A few topics of an industrial nature, but closely related to plant and animal life, are also included.

"It has been the aim throughout to present the topics in such a way that they would be easily understood, and to develop the reasoning powers of the student so that he would be able to make the best use of his chemistry in everyday-life affairs."

- From the Author's Preface.

\section{THE MACMILLAN COMPANY}

64-66 FIFTH AVENUE, NEW YORK 












Gen.Lib.

$$
\text { A.g.R.S. } 7 \text { DAY USE }
$$

RETURN TO DESK FROM WHICH BORROWED

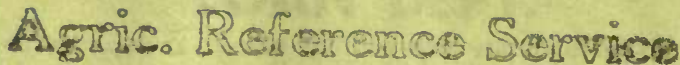

This publication is due on the LAST DATE stamped below.

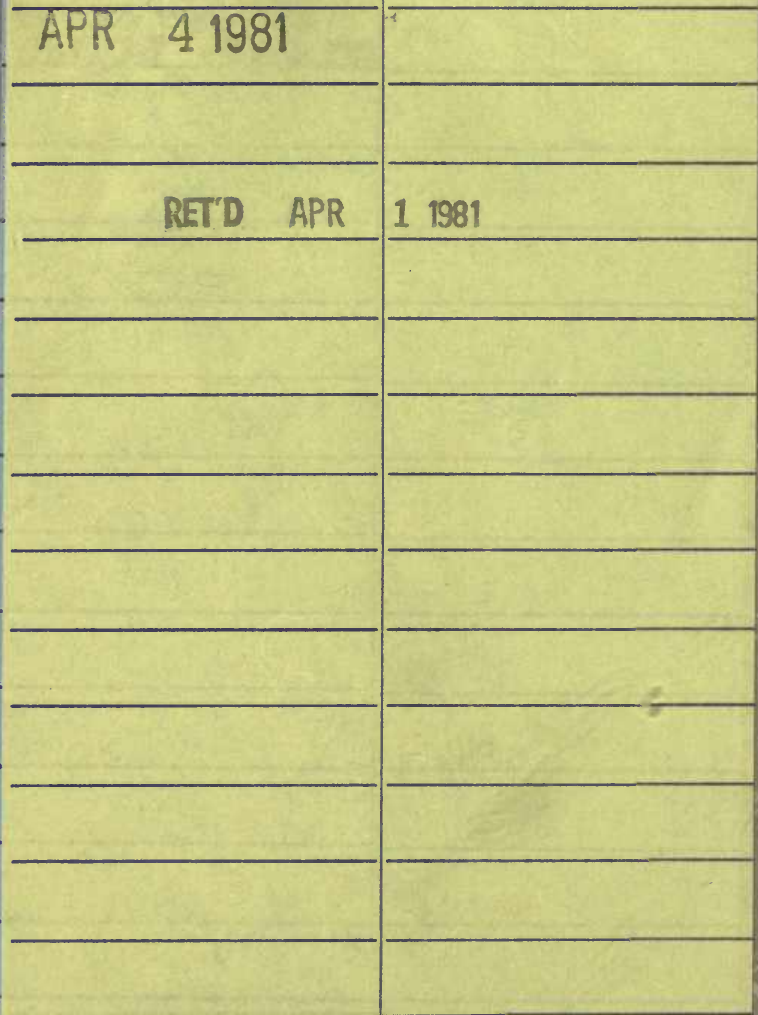

RB 17-60m-6,'59

(A2840s10) 4188 


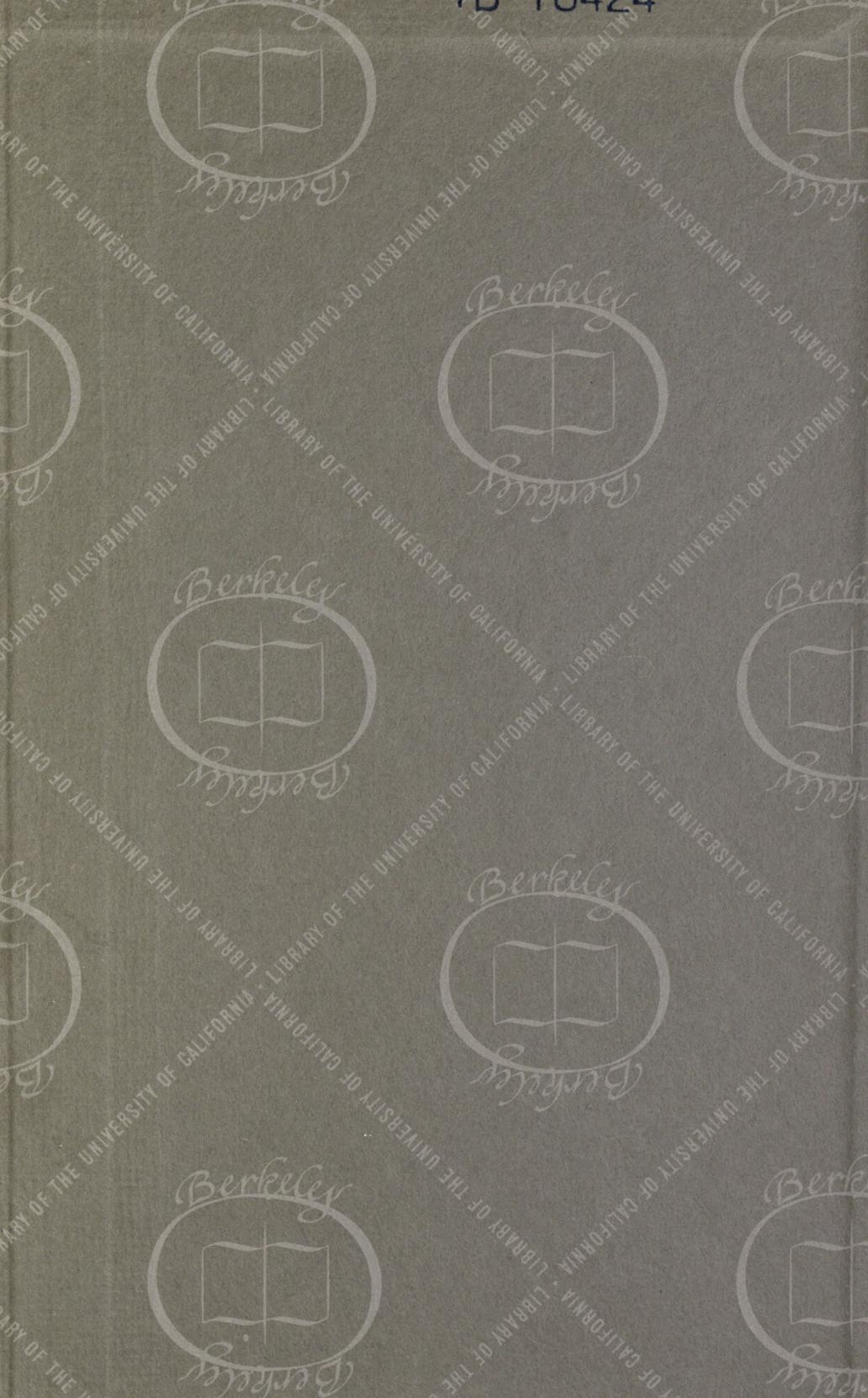


